Florida International University FIU Digital Commons

\title{
The relationship of spirituality and the health promoting behaviors of diet and exercise of African American women
}

Deirdra Nicole Chester

Florida International University

DOI: $10.25148 /$ etd.FI14060191

Follow this and additional works at: https://digitalcommons.fiu.edu/etd

Part of the Dietetics and Clinical Nutrition Commons

\section{Recommended Citation}

Chester, Deirdra Nicole, "The relationship of spirituality and the health promoting behaviors of diet and exercise of African American women" (2003). FIU Electronic Theses and Dissertations. 2159.

https://digitalcommons.fiu.edu/etd/2159 
Miami, Florida

THE RELATIONSHIP OF SPIRITUALITY AND THE HEALTH PROMOTING BEHAVIORS OF DIET AND EXERCISE OF AFRICAN AMERICAN WOMEN

A dissertation submitted in partial fulfillment of the requirements for the degree of

DOCTOR OF PHILOSOPHY

in

DIETETICS AND NUTRITION

by

Deirdra Nicole Chester

2003 
To: Dean Ronald M. Berkman

College of Health and Urban Affairs

This dissertation, written by Deirdra Nicole Chester, and entitled The Relationship of Spirituality and the Health Promoting Behaviors of Diet and Exercise of African American Women, having been approved in respect to style and intellectual content, is referred to you for judgment.

We have read this dissertation and recommend that it be approved.

Sandra L. Lobar

Zisca Dixon

Paulette Johnson

Lorraine J. Weatherspoon

Susan P. Himburg, Major Professor

Date of Defense: July 16, 2003

The dissertation of Deirdra Nicole Chester is approved.

Dean Ronald M. Berkman

College of Health and Urban Affairs

Dean Douglas Wartzok

University Graduate School

Florida International University, 2003

ii 
(C) Copyright 2003 by Deirdra Nicole Chester All rights reserved. 


\section{DEDICATION}

I dedicate this dissertation to my parents, John and Anne, for their unconditional love and support in all of my endeavors. Mom, you are truly my sunshine. John-John and Dayna, you guys know that you are the wind beneath my wings. I also dedicate this dissertation to all those strong spiritual women that are my inspiration, to Josephine, Nettie, Emma, Molly, Arneatha, and Emma. 


\section{ACKNOWLEDGMENTS}

This dissertation research was conducted with fellowships from the Florida

Education Fund; McKnight Doctoral Fellowship and the Florence Bayuk Foundation.

This research was also supported in part by the Gates Millennium Scholars Program. I would like to thank these organizations for their support during this dissertation process.

I would like to thank my committee members, Dr. Lorraine J. Weatherspoon, Dr. Sandra Lobar, Dr. Paulette Johnson, and Dr. Zisca Dixon for their knowledge, support, and direction. I would like to acknowledge Dr. Dian Weddle for her review and critique of this dissertation project. I would like to thank Dr. Terese Maitland for her support throughout this process. I am most appreciative of the commitment, encouragement, and belief in my abilities given to me by my major professor, Dr. Susan Himburg.

I would also like to thank these great men of God who saw my vision, Rev. James H. Chester, Bishop Carlos L. Malone, and Rev. Willie C. Barnes. I would like to give a special thanks to all of the women of the congregations of the Orthodox Zion Primitive Baptist Church, Bethel Full Gospel Baptist Church, and Macedonia Missionary Baptist Church. I would like to thank my sorority, Alpha Kappa Alpha Sorority, Incorporated, for their support.

I would also like to thank my Miami Family for their love and support throughout this process, Jim and Ibis Hillencamp and Tania Rivera.

Most importantly, Ray, thank you for all of your love, support, and encouragement throughout this process.

This research would not have been possible without spiritual guidance. Thank you Father for your love, guidance, patience, and understanding throughout this process. 


\section{ABSTRACT OF THE DISSERTATION}

THE RELATIONSHIP OF SPIRITUALITY AND THE HEALTH PROMOTING

BEHAVIORS OF DIET AND EXERCISE OF AFRICAN AMERICAN WOMEN

by

\section{Deirdra Nicole Chester}

Florida International University, 2003

Miami, Florida

Professor Susan P. Himburg, Major Professor

Public health data show that African-Americans have not adopted healthpromoting behaviors of diet and exercise. Spirituality, important in the lives of many African-American women, may be associated with health-promoting behaviors. This study was designed to determine how spirituality relates to health-promoting behaviors in African-American women. Burkhardt's theoretical framework for spirituality was adopted and measures were selected for the three elements of the framework: connectedness with self, others, and environment.

The study used a descriptive cross sectional correlational design to investigate the relationships of the independent variables of spirituality, sociodemographics, and BMI, to the dependent variables of diet and exercise, to answer the two primary questions: What is the role of spirituality in impacting the health-promoting behaviors of AfricanAmerican women? Of the independent variables of spirituality, sociodemographics, and BMI, which are the best predictors of diet and exercise?

Central and South Floridian African-American women $(n=260)$ between 18 and 82 years of age completed several questionnaires: Rosenberg's Self-Esteem Scale, Health 
Promoting Lifestyle Profile II, Spiritual Perspective Scale, Brief Block Food Frequency, and socio-demographic information.

Hierarchical regression identified $40 \%$ of the variability of diet to be explained by socio-demographic (education) and spirituality variables (stress management and health responsibility) $(\mathrm{p}<.001)$. Twenty-nine percent of the variability of exercise was explained by socio-demographic (education) and spirituality variables (stress management) $(p<.001)$. Canonical correlation analysis identified a significant pair of canonical variates which indicated individuals with good nutrition (.95), increased physical activity (.79), and healthy eating (.42) also had better stress management (.88), better health responsibility (.67), higher spiritual growth (.66), better interpersonal relations $(.50)$, more education (.49), and higher self-esteem (.33). The set explained $57 \%$ of the variability $(\mathrm{p}<.001)$.

An understanding of the factors that influence these women's decision to utilize health-promoting strategies could provide health professionals with additional information to enable them to design culturally and spiritually related health messages for African-American women. The findings of this present study speak of the importance of focusing on stress management, health responsibility, spiritual growth, interpersonal relations and self-esteem along with diet and exercise; this will likely provide improvement in the health-promoting behaviors of African-American women. 


\section{TABLE OF CONTENTS}

CHAPTER

PAGE

I.

INTRODUCTION

Purpose of the Study

Research Questions

Significance of the Study

12

Operational Definitions

II.

REVIEW OF LITERATURE

Relationship Between Obesity and Chronic Disease

The Role of the Black Church

Church-Based Interventions

Spirituality

Measures Related to Spirituality

Health Promoting Behaviors

Measures of Health Promoting Behaviors

Summary

Theoretical Framework

III. METHODOLOGY

Research Questions

Research Design

Conceptual Framework

Feasibility Testing of Instruments

Sampling

Instrumentation

Variable Definition

Data Collection

Data Processing

Data Analysis

IV. RESULTS

Research Question 1

Research Question 2

Research Question 3

Research Question 4

Research Question 5 
V. DISCUSSION

Research Question 1

Research Question 2

Research Question 3

Research Question 4

Research Question 5

Research Question 6

Research Question 7

Summary

Study Strengths and Limitations

VI.

SUMMARY, CONCLUSIONS, AND RECOMMENDATIONS

Summary

Conclusions

Recommendations 


\section{LIST OF TABLES}

TABLE

PAGE

1 Burkhardt Model Descriptions and Measures

$2 \quad$ Research Questions

Significant Research Findings

Demographic Characteristics of African American Women

Religious Characteristics of African American Women

Descriptive Statistics for the Rosenberg Self-Esteem Scale

Descriptive Statistics for the Spiritual Growth of the HPLP II

Descriptive Statistics for the Interpersonal Relations of the HPLP II

9 Descriptive Statistics for Stress Management of the HPLP II

10 Descriptive Statistics for Health Responsibility of the HPLP II

11 Descriptive Statistics for the Spiritual Perspective Scale

12 Dietary Characteristics of African American Women

13 Dietary Intake of Participants Measured Using the Block Dietary Questionnaire

15 Correlations between BMI and Nutrient Intake

16 Correlations between BMI and Nutrient Intake with Age Groups Separately

17 Descriptive Statistics for Nutrition of the HPLP II

18 Descriptive Statistics for Physical Activity of the HPLP II 
22 Correlations Among Sociodemographic Variables

23 Correlations between Spirituality, Sociodemographics, and BMI

24 Correlations between Spirituality, Diet, and Exercise

25 Hierarchical Regression of Sociodemographic, BMI, and Spirituality Variables on the Health Promoting Behavior of Diet as expressed by the HPLP II Nutrition Subscale

26 Hierarchical Regression of Sociodemographic and Spirituality Variables on the Health Promoting Behavior of Physical Activity as expressed by the HPLP II Physical Activity Subscale

27 Hierarchical Regression of Sociodemographic and Spirituality Variables on the Health Eating Scale

28 Correlations, Standardized Canonical Coefficients, Canonical Correlations, Percents of Variance, and Redundancies between Measures of Health Promoting Behaviors and Independent and Moderating Variables

29 Descriptive Statistics for Health Promoting Lifestyle Profile II Total Scale and Subscales 


\section{LIST OF FIGURES}

FIGURE

PAGE

1

Theoretical Framework of Spirituality

9

2

Burkhardt's Theory of Harmonious Interconnectedness

25

3

Correlational Design of Sociodemographics, Anthropometry, Spirituality and Health Promoting Behavior of Diet

Correlational Design of Sociodemographics, Anthropometry, Spirituality and Health Promoting Behavior of Exercise 


\section{CHAPTER I}

\section{INTRODUCTION}

Supporters of preventive health care assert that the presence of health promoting behaviors, such as a healthy diet and exercise, will help people avoid disease and lead healthy productive lives. This message is widespread, yet statistics show that large percentages of the United States (US) population are not influenced enough to adopt these healthier practices (Riebe et al., 2003, Juhaeri et al., 2003). Thus, death and illness, especially from chronic diseases such as heart disease, diabetes mellitus and strokes, remain high, especially in minority groups within the US.

Healthy People 2010 presents a comprehensive, nationwide health promotion and disease prevention agenda. The document serves as a roadmap for improving health of all people in the US. The two overarching goals of Healthy People 2010 are to increase quality and years of healthy life, and eliminate health disparities. Healthy People 2010 also lists specific objectives to be achieved regarding the prevalence of chronic diseases in specific populations as a way to achieve these overall goals (U.S. DHHS, 2000).

Chronic diseases such as heart disease, hypertension, and diabetes are listed among the top ten causes of death in the U.S. population; however, the death and illness burden from these diseases is not evenly distributed among the various population groups (U.S. DHHS, 2000, U.S. DHHS, 1991). Minority populations usually have a disproportionately high percentage of persons who are ill or die from these chronic diseases. As a group, African American women are particularly hard hit by chronic diseases, many of which have nutrition as a risk factor and are managed in part by dietary changes. Obesity is also listed as a risk factor for some of these diseases and again 
nutrition intake is a risk factor for obesity. There is enormous concern about the public health implications of health disparities among minorities in the prevalence and treatment of chronic disease, especially obesity, heart disease, hypertension, and diabetes; therefore, there is a need for effective culturally appropriate interventions for minority populations.

African American women experience disparities in almost every area of health (U.S. DHHS, 2000, U.S. DHHS, 1991; Satcher, 2001). Obesity and overweight are major health concerns, particularly among African American women. Indeed, $60 \%$ of the 34 million African American women, between 45 and 65 years of age, are overweight or obese (Allison et al., 1997, Gore, 1999, Nelson et al., 2002). Coronary heart disease death rates show that African Americans are at a greater risk than any other racial group, with 147 out of 252 deaths per 100,000 attributed to women of African American descent. African Americans also experience 80 deaths per 100,000 from stroke; moreover, as many as $40 \%$ of African Americans age twenty and older have hypertension.

In general, for heart disease in the US, the death rate has been consistently higher in males than in females and higher in the African American population than in the white population. African American women have the highest age-adjusted prevalence of diabetes followed by African American men, White women, and White men (MMWR, 1997). African American women also have a high incidence of diabetes, in part because of high rates of obesity (NIH, 1997; Position of ADA, 1999; U.S. DHHS, 2000; U.S. DHHS, 1991). 
The total cost for cardiovascular disease, stroke, diabetes, and cancer, based on medical costs, productivity losses because of disability, and premature death, are now in excess of $\$ 70$ billion each year (Frazao, 1999). Much of this cost is the result of the increased prevalence of chronic disease in women, especially African American women (Satcher, 2001).

The aforementioned chronic diseases that are prevalent among African American women have several risk factors in common, including obesity and overweight, decreased physical activity, and poor dietary habits (e.g., high salt and sodium intake, inadequate fruit and vegetable consumption and calcium intake, and excessive consumption of fat and kilocalories). Consequently, special attention should be paid to finding effective means to provide messages promoting healthy dietary practices for African American women (e.g., consuming diets low in saturated fat, dietary cholesterol, and total fat as well as adequate energy, and fruit and vegetable consumption) that they are likely to adopt.

In addition to being the most affected by chronic diseases, African American women experience some of the worst health outcomes. Therefore, it cannot be overstated that efforts should be made to achieve the Healthy People 2010 objectives that address improving health status and outcomes of African American women. To do so, ethnicspecific interventions to prevent as well as diagnose and manage chronic disease warrant more attention. It is clear that the one-size-fits-all approach to public health that was so effective for expanding the lifespan of men and women in the last century will not meet the challenges of the new century (Satcher, 2001). This is especially true regarding meeting the health and ethnic-specific needs of women. 
Recently, the realization that women's health care needs are different from those of men led to a series of gender-specific research programs that have produced health information on women and have allowed for a clearer understanding of women's unique health and nutritional needs. This has led to policies and health recommendations specifically for women.

In the field of nutrition, the American Dietetic Association's (ADA) position paper on women's health acknowledges that within the past 10 years women's health has evolved to a much broader paradigm. It recognized that women's health refers to the prevention, diagnosis, and management of conditions or diseases that may be unique to women, be more prevalent in women, or manifest differently in women than in men, and should therefore encompass women's emotional, social, cultural, spiritual, and physical well-being (Position of ADA, 1999). It also recognizes the central role nutrition plays, thus enabling women to be healthy. It added that health promotion is a vital part of disease prevention, stating that optimal nutrition and physical activity promote health and reduce the risk of chronic disease. The ADA position paper emphasized that nutrition is a critical component of risk reduction and treatment and must be included in both clinical and preventive services for women to prevent and treat chronic conditions, for example, cardiovascular disease, cancer, osteoporosis, diabetes, and body weight abnormalities (Position of ADA, 1999). It also recognized that women's spirituality is related to their health.

The present research focused on women because of the health disparities experienced by women, especially African American, and the need to be able to provide them with appropriate care and health education to reduce their chronic disease and 
illness burden as well as to improve their health and well being. This presents a challenge, as a large proportion of African American women are medically underserved (Satcher, 2001). Approximately 40 million of America's 140 million women are members of racial and ethnic minority groups (Satcher, 2001). This number is increasing and by the year 2050 approximately $47 \%$ of American women will belong to ethnic and racial minority groups (e.g., Hispanic, African American, Asian and Pacific Islander, and Native American Indian and Alaska Natives) with African American women comprising one of the largest minority women's groups in the US (Satcher, 2001).

The time has now come to focus on addressing the health needs faced by the different socioeconomic and ethnic groups of American women. The changing demographic profile of the US makes it important that effective, culturally appropriate care and health education be provided for African American women.

Over the years, there has been an increase in the number of nutrition education interventions in the African American community and there have been some decreases in mortality from chronic diseases, however, not to the levels needed to reach the goals of Healthy People 2010 (Domel et al., 1992; Cooper, 1993; Furumoto-Dawson et al., 2003). Chronic disease statistics for African American women show, in many instances, they are the most affected (Satcher, 2001); it would seem that African American women have been overlooked somehow in this era of increased nutrition education.

For a successful health and nutrition intervention program, it is important not only to focus on the desired result, for example, weight loss, but also to focus on understanding the factors that influence the target population's health and nutrition behaviors. Subsequently, an appropriate intervention program can be provided to enable 
these individuals to adopt and maintain the desired healthy behaviors (e.g., consuming an adequate diet and engaging in adequate physical activity to maintain weight loss).

Realizing the central role the church plays in African American life, health promotion specialists have utilized church settings, a common gathering place for African Americans of all ages, genders, and socioeconomic levels, to provide health intervention. These programs established an initial successful track record (Kumanyika et al., 1992; Melynx \& Weinstein, 1994; Pratt, 1994; McNabb et al., 1997). Their long-term success is being followed in a few cases (CDC, 2003; Yanek et al., 2001).

The knowledge that church based studies have been successful with African Americans is not surprising considering the central role the church plays in African American culture. The role that churches play could be used as avenues to influence all aspects of African American behavior. However, equally important and perhaps more influential to African American behavior would be a focus on their spirituality, which is indeed related to, but not the same as, their association with the church (religiosity).

It is possible that the limited success achieved thus far in influencing the health behaviors of African American women, even for church-based intervention, is due to the fact that these programs did not focus on the role played by spirituality in influencing the diets and health promoting behaviors of African American women. In fact, this genre of research studies on African Americans merely used the church environment to access the population. Religion (religiosity) is at the core of the lives of many African Americans; however, religiosity is inherently different from spirituality.

The American Heritage Dictionary (Houghton Miflin, 2000) refers to religiosity or religion as "a set of beliefs, values, and practices based on the teachings of a spiritual 
leader" or "a system grounded in such belief and worship of a creator and governor of the universe." Spirituality is referred to as "of, concerned with, or affecting the soul" or "of, relating to, consisting of, or having the nature of spirit, not tangible or materials" (Houghton Miflin, 2000). Therefore, in essence, religiosity is based in the act of attending a place of worship and believing in a supreme being that created the universe, while spirituality is a measure of the personal relationship the individual has with herself, others, and the environment that influences all of her life. This makes spirituality more critical because of its use as a roadmap by individuals to formulate a worldview of life and how it should be lived. Spirituality, therefore, has the potential to give instruction on how individuals should live, what they should eat, and how they should treat their bodies, that is, it could influence health behavior.

The aforementioned definitions of spirituality differentiate it from religiosity, but do not provide a strong theoretical framework for research. In fact, many studies on religiosity lack a research-based paradigm. A model from the nursing profession provides the strongest link between spirituality and health. Burkhardt (1989) presents a theoretical model of spirituality that describes several components and has been used in research as a framework to measure this concept (Burkhardt, 1989; Nagai-Jacobson \& Burkhardt, 1989). Burkhardt provides the framework/model in order to investigate the components of spirituality, but other questionnaires must then be used to measure these components within the context of the Burkhardt model. Walker's (1987) Health promoting Lifestyle Profile (HPLP II) has been used in various studies to measure the three components of spirituality as identified by Burkhardt, connectedness with self, others, and the environment. 
The present study utilized operational measures of the different components of spirituality as defined by Burkhardt and measured by the HPLP II (Walker et al., 1987), Spiritual Perspective Scale (Reed, 1986, 1987), and Rosenberg's Self-Esteem Scale (Rosenberg, 1965) to examine the relationship of spirituality and health promoting behaviors in African American women. Although other researchers have used the HPLP II and Burkhardt's model, none have used the combination of the HPLP II, Rosenberg's Self-Esteem Scale, and the Spiritual Perspective Scale, which is unique to the present study.

Burkhardt proposed a theory of harmonious interconnectedness to operationalize spirituality. Burkhardt identified the components of spirituality, namely connectedness with self, others, and the environment, that are appropriate for this present research. Harmonious interconnectedness refers to a sense of relatedness to and connectedness with all of life or being in harmony with the universe (Burkhardt, 1989).

In Figure 1, the three components of harmonious interconnectedness (connectedness with self, others, and the environment) are depicted by the measurements of the Health Promoting Lifestyle Profile II, Spiritual Perspective Scale, and Rosenberg's Self-Esteem Scale. Connectedness with self was measured using the Rosenberg SelfEsteem Scale and the HPLP II Spiritual Growth subscale, which together measured selfesteem or self-concept and whether an individual engaged in personal development. Connectedness with others was measured using the HPLP II Interpersonal Relations subscale and HPLP II Stress Management subscale, which together measured whether an individual connects in life-giving ways with family, friends, or social groups; whether an individual engaged in reconciliation; and if there is a loss of connectedness which causes 


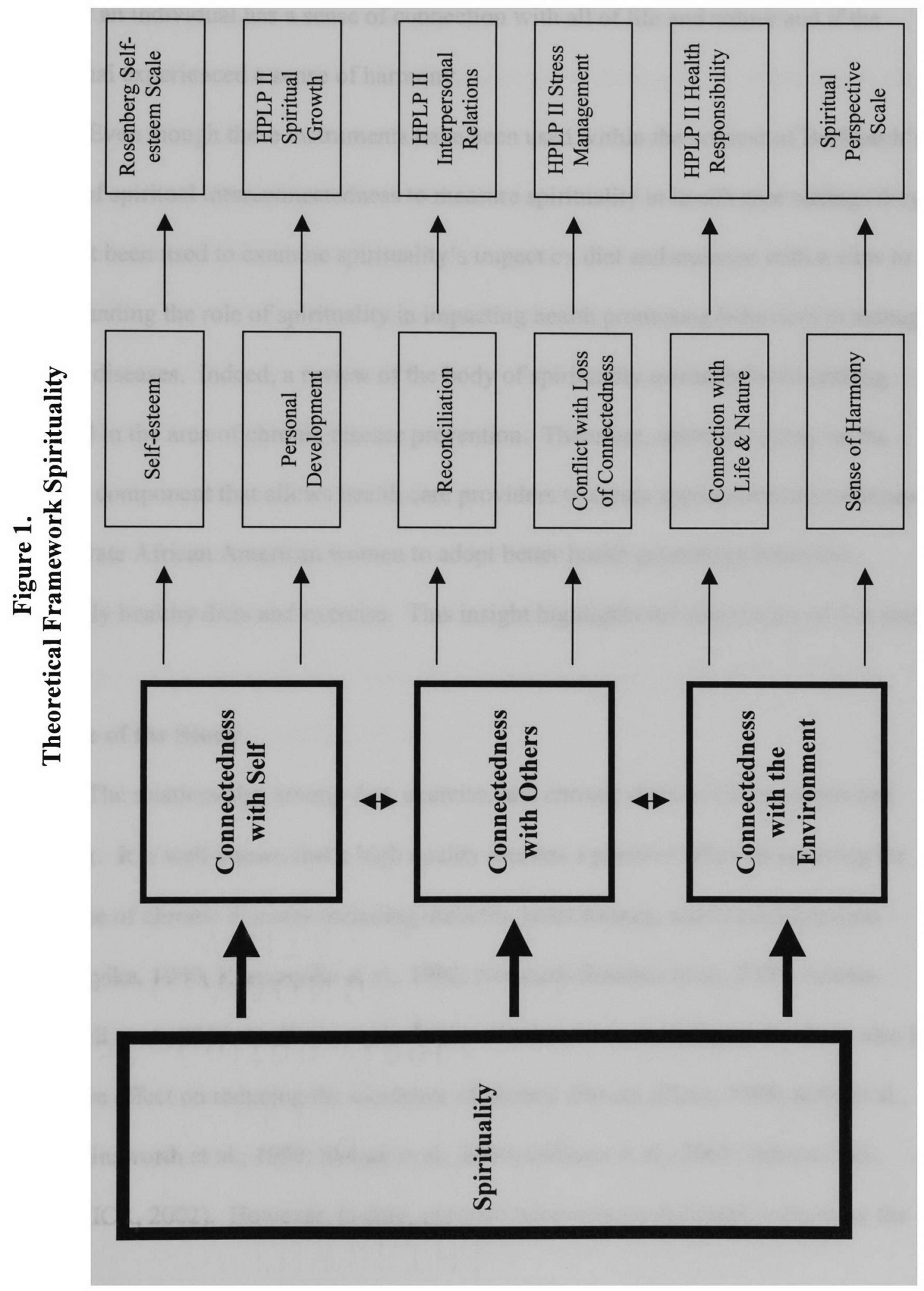


conflict. Finally, connectedness with the environment was measured using the HPLP II Health Responsibility subscale and the Spiritual Perspective Scale, which both measured whether an individual has a sense of connection with all of life and nature and if the individual experienced a sense of harmony.

Even though these instruments have been used within the context of Burkhardt's theory of spiritual interconnectedness to measure spirituality in health care settings they have not been used to examine spirituality's impact on diet and exercise with a view to understanding the role of spirituality in impacting health promoting behaviors to manage chronic diseases. Indeed, a review of the body of spirituality research found nothing reported in the area of chronic disease prevention. Therefore, spirituality may be the missing component that allows health care providers to create appropriate interventions to motivate African American women to adopt better health promoting behaviors, especially healthy diets and exercise. This insight highlights the importance of this study.

\section{Purpose of the Study}

The relationships among diet, exercise, and chronic disease are numerous and complex. It is well known that a high quality diet has a positive effect on reducing the incidence of chronic diseases including diabetes, heart disease, and hyperlipidemias (Kumanyika, 1990; Kumanyika et al., 1992; Neumark-Sztainer et al., 2000; AdamsCampbell et al., 2000; Koffman et al., 2001). Further, increased physical activity also has a positive effect on reducing the incidence of chronic disease (Pleas, 1988; Kohl et al., 1998; Ainsworth et al., 1999; Sevick et al., 2000; Gillman et al., 2001; Jakicic et al., 2002; AICR, 2002). However, to date, exercise interventions designed to decrease the 
mortality and morbidity rates of chronic disease in Americans and in the African American population, specifically, could be more effective (Goodrick \& Foreyt, 1991; Williamson, 1991; Kuczmarski, 1992; Gore, 1999; Kratina \& Tuttle, 2001).

The overall goal of this study was to understand the manner in which spirituality impacts the health promoting behaviors related to diet and exercise habits of African American women. This study examined the relationship between spirituality (using the Burkhardt model) and women's health promoting behaviors of diet (as measured by the HPLP II Nutrition Subscale and the Healthy Eating Scale) and exercise (as measured by the HPLP II Physical Activity subscale). An understanding of the factors (including the mind connection through the components of spirituality) that influence decisions these women make to utilize health promoting strategies such as eating healthy diets and engaging in regular exercise, could provide health professionals with additional information to enable them to design culturally appropriate health messages for African American women. Consequently, this study focused not only on the health of these women, but on their spirituality as well.

\section{Research Questions}

Data for this cross-sectional study included sociodemographic, anthropometric (reported height and weight), dietary, exercise, and spirituality components in order to answer the two primary questions of the study: What is the role of spirituality in impacting the health promoting behaviors (diet and exercise) of African American women? Of the independent variables of spirituality, sociodemographics, and BMI, which are the best predictors of diet and exercise? 
The framework and analysis for the study are represented by the following sequence of questions:

1. What are the sociodemographic characteristics of study participants?

2. How do African American women score on the various spirituality subscales?

3. What is the relationship among dietary intakes, exercise habits, and BMI of African American women?

4. What is the relationship between sociodemographics, dietary patterns (as measured by the HPLP II Nutrition Subscale and the Healthy Eating Scale) and exercise habits of African American women?

5. What is the interrelationship of spirituality, sociodemographics, and BMI?

6. What role does spirituality play in the lives of African American women as it relates to their diet and exercise habits?

7. Of spirituality, sociodemographics, and BMI, which are the best predictors of a healthy diet (as determined by scores from the HPLP II Nutrition Subscale and the Healthy Eating Scale) and exercise patterns in African American women?

\section{Significance of Study}

In this era of increasing health care costs and increased prevalence of chronic disease, especially in minority populations, providing quality preventive health care is a necessity. Emphasis must be placed on finding appropriate avenues for women to access and utilize health promoting information. There is a growing body of evidence in the 
literature that spirituality positively impacts the well-being and longevity of patients who were hospitalized as a result of serious illnesses, for example, cancer and heart attacks (Reed, 1986; Reed, 1987; Reed, 1991). However, very little has been done to determine the extent to which spirituality positively impacts the health promoting behaviors of freeliving individuals. Understanding the role spirituality has in helping African American women adopt health promoting behaviors can facilitate development of culturally appropriate programs. This would be timely and could possibly have a positive impact on the increase in illness and death from chronic disease being experienced by African American women.

In this study, evidence was gathered about the relationship between spirituality and the health promoting behaviors of diet and exercise in African American women. This baseline information on spirituality and health promoting behaviors provides a cross-sectional snapshot of how African American women residing in Central and South Florida view their health within the context of their spirituality. Therefore, findings can provide a basis for future research and intervention that involve incorporating spirituality as it relates to their diet and exercise behavior.

\section{Operational Definitions}

African American - Since there are different Afrocentric groups residing in the United States, for the purpose of this dissertation when referring to the published literature, unless otherwise stated, Black and African American are interpreted as the all-encompassing terms to describe persons of African descent. 
Connectedness with the environment/universe - experiences a sense of connection with all of life and nature; is aware of effects of the environment on one's life and well-being; demonstrates concern for the health of the environment (Burkhardt, 1989).

Connectedness with others - connects in life-giving ways with family, friends, social groups, church, and the like; engages in personal development (Burkhardt, 1989).

Connectedness with self - demonstrates positive self-concept and self-esteem; has a sense of belonging in the world and with family, friends, social groups, church, and the like; pursues creative activities; has a realistic sense of self, realizes own potential; demonstrates love of self; engages in reconciliation (Burkhardt, 1989). Harmonious Interconnectedness - a person experiences harmony in relationships with: self, others, and the environment (Burkhardt, 1989).

Spirituality - realizing that there is no single definition of spirituality, spirituality for the purposes of this research was defined as an individual's connectedness with self, an awareness of one's inner self. A person that is spiritual demonstrates positive selfconcept and self-esteem and has a sense of belonging. A person that is spiritual also demonstrates connectedness with others and the environment in which they live. They demonstrate positive interpersonal relations and have a connection with life and nature. 


\section{CHAPTER II}

\section{THE LITERATURE}

The literature review includes a discussion of chronic disease in African American women and the role that the church plays as a social institution. A discussion of church-based interventions follows. Although women were recruited from Black churches as well as social groups in this study there is a holistic spirituality approach and not one with a basis in religion. A broader definition of spirituality is presented and the potential relationship of spirituality to health promoting behaviors (diet and exercise). Finally, the conceptual framework will be presented, which includes a discussion of the measures related to spirituality.

African American women represent $13 \%$ of the total population of U.S. women (homer.ssd.census.gov., Accessed 11/07/00). The U.S Census Bureau estimates that by the year 2050, 14\% of the American population will be non-Hispanic Black. The ADA position paper on women's health and nutrition states that the disparities in mortality between White and minority women are due to higher poverty rates; social and cultural barriers to health education and promotion, preventive services and medical care; inadequate primary care physicians practicing in rural or urban low-income areas; inadequate local health care facilities; and insensitivity of many health care facilities to the needs of minority women (Position of ADA, 1999). All of the issues mentioned above are important reasons why African American women experience poorer health outcomes.

Although African American women experience some of the same health problems as White women, as a group, they are in poorer health, use fewer health services, and 
continue to suffer disproportionately from premature death, disease, and disabilities (Satcher, 2001). Many of these women also face tremendous social., economic, cultural., and other barriers to optimal health. Health statistics differ greatly between African Americans and Whites in the United States. With age- and gender-adjusted all-cause death rates 60\% higher among African Americans (Whitfield et al., 2002; Carmichael et al., 1998). This increase in death rates among African Americans warrant special attention to this population, thus decreasing death rates from chronic diseases.

Nutrition plays a critical role in decreasing chronic disease risk experienced by African American women. It is well known that a high quality diet will decrease the prevalence of chronic disease. Dietary changes have been implicated in the management of chronic disease, more specifically, hypertension, diabetes, cardiovascular disease, coronary heart disease, and stroke. Consuming a high quality diet means increasing fruit and vegetable intake, thereby increasing dietary fiber ( $>25$ grams), reducing total fat $(<30 \%)$ and saturated fat $(<10 \%)$, increasing complex carbohydrates thus increasing whole grains and dietary fiber, and decreasing sodium intake for management of saltsensitive hypertension (Fox et al., 1996; Furumoto-Dawson et al., 2003; Krause et al., 2000).

Nutrition is essential for growth and development, health, and well-being. African American women have disproportionately high rates of obesity, diabetes, dyslipidemias, and hypertension. It is thought that many chronic diseases can be controlled by healthy habits and diet change (Position of ADA, 2002). African American women are specifically targeted by Healthy People 2010 objectives to improve their 
nutrition and physical activity as a means to decreasing their prevalence of chronic diseases.

\section{Relationship Between Obesity and Chronic Disease}

Behaviors (e.g., poor eating habits and physical inactivity patterns) that contribute to obesity are developed in the context of individuals' lives. For example, the home and the community are specific contexts which influence one's behavior (Pratt, 1994).

Obesity continues to be one of the most pervasive and persistent health problems in the United States. Approximately 34 million Americans are overweight. This problem is magnified in populations of color, especially African American women. Indeed, almost $25 \%$ of American women are overweight, including 30\% European American and $60 \%$ African American women between 45 and 65 years of age (Allison et al., 1997; Gore, 1999; Nelson et al., 2002). Obesity has been noted as a strong associative or risk factor in the incidence of diabetes, hypertension, and hyperlipidemias (Williamson et al., 1991). The problem of obesity itself emphasizes the need for culturally- and spirituallybased nutrition education that will alleviate the problem of obesity in the African American female, since the African American female is more at risk than any other racial or gender group.

Overweight is also a condition of major public health concern in the United States. According to the Surgeon General's Report on Nutrition and Health, overweight is a risk factor in diabetes, hypertension, stroke, coronary heart disease, some types of cancer, and gallbladder disease. Overweight occurs across all subgroups of the 
population, but is particularly prevalent in the predominant ethnic minorities

(Kuczmarski, 1992).

It is clear that overweight and obesity are precursors to many chronic diseases.

To alleviate the problems of both obesity and chronic disease in the African American population, a clearer understanding of the health promoting behaviors that could prevent these conditions are clearly warranted. As revealed in the subsequent discussion, the role of the Black church is a growing area of interest in the milieu of developing culturally appropriate interventions.

\section{The Role of the Black Church}

Research findings suggest that religious involvement is central to the lives of African American people (Musgrave et al., 2002). African Americans' identity is often based in the churches they attend. Hence, more upwardly mobile African Americans travel to the churches in their old neighborhoods. Therefore, these churches often serve as social institutions because they guide personal and political decisions. The following studies included a definition of spirituality in its more narrow perspective of religiosity (i.e., set of beliefs based on a religious leader, attending a place of worship, and believing in a supreme being).

African Americans are more likely to pray privately, practice religious rituals, attend religious services, and believe that the Bible is the Word of God (Jacobson et al., 1990; Johnson et al., 1991). Older African Americans indicate that religion provides comfort during stress (Seaward, 2000). African American caregivers see God as a source of help (Picot et al., 1997). 
Historically, spirituality for Black women has been and is centered in slavery.

Slavery, with its sexual abuse of Black women, and its separation of families, was an attempt to destroy African culture (Williams, 1993). In spite of these hardships, enslaved women were able to transcend and transform their experiences through their religion, which provided hope in personal and community relationships (Musgrave et al., 2002). Enslaved women embraced a religious experience that affirmed the presence of God in their struggles (Collins, 1991). African Americans' spirituality was focused and defined in a communal religious experience (Musgrave et al., 2002). The present research would describe this as religiosity, and not the more holistic definition of spirituality.

Since slavery, the Black church has served a critical role in Black women's lives (Musgrave et al., 2002; Levin, 1984). God is seen as a deliverer from unjust suffering and the comforter in times of trouble (Eugene, 1995). The church provides renewal and empowerment. In Black churches women feel free to receive and exhibit the reviving power of the Supreme Being as a healing resource supplying meaning in the midst of trials and tribulations (Baker-Fletcher, 1998). The overt expression of emotion in Black churches offers an outlet for pent-up anguish. Women become therapists to each other and the church assumes the role of "an asylum of therapeutic assistance" as well as a place of shelter (Eugene, 1995).

Levin (1984) stated that historically, the Black church has been the preserver and perpetuator of the Black ethos, the radix from which its defining values and norms have been generated; furthermore, it is the autonomous social institution that has provided order and meaning to the Black experience in the United States. The Black church is an extremely relevant locus for the practice of community medicine (Levin, 1984). Health 
status indicators for Americans show that African Americans are at greater risk for dietrelated chronic diseases. They are also underserved regarding access to preventive health care.

The present study focused on investigating the relationships between spirituality and health promoting behaviors as they relate to health and nutritional issues. A rapidly growing body of literature points to the relevance of basing strategies of planned social change within the sphere of religion targeting Black Americans (Levin, 1984; Smith, 1989; Kavanaugh, 1997; Hassed, 1999). Although external influences upon the theological orientation of the Black church may vary, its central role has remained essentially unchanged. The Black church continues to take the lead in addressing the needs of Blacks in the United States (Levin, 1984). For this reason, the Black church is often selected as the community vehicle for the prevention and alleviation of health problems and, indeed, obesity in African American women.

The Black church has proven to be important and very influential in the lives of African Americans and in their communities. Churches, as social structures, are influential in inculcating attitudes, knowledge, and values as well as group norms. Churches are conceptualized as having a central role in the socialization of its members to optimize their individual health behaviors. The church is the focal point in the African American community and draws its clientele from a broad geographical area.

Churches and health practitioners are teaming to address health issues (Kumanyika and Charleston, 1992; McNabb et al, 1997). This has been done through focus groups, health fairs, and seminars. One of the rewards of health practitioners working with the church to address the health and nutritional needs of African Americans 
is knowing that the work is easing a great financial strain in the African American community by decreasing the cost related to poor health in this population in the future. There is potential for having the benefit of reaching a population that perhaps would not be reached in other ways.

\section{Church-Based Interventions}

Church-based interventions have become an important component of preventive health programming. They are considered particularly effective in the Black community because of the central role of churches as a social structure in the lives of African Americans. The importance of the Black church has been documented in four areas of community medicine: primary care delivery, community mental health, health promotion and disease prevention, and health policy (Levin, 1984; Blank et al., 2002).

However, literature reports on church based intervention outcomes are mixed. Some study findings have included positive outcomes from church based investigations (Kumanyika and Charleston, 1992; McNabb et al., 1997), while others have not had such definitive outcomes of the role of the church (Smith, 1989). Smith (1989) examined the role of Black churches in supporting compliance with antihypertensive regimens. In this study, a sample of 63 hypertensive subjects from two inner-city Black churches, 33 from a church that had a hypertension screening project and 30 from one that did not, were evaluated. Clients from the church with the project did not score higher on a self-report compliance measure than those from the church without the project. The study concluded that there was no relationship between support and compliance and blood 
pressure control. It was also concluded that the church without a screening program was viewed by clients as more supportive than the one with the program.

Kumanyika and Charleston (1992) conducted the Lose Weight and Win, a churchbased weight loss program for blood pressure control among Black women in Baltimore area churches. The study was conducted with 184 Black and three White women between 18 and 81 years old. The program included nutrition education and a behavioral counseling component for the weight loss program. The core intervention program was a series of eight weekly classes held at the individual churches. Almost $90 \%$ of the women lost some weight and a very small percentage had a net gain. Weight loss increased with attendance: low, medium, and high attenders lost an average of 3, 6, and $9 \mathrm{lbs}$, respectively.

McNabb et al. (1997) conducted the PATHWAYS Church-Based Weight Loss Program for Urban African American Women at Risk for Diabetes in Chicago. Thirtynine obese women were recruited from three urban African American churches. Subjects in the experimental group $(n=19)$ were assigned to receive a 14-week weight loss program and the control group $(n=20)$ was put on a waiting list to receive the program at the conclusion of the study period. After completing the program, the PATHWAYS' participants lost an average of $10.0 \mathrm{lbs}$, and the control group subjects gained an average of $1.9 \mathrm{lbs}$. The study concluded that a weight loss program administered by trained lay volunteers was effective in producing significant and clinically meaningful weight loss among African American women who often do not benefit from typical weight loss programs. 
The aforementioned studies used the church setting, but did not incorporate spirituality as defined by Burkhardt, and used as the theoretical framework for the present study, to institute or determine if screening programs in a church would increase participation in these studies. Would incorporating a component of spirituality increase the weight loss of the women in these studies? The church represents a potentially effective channel for delivering health programs to African Americans. Many Black churches include health as part of their overall mission, offering health services and programs through special committees and ministries; moreover, given the potential ease of participant recruitment and tracking, churches also represent an excellent research setting (Resnicow et al., 2001).

\section{Spirituality}

\section{Definition and Framework}

It is important to understand exactly what spirituality is. It has been asserted in the literature, "there is no single recognized definition of spirituality" (Bensley, 1991). The recognition of the spiritual dimension as a vital component of human wellness has led to an increased interest in spirituality education (Hawks et al., 1995). Spiritual health has been difficult to define because it is thought to have no clear structure, parameters, or measurable components (Eberst, 1984).

However, the work of Burkhardt provides a useful structure and definition that has been used by the nursing profession. This theoretical framework gives the broad view of spirituality that includes a harmonious interconnectedness. This harmonious 
interconnectedness is when an individual experiences harmony in relationships with self, others, and the environment/universe (Burkhardt, 1989) (see Figure 2).

Researchers have studied spirituality, religion, or integrated the two concepts.

Some of these definitions have been related to one's own belief, and some have been related to organized religion (e.g., social structures). "Spiritual well being," also known as "spiritual health," is related to one's own belief, and has been defined as life-affirming relationships or harmonious interconnectedness with deity, self, community, and environment; a process of being and becoming through being; the health of the totality of the inner resources of a person; the wholeness of one's spirit and unifying dimension of health; a process of transcendence; and perception of life as having meaning (Burkhardt, 1989).

Burkhardt (1989) described spirituality as "a process and sacred journey, the essence or life principle of a person, the experience of the radical truth of things, a belief that relates a person to the world, giving meaning to existence, any personal transcendence beyond the present context of reality, a personal quest to find meaning and purpose of life, and a relationship or sense of connection ...". Burkhardt referred to religion as a belief system -- a product of the rational mind. She then referred to "religiosity" pertaining to the knowledge, beliefs, feelings, and practices of a person (Burkhardt, 1989). However, it is possible for an individual to define oneself as religious (e.g., connected to a higher power, God, or universe), but not necessarily be tied with the social institution of a church.

The concept of spirituality has not been adequately defined, researched, grounded in theory, or integrated into the health education curriculum. Health is generally defined 


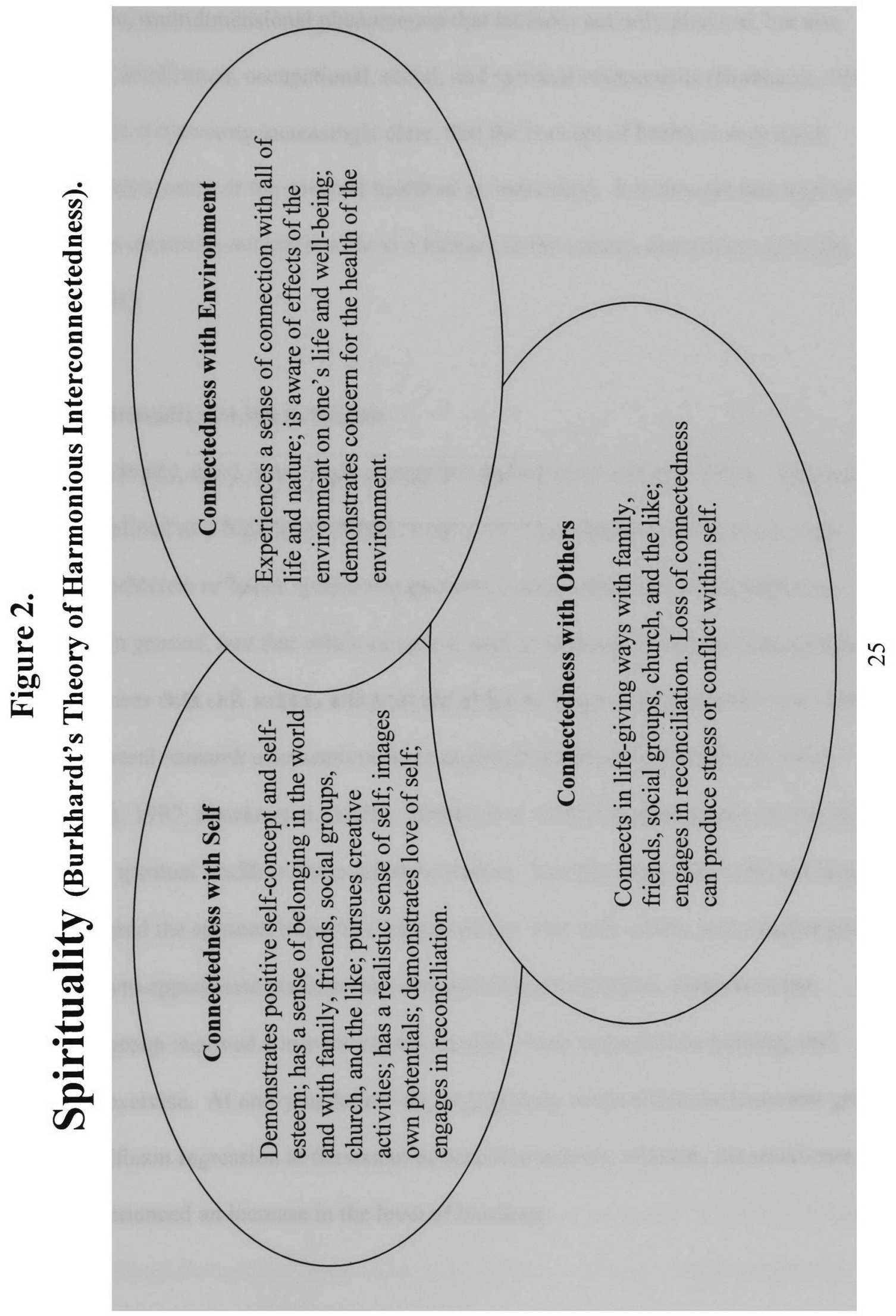


as a holistic, multidimensional phenomenon that includes not only physical, but also emotional, intellectual, occupational, social, and spiritual components (Burkhardt, 1989). However, it is becoming increasingly clear, that the concept of health is very much related to spirituality or the spiritual health of an individual. It is thought that high levels of wellness cannot be achieved without a balance in the various dimensions of health (Reed, 1991).

\section{Spirituality's Link to Health}

Currently, there is no single recognized definition of spiritual health. Spiritual health is defined as a high level of faith, hope, and commitment in relation to a welldefined worldview or belief system that provides a sense of meaning and purpose to existence in general, and that offers an ethical path to personal fulfillment that includes connectedness with self, others, and a higher power or larger reality (Hawks et al., 1995).

Several research interventions have explored spiritual health (Hassed, 1999; Kavanaugh, 1997; Hawks et al., 1995). Hawks et al. (1995) explored three models for enhancing spiritual health in three different studies. The first study, the Lifestyle Heart Trial explored the spiritual impact of connectedness with self, others, and a higher power. In addition to appropriate medical interventions (when necessary), subjects in the treatment group received a low-fat vegetarian diet, stress management training, and moderate exercise. At one-year follow-up, angiography showed that the treatment group had a significant regression in the extent of occluded arteries; whereas, the usual-care group experienced an increase in the level of blockage. 
Hawks et al. (1995) reviewed a research study that explored cancer by using group support with a spiritual impact of meaning and purpose in life, connectedness with self and others, and contemplating a larger reality. This study's impact on behavior was on family communication, doctor-patient communication, treatment compliance, and expressing of emotions. The health impact of this study was decreased mortality, less pain, improved mood and tastes, and enhanced immune function (Hawks et al., 1995).

Hawks et al. (1995) also reviewed a study that used meditation as a form of spiritual intervention in another study. Regular use of stress reduction techniques reduced anxiety, pain, depression, panic attacks, and medical symptoms. The patients also experienced psychological improvement in their attitudes.

In Bensley's (1991) “Defining Spiritual Health: A Review of the Literature," he concluded that total health consists of a variety of components, notably physical., mental., emotional., social., and spiritual dimensions of health. Ram (1988) hypothesized that spiritual health is an inseparable unity of body, mind and spirit; consequently, illhealth can be caused by a disturbance in relationships between these factors.

\section{Measures Related to Spirituality}

The present study utilized operational measures of the different components of spirituality as defined by Burkhardt and measured by the Rosenberg's Self-Esteem Scale (Rosenberg, 1965), HPLP II (Walker et al., 1987), and the Spiritual Perspective Scale (Reed, 1986, 1987). Although other researchers have used the HPLP II and Burkhardt's model, none have used the combination of the HPLP II, Rosenberg's Self-Esteem Scale, and the Spiritual Perspective Scale. This combination is unique to the present study. 
Specific connections of the measures to Burkhardt's framework include: self-esteem and spiritual growth, which are related to the concept of connectedness with self; interpersonal relations and stress management, which are related to connectedness with others; and finally, health responsibility and spiritual perspective scale, which are related to connectedness with the environment/universe.

\section{Self-Esteem}

In Burkhardt's Theoretical Framework, self-esteem is related to the framework in connectedness with self. The framework explains that an individual that exhibits connectedness with self demonstrates a positive self-concept and self-esteem (Burkhardt, 1989), thus this is included as a measure of spirituality in this dissertation research.

Faith et al (1998) examined self-esteem as it related to African Americans in four nationally representative samples. These authors critiqued data sets of previous studies and focused specifically on self-esteem in African American populations. The first study sample examined self-esteem in an adolescent population, a sample of 2,788 , mainly African American females between 13 and 20 years old. The gender breakdown of the sample was $76.4 \%$ female and $23.6 \%$ male. The mean age was $16.14 \pm 1.40$. Only African Americans with complete weight, height, and self-esteem were included in the analysis. This study concluded that there were no significant interactions in terms of BMI, age, and sex as it related to self-esteem. Self-esteem was measured in the second study designed to investigate the life experiences of a nationally representative group of young adults born in the late 1950s and early 1960s. This study sample analyzed a total of 2,589 subjects, who were between 14 and 22 years old, specifically, 1,286 males and 
1,303 females, all of whom considered themselves African American. The mean age score was $17.55 \pm 2.23$. The dependent variable self-esteem was operationalized using the Rosenberg Self-Esteem Scale. Scores in this sample ranged from 10 to 40, with a mean of $22.57 \pm 2.53$. Self-reported measures of height and weight were then converted to BMI. The range of BMI scores was 12.41 to 51.49 with a mean of $23.02 \pm 3.8$. Again, interactions on relative body weight, age, or sex with self-esteem, were not statistically significant.

In the third study sample, self-esteem related to relative body weight in high school African Americans. The study was conducted by the National Center for Education Statistics (NCES) for the purpose of studying longitudinally the educational., vocational., and personal development of young people. Subjects were included from the first wave of sophomores from the 1980 High School and Beyond survey $(n=3,514$ African Americans). The gender breakdown of subjects was $55.9 \%$ female and $44.1 \%$ male. Their mean age was $15.67 \pm 0.82$. The study concluded that when self-esteem was regressed on relative body weight, the resulting $\mathrm{R}^{2}$ was only 0.001 , but reached statistical significance $(\mathrm{p}=0.039)$.

The final study sample by Faith et al. (1998) was designed to examine the cultural experiences of African Americans. This was the first nationally representative crosssectional survey of an adult African American population in the United States. Subjects were 2,107 African Americans, 18 years and older. The gender breakdown was $62.2 \%$ female and $37.8 \%$ male. The mean age of subjects was $43.07 \pm 17.73$. The Rosenberg Self-Esteem Scale was used in the study to determine any relationship with relative body weight in this sample. Relative Body Weight (RBW) was subjectively assessed by the 
interviewer on a 7-point ordinal scale anchored by the two ends with terms

"underweight" and "overweight." Among the subjects analyzed, the mean RBW was

$4.20 \pm 1.08$. This study concluded that there was no significant relationship with selfesteem as it relates to body weight.

There has been an overwhelming belief among researchers that African Americans are relatively unaffected by their body weight. However, the data fail to support the idea that women want to be overweight or that they are unaffected by their weight. Moreover, the reasons why African American women seem relatively "tolerant" of overweight are unknown at this time and warrant further research.

\section{Health Promoting Lifestyle Profile}

There are many subscales of the HPLP II that are connected to Burkhardt's theoretical framework (Walker, 1987). These subscales of the HPLP II are: spiritual growth, health responsibility, physical activity (exercise), nutrition, interpersonal relations, and stress management (Walker, 1987). Specific connections of the HPLP subscales to Burkhardt's framework include: spiritual growth, which is related to the concept of connectedness with self; interpersonal relations and stress management, which are related to connectedness with others; and finally, health responsibility, which is related to connectedness with the environment/universe. Specific connections of the HPLP subscales to the dependent variables of diet and exercise are nutrition and physical activity.

Waite conducted a study to correlate spiritual well-being and health behaviors within a population of the workforce at a large home fitness equipment company located 
in northern Utah. A convenience sample, with a size of 208, was taken from the workforce population (Waite et al., 1999). A combined questionnaire using the Health Promoting Lifestyle Profile II (HPLP II) and an author-created nonsmoking subscale were used. The three subscales (health responsibility, spiritual growth, and interpersonal relations) reflect the multidimensional definition for spiritual health adopted for the Waite et al. study. The nutrition, exercise, and stress management subscales were used to measure health promoting behaviors.

This sample was $87.5 \%$ White, and $64.5 \%$ were 25 years old or younger. In contrast to this study's sample, the U.S. adult workforce is around $46 \%$ female and $85 \%$ White, with only $16 \% 24$ years old or younger. The sample was relatively homogeneous in terms of religious affiliation, with $79 \%$ identified as Latter-day Saints, $7 \%$ identified as Catholics, $2 \%$ identified as Protestants, and $12 \%$ identified as "other." Subjects were also active in their faiths, with $60 \%$ who said they attended church weekly and $14.5 \%$ who said that they attended church monthly (Waite et al., 1999).

The study by Waite et al. found that gender and employment status contributed a statistically significant effect on spiritual health scores, with women scoring higher than men $(\mathrm{p}=.03)$ and white-collar employees scoring higher than blue-collar employees $(p=.02)$. Both race and age approached significance, with Whites scoring slightly higher than non-Whites $(p=.07)$ and those 26 years old and older scoring slightly higher than those 26 years old or younger $(p=.07)$. One limitation was that the sample was atypical because of the young age and the high concentration of Latter-day Saints. Latter-day Saints may be more religiously active and spiritually aware than the average working 
population or Whites in general. However, African American women, the targeted population of this study, are also known to be religiously active.

Ahijevych and Bernhard (1994) investigated the concept of health promoting behaviors of 187 African American women who were between 18 and 69 years old. The purpose of the study was to describe health promoting lifestyle behaviors among a sample of African American women and to compare these findings to other published reports on the HPLP II instrument. The participants were recruited from neighborhood health centers, a community center, a job-training program, and health care and office work sites in a major midwestern city. The subscales with the highest mean were selfactualization $(\mathrm{M}=2.89, \mathrm{SD}=.53)$ and interpersonal support $(\mathrm{M}=2.9, \mathrm{SD}=.59)$, which are components of the original HPLP I instrument. The exercise subscale had the lowest mean $(\mathrm{M}=1.95, \mathrm{SD}=.65)($ Ahijevych \& Bernhard, 1994).

African American women tend to report higher performance on health responsibility than most other groups; however, they have scored low on the physical activity subscale of the HPLP II (Ahijyevych \& Bernhard, 1994; Duelberg, 1992; Brady and Nies, 1999).

A study comparing the lifestyles of obese and non-obese African American and European American women in a southern city used a two-by-two comparative description design (Nies et al., 1998). The sample $(\mathrm{n}=86)$ consisted of women purposefully selected by BMI and race. Twenty were obese (BMI>30) African American women, 22 were obese European American women, 20 were non-obese $(\mathrm{BMI}<25)$ African American women, and 24 were non-obese European American women between 20 and 45 years old. The HPLP II was used to measure health promoting behaviors. The study found that 
obese women scored lower on the HPLP II than did non-obese women for each of the six subscales of the HPLP II and for the total score. The study also concluded that the nutrition subscale of the HPLP II was the only subscale for which African American women had significantly lower scores than European American women, which indicates that African American women had poorer dietary habits when compared to their European counterparts. For the most part, there were no differences on the HPLP II among African American and European American women. These data are consistent with research among African American women as it relates to nutrition intake and scores on the HPLP II Nutrition subscale.

In yet another study, the health promoting practices of Black women at risk for diabetes were examined (Jefferson et al., 2000). The sample consisted of 30 Black women from an urban area who had a history of gestational diabetes and/or a first-degree relative with diabetes. This study utilized the HPLP II to measure the health promoting behaviors of these women, between 25 and 44 years old. These women were of African American, African, and Caribbean descent. Most of the women (26 of 30) were African American. Twenty-eight women resided in New Haven, Connecticut. The mean weight of the participants was 197 pounds, with a range of 130 to 344 . The mean height was 66 inches, and mean BMI was $31.5 \pm 7.6$, with a range of 20 to 54 . The investigators found that health promoting behaviors in this sample, such as diet modification and exercise, were not practiced routinely. In the six subscales studied, out of a possible 4 points, the women had the highest mean scores in spiritual growth $(2.96 \pm 0.59)$, interpersonal relations $(2.95 \pm 0.53)$, and health responsibility $(2.59 \pm 0.59)$. Lower mean scores were obtained in stress management $(2.33 \pm 0.5)$ and nutrition $(2.31 \pm 0.54)$. These data were 
consistent with a plethora of research on the diet and exercise practices of African American women.

\section{Spiritual Perspective Scale}

The Spiritual Perspective Scale (SPS) is related to the Burkhardt framework in connectedness with the environment/universe. The framework explains that an individual that exhibits connectedness with the environment demonstrates that an individual experiences a sense of connection with all of life and nature, is aware of effects of the environment on one's life and well-being, and demonstrates concern for the health of the environment (Burkhardt, 1989); consequently, this framework is included as a measure of spirituality in this dissertation research.

Reed (1986) first compared terminally ill adults with healthy adults for differences in religiousness and a sense of well-being. Reed used two questionnaires, the Religious Perspective Scale (RPS) and the Index of Well-being. The RPS was used to measure religious beliefs and behaviors that exist in a person's life (Reed, 1986). Specifically, the RPS measures "the extent to which persons hold certain religious beliefs and engage in religiously oriented interactions with others and with God". The study looked at 114 participants, a terminally ill group $(n=57)$ and a healthy group $(n=57)$.

This study concluded that there was no difference between the groups on sense of well-being; both groups indicated moderately high levels of well-being. A positive relationship between religiousness and well-being was found in the healthy group $(r=.43$, $\mathrm{p}<.001$ ), but not for the terminally ill group. The majority of the individuals in this study 
were White (85\%), which means that these data cannot be extrapolated to a population of African American women.

Reed (1987) made minor modifications to her RPS based on the analysis done in a previous study (Reed, 1986). The new instrument was named the Spiritual Perspective Scale (SPS). This instrument was modified because religion is a narrower term when compared to spirituality. The new instrument was used to measure the saliency of spirituality. It is a 10-item scale that measures "person's perspectives on the extent to which spirituality permeates their lives and how they engage in spiritually related interactions." This was incorporated because it measures spiritually related interactions versus religiously related interactions that deal with going to a place of worship. The new instrument measures spiritually related interactions that do not have a basis in a religious place of worship.

Reed (1987) measured the significance of spirituality among terminally ill adults. A sample of 300 adults from the same geographical location was distributed into three groups of 100 according to the following criteria: Group 1, terminally ill hospitalized cancer patients who were aware of the terminal nature of their illness; Group 2, nonterminally ill hospitalized patients; and Group 3, healthy nonhospitalized persons. Each participant completed both the SPS and the Index of Well-Being (IWB).

The significant results of this study were that there was a positive relationship between spiritual perspective and well-being in terminally ill hospitalized patients (Group 1). The Pearson product moment correlation was .22 (p<.02) (Reed, 1987). This relationship was not significant for Groups 2 or 3 . The study results also showed that terminally ill hospital adults (Group 1) indicated greater spiritual perspective than either 
nonterminally ill hospital adults (Group 2) or healthy nonhospitalized adults (Group 3)

(Reed, 1987). The mean score on the SPS for Group 1 was 4.530 (SD = 1.38); for Group 2, $4.157(\mathrm{SD}=1.27)$; and for Group 3, $4.160(\mathrm{SD}=1.36)$. Individual SPS scores ranged from 1 to 6 (Reed, 1987).

This study concluded that a significantly larger number of terminally ill adults indicated a change toward increased spirituality than did nonterminally ill or healthy adults (Reed, 1987). The present dissertation research used SPS as part of the measure of spirituality. Although this research is not with terminally ill patients, spirituality may be related to the health promoting behaviors of diet and exercise in this group of African American women.

\section{Health Promoting Behaviors}

\section{Diet}

Dietary patterns of minority groups may differ from those of the general population due to several factors. These factors include the nature of the original diet, the ways the diet has been adapted to or supplanted by dietary patterns from the dominant US culture, availability of preferred foods, and acculturation (Sanjur, 1982; Kittler \& Sucher, 2001). It should be stated at the onset that there is no African American dietary pattern in the same sense that there are Asian, Hispanic, or Native American dietary patterns (Sanjur, 1982). The unique cultural pattern, rather than regional or socioeconomic influence on African American dietary patterns, relates to the types of foods that were available to African Americans during slavery. Slaves who worked in the fields developed meals requiring minimal preparation, which were suitable for preparation in 
large quantities. Characteristic foods made use of cuts of pork that were available or inexpensive and undesirable to Whites (e.g., tail, feet, chitterlings, ears) (Sanjur, 1982; Kittler and Sucher, 2000). Today, the term "soul food" is often used to identify the foods that African Americans have consumed for years, which are high in salt, fat, and calories. In an effort to reach this audience, the Food Guide Pyramid was adapted and the "Soul Food Pyramid" was created (www.soulfoodpyramid.org, Accessed 06/20/03).

Dietary factors are well documented as risk factors for many diseases. Some of these diseases are listed among the ten leading causes of death in African American adults. The eating habits and food purchasing practices of African Americans may be associated with the increased incidence of hypertension, cardiovascular disease, and diabetes in later life. These chronic disease risk factors are commonly explained by dietary habits and African Americans may be at higher risk from these factors compared to Whites. African Americans consume less fruits and vegetables, dietary fiber, calcium, and potassium, while they consume fatty meats, salt, and dietary cholesterol in excess (Kumanyika, 1990).

Although there have been some marked improvements in the diet of African Americans, they are still targeted in Healthy People 2010 as needing an increase in consumption of fruits and vegetables, dietary fiber, while conversely decreasing intakes of total fat and saturated fat. This may be paramount among the reasons for the increased incidence of diabetes, hypertension, and cardiovascular disease within this cultural group. The more recent findings of Dietary Approaches to Stop Hypertension (DASH) point to these same parameters (Sacks et al., 2001). The Seventh Report of the Joint National Committee on Prevention, Detection, Evaluation and Treatment of High Blood Pressure 
recently recommended lifestyle modifications including losing weight if overweight, eating more low-fat dairy foods, fruits and vegetables as part of the DASH eating plan, reducing dietary sodium, exercising more and limiting alcohol consumption (Chobanian et al., 2003).

A study to determine the dietary fat patterns of African American women in an urban setting in East Baltimore was done on a sample of 521 women between 18 and 91 years old with a mean age of $45 \pm 14$ years. These women completed a standardized instrument, the Fat Intake Scale (FIS), to estimate dietary fat intake and usual food choices. Body weight, height, and total serum blood cholesterol were analyzed using standardized measurement techniques. The majority of the women had completed high school and or had some college education ( $82.3 \%)$. Most were employed full time (70.1\%). BMI measurements ranged from 16.6 to 63.4 (mean $30.4 \pm 7.7$ ). Mean total cholesterol was $212.6 \pm 49.5 \mathrm{mg} / \mathrm{dl}$. Cholesterol levels ranged from $<100 \mathrm{mg} / \mathrm{dl}$ to 481 $\mathrm{mg} / \mathrm{dl}$. Thus, the majority or $65 \%$ of the values fell between 193.1 and 262.1 . The study found that $61 \%$ of the women were classified as obese $(p<.001)$ of which more than $81 \%$ had a fat intake score of 25 or greater $(p<.001)$, which was considered to be associated with higher fat and cholesterol intake (Kayrooz et al., 1998).

The National Health and Nutrition Examination Survey (NHANES) is nutrition status survey that is ongoing. The data provides valuable information on several nutrition related conditions. For comparison with studies on African American women, the NHANES, which is a representative sample of the U.S. population, provides a picture of the nutritional status of the nation. An assessment of total fat and energy intake of participants in NHANES III reports percentage total fat and saturated fat intakes of 
$33.9 \%$ and $11.9 \%$, respectively; moreover, the report reveals an average mean energy intake of 2,123 kilocalories for the 13,314 participants $\geq 2$ years old (NCHS, accessed 3/17/03).

The objectives for Healthy People 2010 set several food and nutrient consumption goals because research shows that higher intake of vegetables, fruits, and grains are associated with a variety of health benefits (U.S. Dept. HHS, 2010, 2000). A study to examine baseline rates of fruit and vegetable consumption among adults in a 5-A-Day research trial was done to identify any regional and sociodemographic differences associated with daily servings (Thompson et al., 1999). A nationally representative sample of 15,060 participants was chosen from seven study centers. A 7-item abbreviated food frequency questionnaire was used by all study centers. The seven study centers gathering adult consumption data were located throughout the United States. The regions included Northeast (Dana Farber Cancer Institute, Boston, Massachusetts DFCI), the Southeast (North Carolina Department of Environment, Health, and Natural Resources - DEHNR-NC), the Pacific Northwest (the Fred Hutchinson Cancer Research Center in Seattle, Washington - FHCRC), the Midwest (Minnesota Department of Health, Minneapolis - MDH), the South (University of Alabama at Birmingham - UAB), the Southwest (University of Arizona, Tucson - UAZ), and the East (University of Maryland, Baltimore - UMD). Study centers varied in number of sites ( $n=15$ to 50$)$. There were large variations across centers in all of the characteristics. The percentage of women ranged from $26 \%$ to $100 \%$.

The study found that individuals $<30$ years consumed an average of 3.7 servings of fruits and vegetables per day, as did those $\geq 50$ followed by those between 30 and 49 
years old, who consumed an average of 3.4 servings daily. Blacks consumed 3.7 servings per day, as did those who considered themselves "other," followed by Whites who consumed 3.6 servings per day and finally, Hispanics who consumed an average of 3.0 servings per day. College graduates consumed 3.9 servings per day, followed by those with some college who consumed 3.5 servings per day, and those who have attended some high school or were high school graduates consumed 3.4 servings per day. The study concluded that there were two overall patterns of fruit and vegetable consumption that emerged from the research. Patterns showed lower consumption by Hispanics (DFCI-Northeast; FHCRC-Pacific Northwest; UAZ-Southwest). A second pattern indicated that subjects in the "other" group consumed more than Hispanics.

Both Kumanyika (1990) and Thompson (1999) show that African American women consume too much fat and too little fruits and vegetables. These behaviors are associated with increased incidence of chronic disease.

\section{Exercise}

The relationships between physical activity and health are numerous and complex. The American Heart Association identified physical inactivity as an independent risk factor for the development of coronary heart disease (Fletcher et al., 1992). A trend for decreased physical activity levels in older African American adults, especially women, has been reported. Ainsworth et al. (1992) examined the physical activity and fitness levels of African American men and women and concluded that these levels, especially in females, were low. Kann et al. (1993) found that the pattern of inactivity had already been established as early as ninth grade in African Americans. 
Therefore, one of the goals of this proposal is to determine whether physical activity is influenced by spirituality in this group of women.

Regular aerobic activity increases exercise capacity, and plays a role in both primary and secondary prevention of cardiovascular disease (Fletcher et al., 1992). Exercise can help control blood lipid abnormalities, diabetes, obesity, and improve cardiovascular health. In addition, aerobic exercise adds an independent, modest blood pressure-lowering effect in certain hypertensive groups (Fletcher et al., 1992). Ainsworth et al. (1992) suggested an inverse relationship between physical activity and cardiovascular mortality and inactivity is a risk factor for the development of coronary artery disease (Ainsworth et al., 1992).

In a position paper, The American College of Sports Medicine (1990) addressed questions about recommended amounts and types of exercise for maintaining cardiorespiratory fitness in adults. Their recommendations are based on individual assessments and reflect the difficulties in finding a "one size fits all" exercise regime. However, there is no question that the combination of diet and exercise with weight loss can lead to changes in blood lipid profiles, which may be accompanied by a reduction of the commonly accepted CHD risk factors of obesity and overweight (Fox et al., 1996, Flegal et al., 2002, Freedman et al., 2002, Jakicic et al., 2002).

A study by Brady and Nies (1999) compared the health promoting behaviors and exercise behaviors of older African American women above and below the poverty level. Fifty-eight women between 25 and 45 years old completed a demographic form and the Health Promoting Lifestyle Profile. The research study took place on a Sunday, at a midsouthern Baptist church, after the church service in the Bible study room. Findings 
from this study indicated that African American women living above poverty level engaged in more health promoting behaviors than did African American women living below poverty level. The mean scores of African American women on the exercise subscale of this study were also low $(m=1.72)$ for those living below poverty $(m=2.30)$ on a scale of 1 to 4 (Brady \& Nies, 1999).

Gillis and Perry (1990) examined the interrelationships among physical activity, perceived well-being, self-esteem, health status, health locus of control and health promoting lifestyle activities in 126 women between 35 and 65 years old residing in a rural eastern Canadian province. Women had to be willing to participate in a 12-week program of physical activity and had to be absent of cardiovascular disease. Subjects were randomized into either a control group or an experimental group. The experimental group participated in three 60-minute exercise classes each week for 12 weeks. Several instruments were utilized to collect data in the study, Cantril's Well-Being Ladder (CWBL), Rosenberg's Self-Esteem Scale (RSES), Health Locus of Control (HLC), Health Promoting Lifestyle Profile (HPLP II), and the Health Perceptions Questionnaire (HPQ).

For self-esteem, the impact of exercise on the subjects' basic feeling of self-worth was compared to scores on the RSES for the three times it was measured. The subjects' measures of self-esteem improved over time for both groups. On the HPLP II subscale of exercise, the experimental group showed a consistent and greater improvement in HPLP II scores over time following the exercise classes than the control group. Overall, the study concluded that self-esteem improved with exercise and that the subjects felt they 
were in control of their health. One limitation of this study was the inclusion of only White women, and thus cannot be extrapolated to the general population.

\section{Measures of Health Promoting Behaviors}

\section{Diet}

It is important to realize that because of the complex nature of individual diets and the substantial variability of food intake over time, measurement errors are inevitable (Willett, 2001). Therefore, different methods of dietary analysis should be compared to determine which is appropriate to this nutritional epidemiologic study.

Nutritional exposures are considered among the major modifiable risk factors for several chronic diseases. The most practical and economical method for collection of comprehensive dietary data in epidemiologic studies is the Food Frequency Questionnaire (FFQ). Knowledge about the long-term consequences of diet is centrally dependent on the methods used to measure the intake of foods by individual participants in epidemiologic studies (Willett, 2001). In this context, self-administered questionnaires are usually a practical necessity; several different self-administered food frequency questionnaires have been developed (Willett, 2001). The Willett Food Frequency and the Block Food Frequency questionnaires are the most widely used in both nutrition and epidemiological research. 


\section{Definitions}

\section{Willett Food Frequency Questionnaire}

The Willett Food Frequency queries respondents about 126 foods and is a four page booklet. It does not include separate portion size questions but asks respondents to report their frequency of a given reference portion size. It includes ten dietary supplement questions and ten questions regarding fat intake. The questionnaire is scanned and processed at Harvard University (Subar et al., 2001).

\section{Block Brief Dietary Questionnaire}

The Block Brief Dietary Questionnaire is a quantitative food frequency questionnaire in use by over 700 research groups and public health agencies in the US. The original FFQ was developed using data from NHANES II (Subar et al., 2001), and was made available in 1992 as a scannable version and revised again in 1995 . The Block Brief Dietary Questionnaire has been substantially revised, based on the NHANES III food intake data (Block et al., 1998). The availability of new food data from NHANES III made it possible to revise both the questionnaire and the nutrient database, and also to incorporate foods important in the U.S. diet. The Block FFQ also revised its portion size approach. Portion sizes were previously based on "Small, Medium, Large" questions, but the new questions target specific quantities; moreover, they include portion size photos as an aid in estimating usual portion size for each food. The photos are of simple abstract three-dimensional models representing four different amounts of food. The revised questionnaire remains an eight-page scannable booklet. There are 109 food items, representing at least $90 \%$ of each of the nutrients on the NHANES III database; also, 
additional nutrition-related questions such as servings of fruit and vegetables, frequency and type of fat in cooking, and vitamin supplement usage are incorporated.

The Eating at America's Table Study (EATS) (Subar et al., 2001) sought to validate and compare the Diet History Questionnaire (DHQ) with the Block and Willett FFQs. The DHQ was a 36-page booklet. The DHQ queries the frequency intake of 124 separate food items and asks portion size for most of these by providing a choice of three ranges (Subar et al., 2001). For 44 of the 124 foods, from one to seven additional embedded questions are asked about related factors such as seasonal intake, food type, and/or fat uses or additions (Subar et al., 2001). The DHQ also includes six additional questions and ten dietary supplement questions.

The 1995 Block and the Willett (purple form) instruments were the versions used in EATS, since they were the most common FFQ used to date. The Block FFQ is eight pages and queries 106 foods. It asks usual portion size as "small," "medium," or "large," providing reference medium portion sizes. In addition, it includes 13 dietary supplement questions, six questions on restaurant eating, five summary questions, eight questions on fat use or low-fat foods, and seven demographic/health-related questions (Subar et al., 2001). The four-page Willett FFQ queries 126 foods. It does not include separate questions on portion sizes, but asks respondents to report their frequency of a given reference portion size. It includes ten dietary supplement questions and ten questions primarily regarding fat intake (Subar et al., 2001).

In 1997, the EATS (Subar et al., 2001) was used to survey 1,640 men and women recruited to participate from a nationally representative sample; 1,301 participants completed four telephone 24-hour recalls, one in each season. Participants were 
randomized to receive either a DHQ and Block FFQ or a DHQ and Willett FFQ. With a standard measurement error model, correlations for energy were estimated between estimated truth and the DHQ, Block FFQ, and Willett FFQ; the results were $0.48,0.45$, and 0.18 for women, respectively, and $0.49,0.45$, and 0.21 for men, respectively. For 26 nutrients, correlations and attenuation coefficients were somewhat higher for the DHQ versus the Block FFQ; both were better than the Willett FFQ in models adjusted for energy. The DHQ performed best overall (Subar et al., 2001). These data show that the DHQ and the Block FFQ are better at estimating absolute intakes than is the Willett FFQ, but that after energy adjustment, all three are more comparable for purposes of assessing diet-disease risk.

After reviewing the EATS study by Subar et al. (Subar et al., 2001), it was decided that the best tool for this dissertation research is the revised Block Dietary Questionnaire. This decision was based on the fact that the Block FFQ is a more concise questionnaire and meets the needs of this research topic. Some of the advantages of using this questionnaire are that it is easily administered and it gives a complete picture of not only what this population is consuming, but also important information on how they are preparing these foods. It is well known that dietary patterns of minority groups may differ from those of the general population due to several factors. Some of these factors include the nature of the original diet, purchasing practices, and cooking practices. These behaviors are very much associated with increased incidence of chronic disease in this group of women. This Block FFQ will give valuable information on how much fat this population consumes, their fruit and vegetable consumption, and consumption of 
various vitamins and minerals. All of these behaviors are associated with increased incidence of chronic diseases.

\section{Exercise}

Physical activity is considered to be one of the major modifiable risk factors for several chronic diseases. The most practical and economical method for collection of comprehensive dietary data in epidemiologic studies is to collect information on type and duration of physical activity. Knowledge about the long-term consequences of lack of physical activity is centrally dependent on the methods used to measure physical activity of individual participants in epidemiologic studies (Baecke et al., 1982). In this context, several different measures of physical activity are available.

The Health Promoting Lifestyle Profile II was appropriate for measuring the physical activity of the women in this study. It was the simplest way to get detailed information on their physical activity for the information that was needed for this study. The HPLP II has several questions that relate to physical activity; these questions are known as the subscale of physical activity. The following questions make up the HPLP II subscale physical activity: (1) follow a planned exercise program; (2) exercise vigorously for 20 or more minutes at least three times a week (such as brisk walking, bicycling, aerobic dancing, using a stairclimber); (3) take part in light to moderate physical activity (such as sustained walking 30 - 40 minutes five or more times a week); (4) take part in leisure-time (recreational) physical activities (such as swimming, dancing, bicycling); (5) do stretching exercises at least 3 times per week); (6) get exercise during usual daily activities (such as walking during lunch, using stairs instead of elevators, 
parking car away from destination and walking); (7) check my pulse rate when

exercising; and (8) reach my target heart rate when exercising (Pender et al, 1995).

\section{Summary}

Research on the African American female diet indicates a lack of fruits and vegetables and high fat intake. This lack of fruits and vegetables and high fat intake indicate that these women will be at increased for certain chronic diseases. Their exercise habits have been found to be lower than recommended levels for health promotion. These are two key health promoting behaviors identified to be measured in this dissertation research, diet and exercise.

Burkhardt's theoretical framework for spirituality has been adopted as the model measuring this broad and encompassing concept. The three elements that were examined are connectedness with self, connectedness with others, and connectedness with the environment/universe. Burkhardt often refers to these three elements as harmonious interconnectedness.

The published research presented in this chapter on a few occasions crossed the boundaries of examining the relationship of health promoting behaviors to spirituality. When it did, the measures were perhaps singular or the population did not include African American women. Noticeably lacking is definitive research looking at spirituality as a predictor, among others, of health promoting behaviors of diet and exercise.

There have been several studies that examined health promoting behaviors utilizing the HPLP II including African American populations. None have used an 
overarching model of spirituality such as Burkhardt's, which encourages other measures of spirituality to be examined. In summary, this dissertation research used this broader framework of spirituality linked with diet and exercise.

\section{Theoretical Framework}

Burkhardt (1989) suggested that there are three concepts that foster a spiritual interconnectedness: connectedness with self, connectedness with others, and connectedness with the environment/universe (see Figure 2). This theoretical framework was the foundation of this dissertation and was the basis for viewing the spirituality of African American women (see Figure 1). Table 1 further defines the Burkhardt model components with the subconcepts and measurements used in this study.

Connectedness with self is when an individual demonstrates positive self-concept and self-esteem; has a sense of belonging in the world and with family, friends, and social groups, church, and the like, and has a realistic sense of self. Connectedness with self was measured using the Rosenberg Self-Esteem Scale and the HPLP II Spiritual Growth subscale. These instruments together essentially measured the spiritual views of these women and how they engage in spiritually related interactions. They also measured their self-acceptance, self-esteem, and the basic feeling of self-worth. Whether these women engaged in personal development was also measured.

Connectedness with others demonstrates whether individuals connect in lifegiving ways with family, friends, social groups, church, and the like; also, it ascertains whether they engage in reconciliation. It will further determine whether they have conflict with loss of connectedness, causing stress. Connectedness with others was 
Table 1. Burkhardt Model Descriptions and Measures

\begin{tabular}{|c|c|c|c|c|}
\hline $\begin{array}{l}\text { Burkhardt's } \\
\text { components }\end{array}$ & Subconcepts & Measures & Description & $\begin{array}{l}\text { Rationale for } \\
\text { Use }\end{array}$ \\
\hline \multirow[t]{2}{*}{$\begin{array}{l}\text { Connectedness with } \\
\text { self: positive self- } \\
\text { concept and self- } \\
\text { esteem; has a sense } \\
\text { of belonging in the } \\
\text { world and with } \\
\text { family, friends, and } \\
\text { social groups, } \\
\text { church, and the like } \\
\text { and has a realistic } \\
\text { sense of self. }\end{array}$} & $\begin{array}{l}\text { Self-esteem: } \\
\text { pride in } \\
\text { oneself }\end{array}$ & $\begin{array}{l}\text { Rosenberg Self- } \\
\text { Esteem Scale }\end{array}$ & $\begin{array}{l}\text { Measures the } \\
\text { self-acceptance } \\
\text { component of } \\
\text { self-esteem as a } \\
\text { basic feeling of } \\
\text { self-worth }\end{array}$ & $\begin{array}{l}\text { It is designed } \\
\text { to measure } \\
\text { self-esteem } \\
\text { and is } \\
\text { closely } \\
\text { matched to } \\
\text { the } \\
\text { Burkhardt } \\
\text { model. This } \\
\text { instrument } \\
\text { has not been } \\
\text { used } \\
\text { previously } \\
\text { with this } \\
\text { model. }\end{array}$ \\
\hline & $\begin{array}{l}\text { Personal } \\
\text { Development: } \\
\text { sense of } \\
\text { purpose and } \\
\text { self worth }\end{array}$ & $\begin{array}{l}\text { HPLP II } \\
\text { Spiritual Growth } \\
\text { subscale }\end{array}$ & $\begin{array}{l}\text { Focuses on } \\
\text { feeling } \\
\text { connected with } \\
\text { a force greater } \\
\text { than oneself, } \\
\text { having a sense } \\
\text { of purpose in } \\
\text { life, and seeking } \\
\text { personal } \\
\text { development }\end{array}$ & $\begin{array}{l}\text { It is designed } \\
\text { to measure } \\
\text { whether an } \\
\text { individual is } \\
\text { developing } \\
\text { their self } \\
\text { worth and } \\
\text { relates to } \\
\text { those outside } \\
\text { oneself. }\end{array}$ \\
\hline \multirow{2}{*}{$\begin{array}{l}\text { Connectedness with } \\
\text { others: demonstrates } \\
\text { whether individuals } \\
\text { connect in life-giving } \\
\text { ways with family, } \\
\text { friends, and social } \\
\text { groups, church, and } \\
\text { the like; and whether } \\
\text { they engage in } \\
\text { reconciliation. }\end{array}$} & $\begin{array}{l}\text { Reconciliation: } \\
\text { to make } \\
\text { compatible by } \\
\text { engaging in } \\
\text { relationship } \\
\text { with other } \\
\text { individuals }\end{array}$ & $\begin{array}{l}\text { HPLP II } \\
\text { Interpersonal } \\
\text { Relations } \\
\text { subscale }\end{array}$ & $\begin{array}{l}\text { Pertains to } \\
\text { maintaining } \\
\text { relationships } \\
\text { that involve a } \\
\text { sense of } \\
\text { closeness and } \\
\text { intimacy }\end{array}$ & $\begin{array}{l}\text { It is designed } \\
\text { to measure } \\
\text { whether an } \\
\text { individual } \\
\text { maintains } \\
\text { close } \\
\text { relationships } \\
\text { with others. }\end{array}$ \\
\hline & $\begin{array}{l}\text { Conflict with } \\
\text { loss of conn- } \\
\text { ectedness: } \\
\text { when there is a } \\
\text { loss of conn- } \\
\text { ection with } \\
\text { others; when } \\
\text { an individual } \\
\text { experiences } \\
\text { distress }\end{array}$ & $\begin{array}{l}\text { HPLP II Stress } \\
\text { Management } \\
\text { subscale }\end{array}$ & $\begin{array}{l}\text { Pertains to } \\
\text { recognizing } \\
\text { stressful } \\
\text { situations and } \\
\text { acting to } \\
\text { confront those } \\
\text { and achieve } \\
\text { relaxation }\end{array}$ & $\begin{array}{l}\text { It is designed } \\
\text { to measure } \\
\text { whether an } \\
\text { individual is } \\
\text { capable of } \\
\text { achieving } \\
\text { stress free } \\
\text { situations. }\end{array}$ \\
\hline
\end{tabular}


Table 1 Continued

\begin{tabular}{|c|c|c|c|c|}
\hline $\begin{array}{l}\text { Burkhardt's } \\
\text { components }\end{array}$ & Sub-concepts & Measures & Description & $\begin{array}{l}\text { Rationale for } \\
\text { Use }\end{array}$ \\
\hline $\begin{array}{l}\text { Connectedness with } \\
\text { the } \\
\text { environment/universe } \\
\text { which demonstrates } \\
\text { if individuals } \\
\text { experience a sense of } \\
\text { connection with all } \\
\text { of life and nature; is } \\
\text { aware of effects of } \\
\text { the environment on } \\
\text { one's life and well- } \\
\text { being; and } \\
\text { demonstrates concern } \\
\text { for the health of the } \\
\text { environment. It } \\
\text { further determined if } \\
\text { they had a sense of } \\
\text { reflection and } \\
\text { harmony in their } \\
\text { lives. }\end{array}$ & $\begin{array}{l}\text { Connection } \\
\text { with life \& } \\
\text { nature: } \\
\text { relationship } \\
\text { with health } \\
\text { and well-being }\end{array}$ & $\begin{array}{l}\text { HPLP II Health } \\
\text { Responsibility }\end{array}$ & $\begin{array}{l}\text { Focuses on } \\
\text { acceptance of } \\
\text { responsibility } \\
\text { for one's health, } \\
\text { being educated } \\
\text { about health, } \\
\text { and seeking } \\
\text { help from } \\
\text { health } \\
\text { professionals } \\
\text { when needed. }\end{array}$ & $\begin{array}{l}\text { It is designed } \\
\text { to measure if } \\
\text { an individual } \\
\text { maintains } \\
\text { actions that } \\
\text { achieve } \\
\text { health and } \\
\text { well-being. }\end{array}$ \\
\hline & $\begin{array}{l}\text { Sense of } \\
\text { harmony: } \\
\text { being of one } \\
\text { accord. }\end{array}$ & $\begin{array}{l}\text { Spiritual } \\
\text { Perspective } \\
\text { Scale }\end{array}$ & $\begin{array}{l}\text { Measures } \\
\text { participant's } \\
\text { perceptions of } \\
\text { the extent to } \\
\text { which they hold } \\
\text { certain spiritual } \\
\text { views and } \\
\text { engage in } \\
\text { spiritually- } \\
\text { related } \\
\text { interactions. }\end{array}$ & $\begin{array}{l}\text { It is designed } \\
\text { to measure } \\
\text { whether an } \\
\text { individual } \\
\text { maintains } \\
\text { harmonious } \\
\text { connections. } \\
\text { This } \\
\text { instrument } \\
\text { has not been } \\
\text { previously } \\
\text { used with } \\
\text { this model. }\end{array}$ \\
\hline
\end{tabular}

measured using the HPLP II Interpersonal Relations subscale and the HPLP II Stress

Management subscale. This measurement was taken to determine if these women

connect with others, including family, friends, social groups, and churches.

Connectednesses with the environment/universe demonstrates if individuals

experience a sense of connection with all of life and nature and are aware of effects of the 
environment on one's life and well-being; this concept also measures concern for the health of the environment. A sense of reflection and harmony in one's lives is also reflected in connectedness with the environment. The HPLP II Health Responsibility and the Spiritual Perspective Scale measured connectedness with the environment/universe. These three components of connectedness with self, others, and the environment comprise the theoretical framework being used for this dissertation research.

This author believes that increased spirituality ha a positive effect on both diet and physical activity. Previous research confirms that participation in these health promoting behaviors decreases chronic disease incidence, thereby increasing quality of life and decreasing health care costs in this group of women. The results of this study could be used as a guide for program planning for dietetics professionals. It will allow them to see the benefit of spirituality in developing intervention protocols to address the health promoting behaviors of diet and exercise in African American women. 


\section{CHAPTER III}

\section{METHODOLOGY}

This chapter describes the techniques, instruments, and measurements used to recruit participants and analyze data collected in this study that examined the relationship between spirituality and the health promoting behaviors of diet and exercise of African American women.

\section{Research Questions}

Sociodemographic, anthropometric (self-reported height and weight), dietary, exercise, and spirituality data were collected in this descriptive cross-sectional correlational study collected to answer the two primary questions of the study: What is the role of spirituality in impacting the health promoting behaviors (diet and exercise) of African American women? Of the independent variables of spirituality, sociodemographics, and BMI, which are the best predictors of diet and exercise?

The framework for the study and analysis is represented by the following sequence of questions:

1. What are the sociodemographic characteristics of the study participants?

2. How do African Americans score on the various spirituality subscales?

3. What is the relationship among dietary intakes, exercise habits, and BMI of African American women?

4. What is the relationship among sociodemographics, dietary patterns, as measured by the HPLP II Nutrition Subscale and the Healthy Eating Scale), and exercise habits of African American women? 
5. What is the interrelationship of spirituality, sociodemographics, and BMI?

6. What role does spirituality play in the lives of African American women as it relates to their diet and exercise habits?

7. Of the independent variables of spirituality, sociodemographics, and BMI, which are the best predictors of a healthy diet (as determined by scores from the HPLP II Nutrition Subscale and the Healthy Eating Scale) and exercise patterns in African American women?

\section{Research Design}

A descriptive cross-sectional correlational design was used to investigate the relationships among the independent variables of spirituality, sociodemographics, and BMI and the dependent variables of health promoting behaviors of diet and exercise in African American women. The design was the most appropriate for research in which variables have been identified but relationships among these variables are not known. The design also allowed the investigator to identify and examine the associations among spirituality and other independent variables of interest in African American women as they relate to their health promoting behaviors.

The independent variables were chosen to determine their influence as potential predictors for diet and exercise patterns in this group of women. Spirituality was chosen as an independent variable to determine if these women's spirituality affected their diet and exercise habits. Similarly, BMI was chosen because the focus was not weight loss but to determine if BMI was a determinant of diet and exercise activities. It is important 
to note that elevated BMI is an important risk factor in chronic disease incidence.

Sociodemographics were also chosen to determine their effect on diet and exercise.

\section{Conceptual Framework}

The conceptual framework for the study was developed using Burkhardt's Theory of Spiritual Interconnectedness. The work of Burkhardt provides a useful structure and definition of spirituality and has been used by the nursing profession. This theoretical framework gives the broad view of spirituality that includes a harmonious interconnectedness. This harmonious interconnectedness is when an individual experiences harmony in relationships with self, others, and the environment/universe (Burkhardt, 1989) (see Figure 2). The Burkhardt framework (1989) was adopted by the investigator to explain the variables of interest.

The Theoretical Framework was operationalized with specific measures. The independent variable of spirituality was measured using the following questionnaires: The Rosenberg Self-Esteem Scale, HPLP II Spiritual Growth, HPLP II Interpersonal Relations, HPLP Stress Management, HPLP II Health Responsibility, and the Spiritual Perspective Scale. The independent variable of sociodemographics was collected using a Sociodemographic Data Sheet, and height and weight were collected using the Block Brief Food Questionnaire, this information was used to determine BMI. The dependent variable of diet was measured using the Block Brief Dietary Questionnaire and the HPLP II Nutrition Subscale; exercise was measured using the HPLP Physical Activity Subscale. Dietary information from the Block Dietary Questionnaire answered questions on the total fat, saturated fat, fruit and vegetable intake, vitamin and mineral intake, and 
carbohydrate and protein intake consumed over a period of one year. The information collected on the HPLP II Physical Activity is mentioned elsewhere in this dissertation.

This conceptual framework was used in this study to investigate the interrelatedness of the dependent, and independent variables on these women's decisions to participate in the health promoting behaviors of diet and exercise.

\section{Feasibility Testing of Instruments}

The instruments were field tested to determine the feasibility of the data collection process, the optimum time of interview administration, and the readability of instruments. A total of 35 women between 18 and 55 years old, who lived in the same communities as the one planned for the main study, were recruited for the feasibility study, according to the protocol outlined in Appendix A. All instruments were administered and times recorded. At the end of the interview, participants were asked to provide feedback on the questions within the instruments. The mean time administration of the questionnaires was 1 hour 22 minutes. The information provided by the impact of duration on the instrument administration proved that collecting data in a group format was most appropriate. The feasibility study also found the questions on each questionnaire to be clearly understood by respondents.

\section{Sampling}

For the purposes of this study, the terms Black and African American will be used interchangeably. The term African American is used to describe the different Afrocentric groups residing in the United States. For the purposes of this dissertation when referring 
to the published literature, unless otherwise stated, Black and African American are interpreted as the all-encompassing terms to describe persons of African descent, whether they were African American or Caribbean American.

According to the 2000 Census, African Americans account for $21 \%$ of the population of Miami-Dade County, $14 \%$ of the population of Palm Beach County, and $18 \%$ of the population of Orange County (Orlando \& Eatonville). Specifically, 32\%, $30 \%$, and $31 \%$ of African American women in Miami-Dade, Palm Beach and Orange Counties, respectively, were in the target age group (homer.ssd.census.gov., Accessed 11/07/00). The sample was derived from these 3 counties and provided access to the 180 African American women needed to participate in the proposed study.

Census information (homer.ssd.census.gov., Accessed 11/07/00) was used to provide information on the areas where African American concentration was greatest. Therefore, particular areas of the cities chosen were used. The majority of persons living in Central Florida were located in the city of Eatonville, the community of Washington Shores, and the community of Pine Hills. For Palm Beach County, the majority of African Americans were located in Riviera Beach. For Miami-Dade County, the area of Richmond Heights was chosen because of its large population of African American women.

It was also taken into consideration that churches and local community groups would be ideal locales to collect these data, thus providing a comfortable setting for these women. Therefore, churches and community groups were targeted in areas that had a large percentage of African Americans. 
The sample was drawn from two different settings. The first setting was three African American Baptist Churches in Central and South Florida. The importance of religion at the core of African American life is well documented (Levin, 1984; Smith, 1989). It is also well known that the majority of African Americans in the South attend Baptist denominations; hence, the recruitment of subjects were from the Baptist church. The second setting was African American women's sorority and social groups. Two sorority group meetings and one social group meeting were attended to collect data. The leader of each of the aforementioned churches and women's groups agreed to allow the investigator access to the groups to recruit study participants.

Based on the investigator's knowledge of the geographical areas, a total of six churches were contacted. The Pastor or community leader of each church or community setting group was contacted and given information about the study. After three churches (one from each geographical location) agreed, the other churches were no longer pursued. A total of five women's groups were contacted, and after one women's group from each geographical location agreed, the other women's groups were not pursued further. After the church or community group agreed to allow the study recruitment from their church or community group, instruments and consent forms were sent for approval of the study.

A total of three Baptist churches and three community settings in Central and South Florida (Orlando, West Palm Beach, and Miami) were contacted (see Appendix B) by phone. The study was explained to them and they were asked for access to recruit participants from their various women's groups.

Interested churches and women's social groups identified a person who served as a liaison to facilitate the collection of data within the women's groups. The liaison was 
responsible for setting up the meeting time and place and giving the women's group leader or community group leader information relevant information about the study. The liaison also made sure that the meeting and the survey were advertised in the church well in advance of the actual meeting. The group meeting was advertised by flyers, in the church bulletins, on the marquis outside of churches, and on big screen televisions that advertise during worship services, to ensure optimum participation. The liaison was also responsible for setting up refreshments and designating two volunteers to help with the collection of data. The volunteers were needed since it was anticipated that a large group of women were expected at each data collection site. The volunteers were contacted and given information about the study and trained to proctor data collection meetings by the investigator to help with the data collection process.

Flyers detailing the survey (see Appendix C) were disseminated in churches and local community groups. Potential participants were asked by their church or community setting leaders if they would like to participate in the study. Group setting data collection meetings were set and again flyers were posted by the liaison. Participants who met the eligibility criteria were invited to attend the meetings for participation in the study by the designated liaison.

\section{Sample Size and Power}

Power analysis suggested that a sample size of 180 would have $80 \%$ power to detect an $\mathrm{R}^{2}$ of $10 \%$ using multiple regression with an alpha $=0.05$. This sample size was sufficient for correlation coefficient analysis and for canonical correlations. A sample size of 286 was used to allow for inclusion of women from more than one 
geographic area. After data were filtered to encompass only completed questionnaires, a total of 260 respondents were included in the data analysis.

\section{Inclusion Criteria}

Women who met the following criteria were included:

a) Self-identified as African American or Black

b) Florida residents $\geq 12$ months

c) Women who attended church or were involved in a women's sorority or social group.

The race/ethnicity inclusion criterion was related to interest in assessing the health promoting behaviors of African American women. Considerations of other racial/ethnic groups was outside of the scope of the proposed study, furthermore, participant availability was not feasible due to the estimated small numbers of members of other racial/ethnic groups present at the study sites.

\section{Participant Selection}

Participants were screened by the investigator to determine eligibility. Eligible women were advised that participation in the study was optional and that confidentiality would be maintained by assigning identification numbers when subjects agreed to fill out the questionnaires. Subjects were assured that no individuals would be identified by name in any publication/reports of the survey's results. Informed consent was obtained as an agreement to participate in the surveys (see Appendix D). The surveys were kept in a locked file cabinet in the major professor's office for the duration of the study. An 
application for the Institutional Review Board of Human Subjects was approved by Florida International University (090701-00) (see Appendix E).

In appreciation for their participation in the study, participants were given information on women's health. The participants were also given a 15 -minute nutritional information session and allowed to ask questions on women's health issues. A total of 286 women completed the instruments that were administered by the investigator with the help of the designated liaison.

\section{Instrumentation}

Research questions of the study, instruments, and analysis are shown in Table 2. Once the participants' eligibility was determined, the informed consent and five questionnaires (see Appendix F) were interviewer-administered in the following sequence:

Informed Consent: The risks and benefits of the study, as well as the participant's rights were outlined. Participants read and signed an informed consent, agreeing to participate in the study (see Appendix D).

Rosenberg Self-Esteem Scale: (Form \#1) The Rosenberg Self-Esteem Scale is a 10-item Likert-type scale that measured the self-acceptance component of self-esteem as a basic feeling of self-worth. Responses range from strongly agree (1) to strongly disagree (4). Lower scores reflect higher self-esteem, while higher scores represent lower self-esteem. The scale has a reported reproducibility coefficient of .92 and a scalability coefficient of .72. The coefficient alpha is .88 (Rosenberg, 1965). The 
Table 2. Research Questions

\begin{tabular}{|c|c|c|}
\hline Research Question & Form & Test \\
\hline $\begin{array}{l}\text { 1. What are the sociodemographic } \\
\text { characteristics of study participants? }\end{array}$ & Form \#4 & Descriptives \\
\hline $\begin{array}{l}\text { 2. How do African American women score } \\
\text { on the various spirituality subscales? }\end{array}$ & $\begin{array}{l}\text { Form \#1 } \\
\text { Form \#2 } \\
\text { Form \#3 }\end{array}$ & Descriptives \\
\hline $\begin{array}{l}\text { 3. What is the relationship among dietary } \\
\text { intakes, exercise habits, and BMI of African } \\
\text { American women? }\end{array}$ & $\begin{array}{l}\text { Form \#2 } \\
\text { Form \#5 }\end{array}$ & $\begin{array}{l}\text { Correlations } \\
\mathrm{X}^{2} \\
\text { One-way Anova }\end{array}$ \\
\hline $\begin{array}{l}\text { 4. What is the relationship between } \\
\text { sociodemographics, dietary patterns, and } \\
\text { exercise habits of African American women? }\end{array}$ & $\begin{array}{l}\text { Form \#2 } \\
\text { Form \#4 } \\
\text { Form \#5 }\end{array}$ & Correlations \\
\hline $\begin{array}{l}\text { 5. What is the interrelationship of spirituality, } \\
\text { sociodemographics, and BMI? }\end{array}$ & $\begin{array}{l}\text { Form \#1 } \\
\text { Form \#2 } \\
\text { Form \#3 } \\
\text { Form \#4 } \\
\text { Form \#5 }\end{array}$ & Correlations \\
\hline $\begin{array}{l}\text { 6. What role does spirituality play in the lives } \\
\text { of African American women as it relates to } \\
\text { their diet and exercise habits? }\end{array}$ & $\begin{array}{l}\text { Form \#1 } \\
\text { Form \#2 } \\
\text { Form \#3 } \\
\text { Form \#5 }\end{array}$ & Correlations \\
\hline $\begin{array}{l}\text { 7. Of the independent variables of } \\
\text { spirituality, sociodemographics, and BMI, } \\
\text { which variables are the best predictors of a } \\
\text { healthy diet and exercise patterns in African } \\
\text { American women? }\end{array}$ & $\begin{array}{l}\text { Form \#1 } \\
\text { Form \#2 } \\
\text { Form \#3 } \\
\text { Form \#4 } \\
\text { Form \#5 }\end{array}$ & $\begin{array}{l}\text { Canonical Correlations } \\
\text { Multiple Regression }\end{array}$ \\
\hline
\end{tabular}

Rosenberg Self-Esteem Scale has been used in a variety of settings of all age groups and all ethnic groups (Blascovich \& Tomaka, 1991; Tran et al., 1994; Fletcher, 1995).

Health Promoting Life-Style Profile II (HPLP II): (Form \#2) The HPLP II is a 52-item scale, divided into six subscales: health responsibility (9 questions), physical activity (8 questions), nutrition (9 questions), spiritual growth (9 questions), 
interpersonal relations (9 questions), and stress management (8 questions). The responses were coded as 1 for "Never," 2 for "Sometimes," 3 for "Often," and 4 for "Routinely." The health responsibility scale focuses on acceptance of responsibility for one's health, being educated about health, and seeking help from health professionals when needed. The physical activity scale pertains to adherence to a regular pattern of physical activity. The nutrition scale focuses on adherence to the principles set forth in the Food Guide Pyramid food categories, making food choices, and reading food labels. The spiritual growth scale focuses on feeling connected with a force greater than oneself, having a sense of purpose in life, and seeking personal development. The interpersonal relations scale pertains to maintaining relationships that involve a sense of closeness and intimacy. Finally, the stress management scale pertains to recognizing stressful situations and acting to confront those and achieving relaxation. The alpha reliability coefficient for the total scale is .92; alphas for the subscales range from .70 to .90 . The HPLP II has been used in several different populations, different age groups, and extensively in the African American population.

Foster (1992) used the HPLP II to describe and analyze the relationships between health promoting behaviors, perceived current health status, and life satisfaction in older Black adults. The study has also been used to compare racial differences in health definition, health value, and health promoting behaviors of Black and White college age women (Felton et al., 1997). Ahijevych and Bernhard described the health promoting lifestyle behaviors among a sample of African American women (Ahijevych \& Bernard, 1994). The HPLP II has been used to compare lifestyles of obese and nonobese African American and European American women (Nies et al., 1998). The tool has also been 
used to compare older African American women above and below the poverty level (Brady \& Nies, 1999) and describe the health promoting behaviors of African American women in rural northwest Florida (Frank et al., 1998).

Spiritual Perspective Scale (SPS): (Form \#3) The SPS measured the saliency of spiritual views in the participant's life. Specifically, the 10-item scale that uses a 6-point Likert-type scale that measures participants' perceptions of the extent to which they hold certain spiritual views and engage in spiritually related interactions. For the first four questions of the questionnaire, responses range from "Not at all" (1) to "About once a day" (6). For the last six questions, the responses range from "Strongly Disagree" (1) to "Strongly Agree" (6). Reliability, estimated by Cronbach's alpha, is rated consistently above .90 with minimal redundancy among the items. Average inter-item correlations range from .54 to .60 across adult groups. All item scale correlations are above .60 . The SPS has demonstrated criterion-related validity and discriminant validity (Reed, 1986, 1987). The SPS has been used with terminally ill hospitalized adults, nonterminally ill hospitalized, and healthy nonhospitalized individuals of all ethnic groups (Reed, 1987, 1991). The SPS has also been used in nursing studies to measure spiritual perspectives of nurses (Pullen, 1996).

Sociodemographic Data Sheet: (Form \#4) Sociodemographic data were collected for the purpose of describing the sample and interpreting the results. The sociodemographic information was collected using a sociodemographic data sheet (Form \#4) created by the investigator. The variables included ethnic origin, length of time having lived in the US, educational level, occupation, employment status, marital status, household status, income, church denomination, and questions on religious activities. 
The sociodemographic data form was analyzed for content validity by a panel of expert professionals with similar published research. The expert panel consisted of three $\mathrm{PhD}$, $\mathrm{RD}$; one $\mathrm{PhD}, \mathrm{RN}$; and one $\mathrm{PhD}$ Statistician. The data form was analyzed to ensure that the wording of questions was appropriate for the population in which they were to be used. Field-testing of this instrument verified these attributes.

Block Brief 2000 Dietary Questionnaire: (Form \#5) This 109-item, which represents a validated, standardized, and quantitative food frequency questionnaire was used to gather information on food these women consumed in the past year. This questionnaire was self-reported and is used in conjunction with portion size photos as an aid in estimating usual portion size for each food.

The food frequency approach entails a report of the usual frequency of consumption of each food from a list of foods for which consumption is associated with disease risk, most notably cancer, obesity, and heart disease. It reports usual eating habits in the past year. This includes all meals or snacks, at home or in a restaurant. The Block Brief 2000 Dietary Questionnaire includes questions on sociodemographics (sex, age, weight, height, and ethnic group); lifestyle factors such as smoking and alcohol consumption; and vitamin and mineral supplementation in addition to the food consumption.

The instrument groups food together in various categories (e.g., bananas, apples, pears, and oranges are included in the "fruit group" category). Participants respond to how often, on average, did you eat the food during the past year. There are nine possible responses that range from "never" to "everyday." Participants also must indicate the amount they usually eat of the food. There are four responses for how many, which 
range from 1 to 4 . This was done to indicate choices for example, "how many eggs?" or "how many glasses?" There are also responses for how much each time, with responses ranging from " $\mathrm{A}$ " to " $\mathrm{D}$ " referring to the pictures used along with the Block Dietary Questionnaire. Additional items not included in the frequency format include brand and dose of multiple vitamins and /or single vitamin and supplements taken, types of fat or oil used in cooking, frequency of fat or oil used in cooking, and brand of cold cereal are consumed.

The Block Dietary Questionnaire is a quantitative food frequency questionnaire in use by over 700 research groups and public health agencies in the US. The original FFQ was developed using data from NHANES II (Subar et al., 2001); it was made available in 1992 as a scannable version and revised again in 1995. The Block Food Frequency Questionnaire has been substantially revised based on the NHANES III food intake data (Block et al., 1998). The availability of new food data from NHANES III made it possible to revise both the questionnaire and the nutrient database, while incorporating foods important in the U.S. diet. The Block FFQ also revised its portion size approach. Previously portions sizes were based on "Small, Medium, Large" questions, but the new questions ask specific questions on amount; additionally, portion size photos as an aid in estimating usual portion size for each food are included. The photos are of simple abstract three-dimensional models representing four different amounts of food. The revised questionnaire remains an eight-page scannable booklet. There are 109 food items, representing at least $90 \%$ of each of the nutrients on the NHANES III database, plus additional nutrition-related questions such as servings of fruit and vegetables, frequency and type of fat in cooking, and vitamin supplement usage. 


\section{Variable Definition}

\section{Healthy Eating Scale}

Information gathered from the Brief Block 2000 Dietary Questionnaire was used to determine the Healthy Eating Scale (HES). The scale was compiled by the investigator using several aspects of the American Heart Association Dietary Guidelines (U.S. Dietary Guidelines, 2000). The Dietary Guidelines set forth were to reduce the incidence of chronic disease risk factors and occurrence of CHD in the general population, focusing on both dietary and lifestyle goals, some of which were used to construct the Healthy Eating Scale. The Healthy Eating Scale was created using a scale from 0 to 5 with one point awarded for each of the following: at least 25 grams of dietary fiber, five or more servings of fruits and vegetables per day, less than $30 \%$ of kcalories from fat, more than $55 \%$ of kcalories from carbohydrates, and less than $10 \%$ of kcalories from saturated fat.

These five major dietary parameters have been used to determine overall dietary health (Krauss et al., 2000; Healthy People, 2000; Healthy People, 2010; U.S. Dietary Guidelines, 2000). The analysis data of the Block Brief Dietary Questionnaire provided the first four elements of the scale. The percentage of Kcal from saturated fat was calculated by formula ( $9 \mathrm{Kcal}$ per gm $\mathrm{x}$ gm saturated fat/total Kcal). A correlation of the HES with the HPLPII Nutrition subscale validated this use of combined parameters.

\section{Body Mass Index (BMI)}

Obesity-related disease risk was calculated using body mass index (BMI). BMI was computed using self-reported height and weight collected on the Block Brief 2000 
Dietary Questionnaire. Weight was converted from pounds to kilograms and height was converted from inches to meters. Then BMI was calculated as weight in kilograms divided by height in meters squared (Mahan \& Escott-Stump, 2000). The BMI was then coded into a BMI category with the following: those with BMI under 18.5 were characterized underweight, those with BMI 18.5 - $<25$ were characterized as normal weight, those with BMI 25 - $<30$ were characterized as overweight, and those with a BMI greater than 30 were characterized as obese (U.S. Dietary Guidelines, 2000).

\section{Data Collection}

The surveys were administered by the investigator in churches at women's group meetings and also at women's social groups in the community. The community settings were at monthly sorority meetings or at women's conferences.

The women met at either a church meeting hall or a community center meeting place that was set up by the liaison provided by the leader of the church or women's social group. The study was explained to all eligible women. It was also explained to them what was expected for participation in the study. The participants were asked if they had any questions pertinent to the interview. The eligible women who met the inclusion criteria were given an informed consent to read; they were then asked if they understood the consent, after which they were requested to sign it. The informed consents were then collected so that the participants would remain anonymous. The study instruments were distributed with the help of two volunteers who had previously been designated by the liaison and trained to help with the collection of data. The participants were allowed ample time to complete the questionnaires, allowing for 
additional or follow-up questions. The investigator replied to any questions that the respondents had about the instruments. The respondents turned in the instruments as they finished and the investigator ensured that all instruments were complete.

The data collection phase followed a structured, uniform format that was used to collect data throughout the study to ensure uniformity of data collection as described in Appendix G. A total of five instruments were administered to the women (see Appendix F). The majority of questions were in a closed-ended format, with the exception of one question. The closed-ended questions were Likert-type scale questions.

After each session, refreshments were served. In most instances, the refreshments were provided either by the church or by the community center. After all participants had completed the instruments, there was a 15-minute informational session on nutrition issues related to women. The respondents were encouraged to ask any health-related questions that they had regarding the topics discussed. There was also distribution of nutrition "goody bags," which contained nutrition information on women's health issues (see Appendix H).

\section{Data Processing}

Following the administration of the questionnaires, data were reviewed prior to data entry. A computerized log of participants was kept and used to keep track of study participants who had completed the interview process, as well as tracking the church or community center location where the respondent completed the information.

After collection of data, all participants' data were kept in locked file cabinets. To ensure confidentiality of participant records, each participant was assigned a Personal 
Identification Number (PIN). The log of PIN numbers was maintained for security purposes. All statistical analysis was done using PIN only.

The investigator maintained consistency by performing all data coding and data entry. Except for the Brief Block 2000 Dietary Questionnaire, data entry was completed using Microsoft Excel 2000. This is a Microsoft spreadsheet program that generates text files, which was then read into and analyzed using SPSS Version 11.0 for Windows. The coded FFQs were sent to Nutritionquest to be analyzed by the Block Dietary Data System. The data from Nutritionquest was sent back as an ASCII file and subsequently read into SPSS for further analysis. Data was checked using cross-tabulations, frequencies, and other descriptive and summary statistics.

\section{Data Analysis}

The following statistical analyses were done to address the research questions: SPSS generated descriptive and summary statistics of sociodemographics and BMI data. Descriptive and summary statistics were also performed on the different spirituality subscales, dietary data, and exercise subscale scores. One-way analysis of variance was performed on total kilocalories and total fat calories by BMI categories for each age group. The significant $F$ tests, Fisher's LSD post hoc test was performed at $p<.05$. The Pearson product-moment correlations and cross-tabulations with chi-square tests were used to evaluate the relationships of the independent variables (spirituality, sociodemographics, and BMI), and the dependent variables (diet and exercise) (see Figures $3 \& 4$ ). There were several different measures for the independent variable of spirituality (Rosenberg Self-Esteem Scale, HPLP II Spiritual Growth, HPLP II 


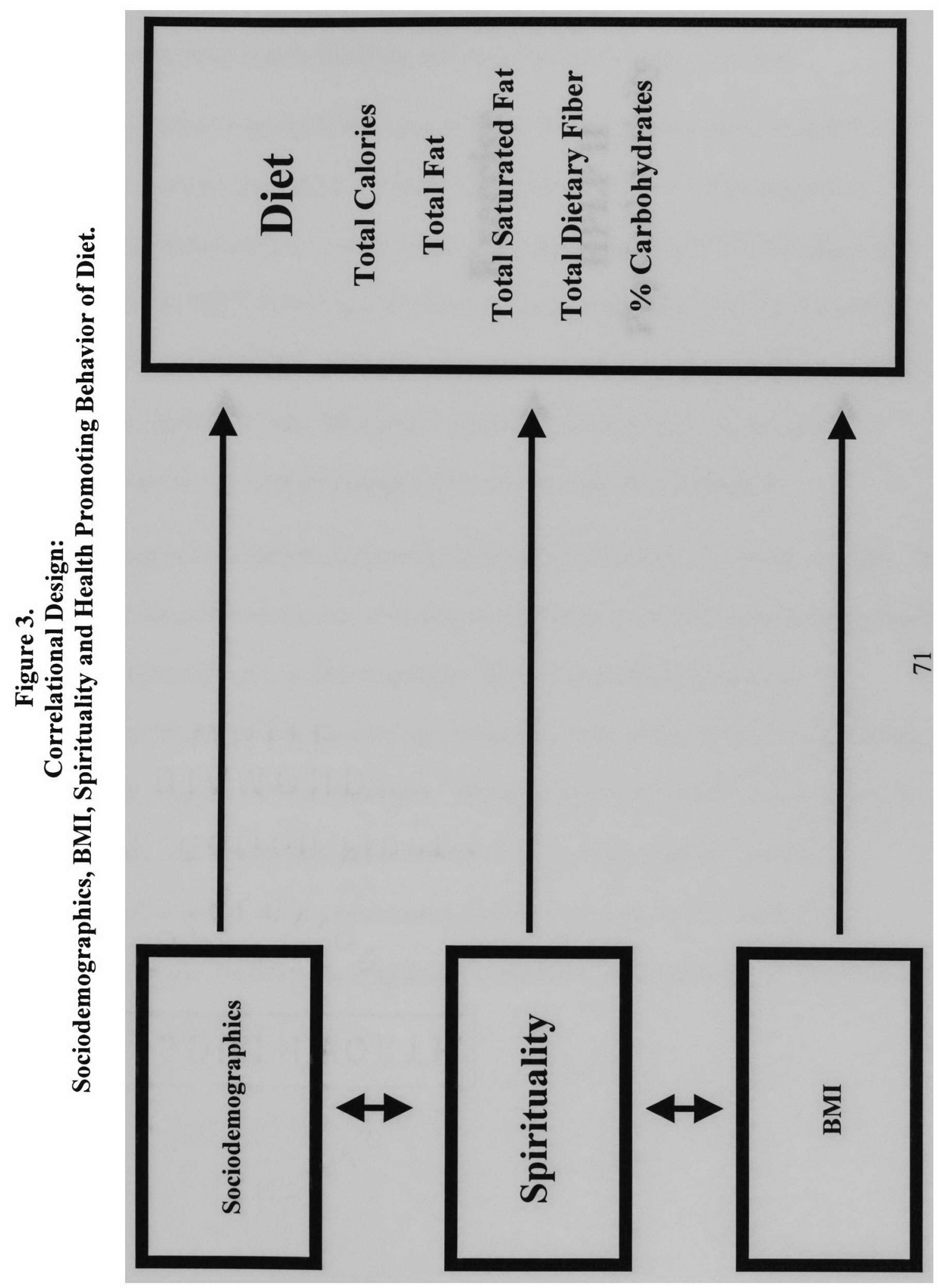




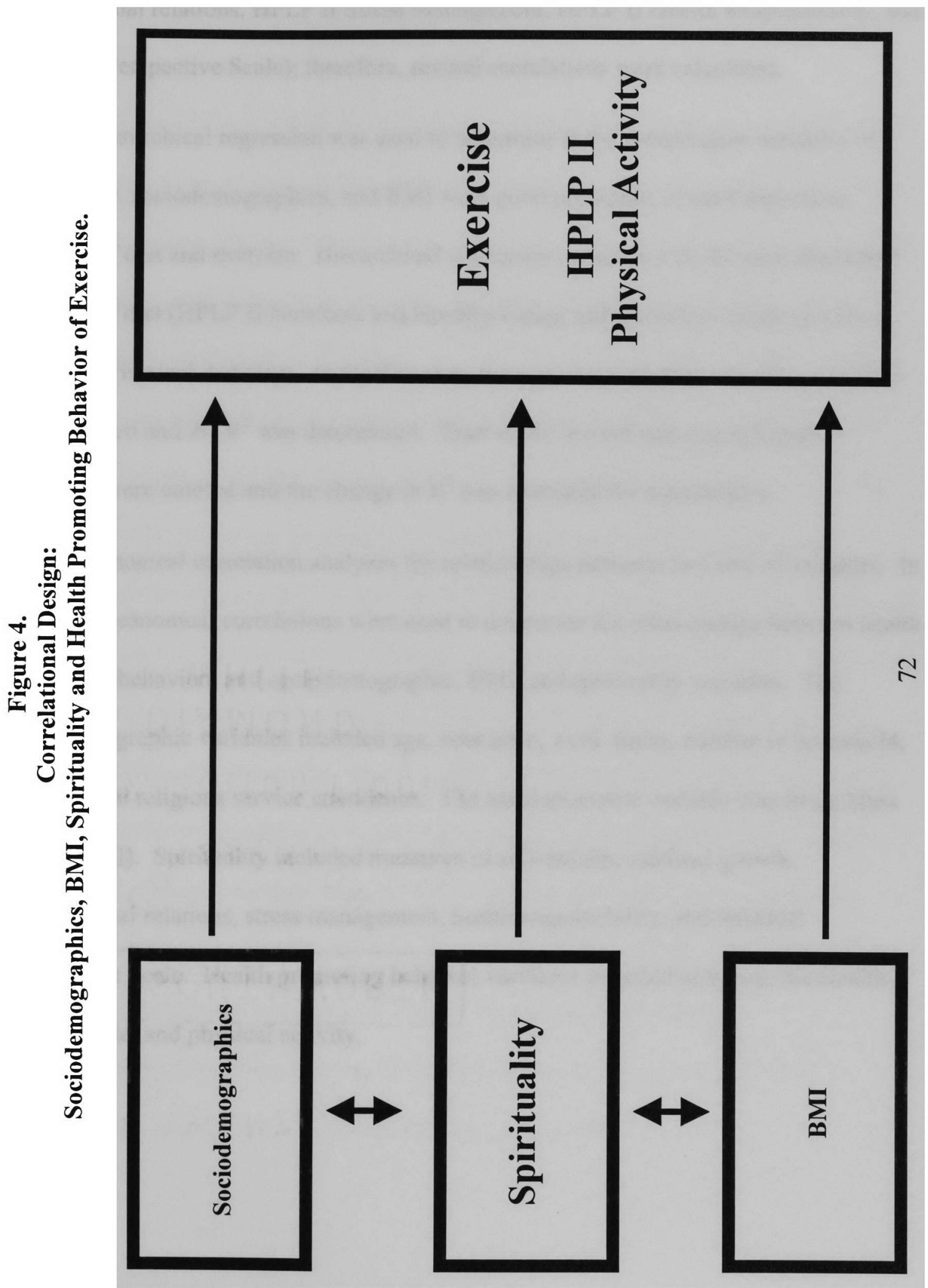


Interpersonal relations, HPLP II Stress Management, HPLP II Health Responsibility, and Spiritual Perspective Scale); therefore, several correlations were calculated.

Hierarchical regression was used to determine if the independent variables of spirituality, sociodemographics, and BMI were good predictors of each dependent variable of diet and exercise. Hierarchical regression model was fit for each dependent variable of diet (HPLP II Nutrition and Healthy Eating Index) and for physical activity (HPLP II Physical Activity). In the first step, the sociodemographic variables and BMI were entered and the $\mathrm{R}^{2}$ was determined. Then in the second step, the spirituality variables were entered and the change in $\mathrm{R}^{2}$ was evaluated for significance.

Canonical correlation analyzes the relationships between two sets of variables. In this study, canonical correlations were used to determine the relationships between health promoting behaviors and sociodemographic, BMI, and spirituality variables. The sociodemographic variables included age, education, work status, number in household, income, and religious service attendance. The anthropometric variable was Body Mass Index (BMI). Spirituality included measures of self-esteem, spiritual growth, interpersonal relations, stress management, health responsibility, and Spiritual Perspective Scale. Health promoting behavior variables included nutrition, the Healthy Eating Scale, and physical activity. 


\section{CHAPTER IV}

\section{RESULTS}

This study was conducted with 286 participants. The sample was recruited from churches and women's organizations in Central and South Florida. Initially, a combined total of 286 questionnaires were collected. Prior to data analysis, 26 of these participants were excluded since they did not complete the entire questionnaire, leaving a study sample of 260 participants for analysis.

The overall goal of this study was to understand the manner in which spirituality impacts the health of African American women. This study examined the relationship between spirituality (using the Burkhardt model) and women's health promoting behaviors of diet (as measured by the HPLP II Nutrition subscale and the Healthy Eating Scale) and exercise (as measured by the HPLP II Physical Activity subscale). This crosssectional study used sociodemographic, anthropometric (reported height and weight), dietary, exercise, and spirituality data to answer the two primary questions of the study: What is the role of spirituality in impacting the health promoting behaviors (diet and exercise) of African American women? Of the independent variables of spirituality, sociodemographics, and BMI, which are the best predictors of diet and exercise? The results are organized according to the research questions of the study.

Results of the study in terms of research questions are shown in Table 3. Following the summary, each research question is presented. 
Table 3. Significant Research Findings

\begin{tabular}{|c|c|}
\hline Research Question & Significant Findings \\
\hline $\begin{array}{l}\text { 1. What are the sociodemographics } \\
\text { characteristics of study participants? }\end{array}$ & $\begin{array}{l}87 \% \text { had at least some college education, } \\
46 \% \text { earn more than } \$ 45 \mathrm{~K}, 40 \% \text { married }\end{array}$ \\
\hline $\begin{array}{l}\text { 2. How do African American } \\
\text { women score on the various } \\
\text { spirituality subscales? }\end{array}$ & $\begin{array}{l}\text { Spiritual Perspective Scale above average. } \\
\text { Spiritual growth highest of HPLP II } \\
\text { measures followed by interpersonal } \\
\text { relations, health responsibility, stress } \\
\text { management. Self-esteem moderate. }\end{array}$ \\
\hline $\begin{array}{l}\text { 3. What is the relationship among } \\
\text { dietary intakes, exercise habits, and } \\
\text { BMI of African American women? }\end{array}$ & $\begin{array}{l}66 \% \text { overweight/obese }(\mathrm{BMI}) \text {; Fruit } \\
\text { intake less than } 2, \text { vegetables } 3 / \text { day; Low } \\
\text { dairy intake }(<1) ; 34 \% \text { fat in diet. No } \\
\text { association was found between BMI and } \\
\text { health promoting behaviors. }\end{array}$ \\
\hline $\begin{array}{l}\text { 4. What is the relationship between } \\
\text { sociodemographics, dietary patterns, } \\
\text { and exercise habits of African } \\
\text { American women? }\end{array}$ & $\begin{array}{l}\text { There were significant relationships } \\
\text { between the sociodemographic measures } \\
\text { of education and diet and exercise habits } \\
\text { of African American women. Those } \\
\text { individuals with higher education had } \\
\text { better diet and exercise patterns. }\end{array}$ \\
\hline $\begin{array}{l}\text { 5. What is the interrelationship of } \\
\text { spirituality, sociodemographics, and } \\
\text { BMI? }\end{array}$ & $\begin{array}{l}\text { Positive association between education } \\
\text { and income and spirituality measures; Age } \\
\text { and being married were moderately } \\
\text { positively associated with spirituality } \\
\text { measures; BMI positively associated with } \\
\text { Spiritual Perspective Scale and negatively } \\
\text { associated with self-esteem. }\end{array}$ \\
\hline $\begin{array}{l}\text { 6. What role does spirituality play in } \\
\text { the lives of African American } \\
\text { women as it relates to their diet and } \\
\text { exercise habits? }\end{array}$ & $\begin{array}{l}\text { Spirituality plays an important role in the } \\
\text { lives of African American women as it } \\
\text { relates to their health promoting } \\
\text { behaviors, more specifically self-esteem, } \\
\text { spiritual growth, interpersonal relations, } \\
\text { stress management, and health } \\
\text { responsibility. }\end{array}$ \\
\hline $\begin{array}{l}\text { 7. Of the independent variables of } \\
\text { spirituality, sociodemographics, and } \\
\text { BMI, which variables are the best } \\
\text { predictors of a healthy diet and } \\
\text { exercise patterns in African } \\
\text { American women? }\end{array}$ & $\begin{array}{l}\text { The constructs of self-esteem, spiritual } \\
\text { growth, interpersonal relations, stress } \\
\text { management, and health responsibility } \\
\text { were the best spirituality predictors. } \\
\text { Education is the best sociodemographic } \\
\text { predictor. }\end{array}$ \\
\hline
\end{tabular}




\section{Research Q1: What are the sociodemographic characteristics of the study participants?}

A total of 260 respondents completed all of the questionnaires and were used for the analyses. Table 4 summarizes sociodemographic factors. The age of the respondents ranged from between 18 and 82 years old, with a mean of $41.27 \pm 12.71$. The majority of the respondents identified themselves as African American (85\%), followed by those who considered themselves Caribbean (11\%) and Black Hispanic (2\%), and those who considered themselves as other $(2 \%)$. The majority of the respondents were married (40\%), followed by those who were single, never married (34\%), and those who were divorced/separated or widowed (26\%). Only $1 \%$ of the respondents had less than a high school education, while $12 \%$ had at least a high school education, $19 \%$ had some college and $68 \%$ had some type of vocational or college degree. The majority of the respondents were working full time (59\%), followed by those who did not work (21\%), those who worked part time (15\%), and finally, those working full and part time (5\%). The majority of the respondents household income was over $\$ 60,000(27 \%)$, followed by those with incomes between $\$ 15,001-\$ 30,000(24 \%)$, those with incomes between $\$ 30,001$ $\$ 45,000(19 \%)$, those with an incomes between $\$ 45,001-\$ 60,000(19 \%)$, and those with incomes less than $\$ 15,000(11 \%)$.

\section{Religious Characteristics}

Table 5 identifies the religious characteristics of the participants. The majority of the respondents considered themselves Baptist (65\%), followed by other 
Table 4

Demographic Characteristics of African American Women (N=260)

Characteristic

Mean + SD

Range

Age (years)

$41.27 \pm 12.71$

$18-82$

Gender

Female

$\underline{\mathbf{n}}$

\%

260

100.0

Race

African American

220

Caribbean

29

84.6

Black, Hispanic

5

11.2

Other

6

1.9

2.3

Marital Status

Single, never married

88

33.8

Divorced/separated

59

22.7

Widowed

8

Married

105

3.1

40.4

Work Status

Not Working $\quad 55$

Part Time 39

21.2

Full Time

153

15.0

Full + Part Time

58.8

5.0

Education Level

Less than HS

1.2

High School Graduate

Some College

49

11.9

Vocational

14

18.8

AA/AS

19

5.4

BA/BS

65

7.3

MS

73

25.0

$\mathrm{PhD} / \mathrm{MD}$

28.1

6

2.3

Annual Household Income

$\$ 15,000$ or less

28

10.8

$\$ 15,001-\$ 30,000$

62

23.8

$\$ 30,001-\$ 45,000$

50

19.2

$\$ 45,001-\$ 60,000$

49

18.8

Over $\$ 60,000$

71

27.3 
Table 5

Religious Characteristics of African American Women ( $\mathrm{N}=\mathbf{2 6 0})$

\section{Characteristic}

Religious Denomination

Baptist

African Methodist Episcopalian (AME)

Episcopalian

Other

$\underline{\mathbf{n}}$

167

23

5

61
\%

65.2

9.0

2.0

23.8

\section{Religious Service Attendance}

Never 7

Rarely

Occasionally

Frequently

Once a week

More than once a week

2.7

7.3

6.9

15.4

21.9

45.8

(24\%), then by African Methodist Episcopalian (9\%), and finally by those that considered themselves Episcopalian (2\%). Most respondents attended religious services more than once a week ( $46 \%)$, followed by those who attended once a week $(22 \%)$, those who attended frequently (15\%), those who attended occasionally (7\%), those who attended religious services rarely (7\%), and those who never attended religious services (3\%).

A cross-tabulation was performed to see if there was a significant relationship between religious service attendance and religious denomination. There was no significant relationship between the two. For those participants who attended church more than once a week, $50.3 \%$ were of the Baptist denomination, followed by $40 \%$ Episcopalian, 39.1\% were of AME denomination, and 36.1\% classified their denomination as other. For participants who attended church at least once a week, $40 \%$ were Episcopalian, $34.8 \%$ were AME, $21 \%$ were Baptist, and $18 \%$ were from other 
denominations. For participants who attended church frequently, defined as $1-3$ timesper-month, $17.4 \%$ were Episcopalian, $16.2 \%$ were Baptist, and $14.8 \%$ were from other denominations. For participants who attended church occasionally, defined as $6-12$ times per year, $13 \%$ were from other denominations and $6 \%$ were Baptist. For participants who attended church rarely, defined as 1 - 5 times-per-year, $20 \%$ were Episcopalian, $11.5 \%$ were from other denominations, $5.4 \%$ were Baptist, and $4.3 \%$ were AME. For participants who never attended church, $6.6 \%$ were from other denominations, followed by $4.3 \%$ who were AME, and finally $1.2 \%$ who characterized themselves as Baptist.

\section{Research Q2: How do African American women score on the various spirituality subscales?}

\section{Spirituality}

Burkhardt's theoretical framework was adopted as the model to measure this broad and encompassing concept of spirituality. The three elements examined in the framework are connectedness with self, connectedness with others, and connectedness with the environment/universe. These three elements are often referred to as harmonious interconnectedness of spirituality. Burkhardt (1989) suggested that these three concepts foster a spiritual interconnectedness.

Connectedness with self was measured using the Rosenberg Self-Esteem Scale and the HPLP II Spiritual Growth subscale. These two instruments together measured the spiritual views of these women and also measured how they engaged in spiritually 
related interactions. Additionally, the instruments measured self-acceptance, self-esteem, and the basic feeling of self-worth of these women.

Connectedness with others was measured using the HPLP II Stress Management subscale and the HPLP II Interpersonal Relations subscale. This measurement was taken to determine if these women connect with others, including family, friends, social groups, and churches.

The Spiritual Perspective Scale and HPLP II Health Responsibility measured connectedness with the environment/universe. Connectedness with the environment demonstrates if individuals experience a sense of connection with all of life and nature; if the individual is aware of the effects of the environment on one's life and well-being; and demonstrates concern for the health of the environment. It further determined if they have a sense of reflection and harmony in their lives. Further, the questions of whether these women are responsible for their own health was also measured using the HPLP II Health Responsibility subscale.

This section presents results in the order of the Burkhardt model. First, there is a discussion of results from the first component, connectedness with self, which includes Rosenberg's self-esteem scale, followed by the HPLP II subscale of spiritual growth. Next, there will be a discussion of results from the second component, connectedness with others, HPLP II subscale of interpersonal relations and HPLP II Stress Management. Finally, there is a discussion of results from the third component, connectedness with the environment and universe, HPLP II subscale of Health Responsibility, and the Spiritual Perspective Scale. 


\section{Self-Esteem}

The Rosenberg Self-Esteem scale is a measure of connectedness with self in Burkhardt's model of spiritual interconnectedness. Table 6 summarizes descriptive statistics for the Rosenberg Self-Esteem Scale. The scale is a 10-item Likert-type scale that measured the self-acceptance component of self-esteem as a basic feeling of selfworth. Reliability estimated by Cronbach's alpha was 0.84 . The Rosenberg Self-Esteem Scale has demonstrated criterion-related validity and discriminant validity.

The range of responses for each of the questions were from 1 to 4 , with 1 being "strongly agree" to 4 being "strongly disagree." The instrument is designed to alternate questions in random order indicating positive or negative aspects of self-esteem. The mean scores on the questions for which a response of "agree" is positive are as follows: "On the whole, I am satisfied with myself," the mean was 2.22 ; "I am able to do things as well as most other people," the mean was 2.42 ; "I feel that I am a person of worth, at least on an equal plane with others," the mean was 2.51 ; "I take a positive attitude toward myself," the mean was 2.58 ; and "I feel that I have a number of good qualities," the mean was 2.66. In other words, the first two questions with mean responses of less than 2.50 indicate more agreement on average than disagreement with these positive self-esteem attributes.

The individual ranked scores on the questions for which a response of "disagree" is positive are as follows: "I wish I could have more respect for myself" the mean was 2.24; "I certainly feel useless at times," the mean was 2.34 ; "At times, I think I am no good," the mean was 2.40 ; "I feel I do not have much to be proud of, " the mean was 2.55; and "All in all, I am inclined to feel that I am a failure," the mean was 2.76. In 
Table 6

Descriptive Statistics for the Rosenberg Self-Esteem Scale ( $\mathbf{N}=\mathbf{2 6 0})$

Scale Items

Mean \pm

SD

On the whole, I am satisfied with myself. (P)

2.22

.73

At times, I think I am no good. (N)

2.40

.81

I feel that I have a number of good qualities. (P)

2.66

.58

I am able to do things as well as most other people. (P)

2.42

.64

I feel I do not have much to be proud of. (N)

2.55

.79

I certainly feel useless at times. $(\mathrm{N})$

2.34

.80

I feel that I am a person of worth, at least on an equal plane with others. $(\mathrm{P})$

I wish I could have more respect for myself. (N)

All in all, I am inclined to feel that I am a failure. (N)

2.76

.50

I take a positive attitude toward myself. (P)

2.58

.64

Cronbach's alpha $=.84$, range $1-4$ where $1=$ strongly agree, $2=$ agree, $3=$ disagree, $4=$ strongly disagree

$P=$ positive scale item $N=$ negative scale item 
other words, the last two questions with mean responses of more than 2.50 indicate more disagreement on average than agreement with these negative self-esteem attributes.

\section{HPLP II Spiritual Growth}

The HPLP II Spiritual Growth subscale is a measure of connectedness with self in Burkhardt's model of spiritual interconnectedness. Table 7 summarizes the descriptive statistics for spiritual growth of the HPLP II scale. The spiritual growth scale focuses on feeling connected with a force greater than oneself, having a sense of purpose in life, and seeking personal development. The range of scores for each question was 1 (never) to 4 (routinely). The Cronbach's alpha for the spiritual growth subscale was 0.84 . The average response fell into the range of occurred more than "often," but less than "routinely" for the following questions: "feel connected with some force greater than myself," $(m=3.52)$; "believe that my life has purpose," $(m=3.46)$; "look forward to the future," $(m=3.45)$; "am aware of what is important to me in life," $(m=3.41)$; "work toward long-term goals in my life," $(m=3.16)$; "feel content and at peace with myself," $(\mathrm{m}=3.07)$; and "feel I am growing and changing in positive ways," $(\mathrm{m}=3.04)$.

Two questions were responded to more than "sometimes," but less than "often" on average: "find each day interesting and challenging" $(\mathrm{m}=2.99)$; and "expose myself to new experiences and challenges" $(\mathrm{m}=2.95)$.

The HPLP II Spiritual Growth subscale with an overall respondent average of 3.22 with a standard deviation of 0.51 was the highest of all the HPLP II subscales for this particular population. The item: which states, "feel connected with some force 


\section{Table 7}

Descriptive Statistics for Spiritual Growth of the HPLP II (N=260)

Scale Items

Mean \pm

SD

Feel I am growing and changing in positive ways.

Believe that my life has purpose.

Look forward to the future.

Feel content and at peace with myself.

Work toward long-term goals in my life.

Find each day interesting and challenging.

Am aware of what is important to me in life.

Feel connected with some force greater than myself.

Expose myself to new experiences and challenges.

Spiritual Growth Overall Subscale mean $3.22 \pm .51$

Cronbach's alpha $=.84$, range $1-4$ where $1=$ never, $2=$ sometimes, $3=$ often, $4=$ routinely

greater than myself," $(m=3.52)$ was the highest single mean response on all HLPL II scales for this sample.

\section{HPLP II Interpersonal Relations}

The HPLP II Interpersonal Relations subscale is a measure of connectedness with others in Burkhardt's model of spiritual interconnectedness. Table 8 summarizes the 
Discuss my problems and concerns with people close to me.

Praise other people easily for their achievements.

Maintain meaningful and fulfilling relationships with others.

Spend time with close friends.

Find it easy to show concern, love and warmth to others.

Touch and am touched by people I care about.

Find ways to meet my needs for intimacy.

Get support from a network of caring people.

Settle conflicts with others through discussion.

Interpersonal Relations overall subscale mean 3.08+.50

Cronbach's alpha $=.79$, range $1-4$ where $1=$ never, $2=$ sometimes, $\mathbf{3}=$ often, 4 = routinely

descriptive statistics for interpersonal relations of the HPLP II scale. The interpersonal relations scale pertains to maintaining relationships that involve a sense of closeness and intimacy. The range of scores for each question was 1 (never) to 4 (routinely). The Cronbach's alpha for these questions was 0.79 . Most of the mean responses fell into the range of occurred more than "often," but less than "routinely" for the following 
questions: "find it easy to show concern, love and warmth to others," the mean was 3.44 ; "maintain meaningful and fulfilling relationships with others," the mean was 3.38; "touch and am touched by people I care about," the mean was 3.36; "praise other people easily for their achievements," the mean was 3.33; "spend time with close friends," the mean was 3.03; and "settle conflicts with others through discussion," the mean was 3.00 .

Three questions averaged responses more than "sometimes," but less than "often": "get support from a network of caring people," the mean was 2.94; "discuss my problems and concerns with people close to me," the mean was 2.71 ; and "find ways to meet my needs for intimacy," the mean was 2.55 .

The HPLP Interpersonal Relations subscale with an overall respondent average of 3.08 with a standard deviation of 0.50 was the second highest of all the HPLP II subscales for this particular population.

\section{HPLP II Stress Management}

The HPLP II Stress Management subscale is a measure of connectedness with others in Burkhardt's model of spiritual interconnectedness. Table 9 summarizes the descriptive statistics for stress management of the HPLP II scale. The stress management scale pertains to recognizing stressful situations and acting to confront those and achieve relaxation. The range of scores for each question was 1 (never) to 4 (routinely). The Cronbach's alpha for these questions was 0.79 . Only one of the average responses fell into the range of occurred more than "often," but less than "routinely" for the following question: "accept those things in my life which I can not change" $(m=3.00)$. The remainder of the questions averaged responses more than "sometimes," but less than 


\section{Table 9}

\section{Descriptive Statistics for Stress Management of the HPLP II (N=260)}

Scale Items

Mean \pm

2.54

2.55

3.00

2.88

2.41

2.50

2.01

.97

Practice relaxation or meditation for 15-20 minutes daily.

Pace myself to prevent tiredness.

\section{Stress Management Subscale Mean 2.52 \pm .56}

Cronbach's alpha $=.77$, range $1-4$ where $1=$ never, $2=$ sometimes, $3=$ often, $4=$ routinely

"often": "concentrate on pleasant thoughts at bedtime" $(\mathrm{m}=2.88)$; "take some time for relaxation every day" $(\mathrm{m}=2.55)$; "get enough sleep" $(\mathrm{m}=2.54)$; "balance time between work and play" $(\mathrm{m}=2.50)$; "pace myself to prevent tiredness" $(\mathrm{m}=2.28)$; and and "practice relaxation or meditation for 15-20 minutes daily" $(m=2.01)$. The HPLP Stress Management subscale with an overall respondent average of 2.52 with a standard deviation of 0.56 was the fourth highest of the six HPLP II subscales for this particular population. 


\section{HPLP II Health Responsibility}

The HPLP II Health Responsibility subscale is a measure of connectedness with the environment or universe in Burkhardt's model of spiritual interconnectedness. Table 10 summarizes the descriptive statistics for health responsibility of the HPLP II scale. The Health Responsibility scale focuses on acceptance of responsibility for one's health, being educated about health, and seeking help from health professionals when needed. The Cronbach's alpha for the Health Responsibility subscale was 0.81 . The range of scores for each question was 1 (never) to 4 (routinely); only one of the average responses fell into the category "often," "report any unusual signs to a physician" $(\mathrm{m}=3.04)$. Most of the questions average responses more than "sometimes," but less than "often": "question health professionals" $(\mathrm{m}=2.89)$; "discuss my health concerns with health professionals" $(\mathrm{m}=2.84)$; "inspect my body at least monthly for physical changes" $(\mathrm{m}=$ 2.77); "seek guidance or counseling when necessary" ( $\mathrm{m}=2.51)$; "ask for information from health professionals" $(\mathrm{m}=2.51)$; "read or watch TV programs about improving health" $(\mathrm{m}=2.35)$; and "get a second opinion" $(\mathrm{m}=2.32)$.

Finally, one question average response was above "never," but less than "sometimes": "attend educational programs on personal health care" $(\mathrm{m}=1.87)$. It should be noted that this item within the HLPL II measures of spirituality had the lowest mean.

The HPLP Health Responsibility subscale with an overall respondent average of 2.53 with a standard deviation of 0.59 was the third highest of six of the subscales for this particular population. 
Scale Items

$\operatorname{Mean} \pm$

2.35

2.89

2.32

.99

Get a second opinion.

Discuss my health concerns with health professionals.

Inspect my body at least monthly for physical changes.

Ask for information from health professionals.

Attend educational programs on personal health care.

Seek guidance or counseling when necessary.

Health Responsibility Subscale Mean $2.57 \pm .59$

Cronbach's alpha $=.81$, range $1-4$ where $1=$ never, $2=$ sometimes, $3=$ often, 4 = routinely

\section{Spiritual Perspective Scale}

The Spiritual Perspective Scale (SPS) is a measure of connectedness with the environment or universe in Burkhardt's model of spiritual interconnectedness. Table 11 summarizes descriptive statistics for the SPS. The scale consisted of 10 questions regarding the prominence of spiritual views in the participant's life. Specifically, the 10 item scale measured participants' perceptions of the extent to which they hold certain 
In talking with family and friends, how often do you mention spiritual matters?

How often do you share with others the problems and joys of living according to your spiritual beliefs?

How often do you read spiritually related materials?

How often do you engage in private prayer or meditation? 5.79

Forgiveness is an important part of my spirituality.

I seek spiritual guidance in making decisions in my everyday life.

I frequently feel very close to God or a "higher power" in prayer, during public worship, or at important moments in my daily life.

My spirituality is especially important to me because it answers many questions about the meaning of life.

Spiritual Perspective Scale Mean $5.54 \pm .64$

Cronbach's alpha $=.92$, ranged from 1 to 6 , where $1=$ not at all, $2=$ less than once a year, $3=$ about once a year, $4=$ about once a month, $5=$ about once a week, $6=$ about once a day for the first four items. 1 = strongly disagree, $2=$ disagree, $3=$ disagree more than agree, $4=$ agree more than disagree, $5=$ agree, $6=$ strongly agree for the last six items.

spiritual views and engage in spiritually related interactions. Reliability, estimated by Cronbach's alpha, was 0.92 with minimal redundancy among the items. Based on the 
reliability scores in this population, the SPS has demonstrated criterion-related validity and discriminant validity.

The ranges of responses for the SPS questionnaire were from $1-6$, where $1=$ not all, $2=$ less than once a year, $3=$ about once a year, $4=$ about once a month, $5=$ about once a week, and 6 = about once a day. For the first four questions of this questionnaire, Cronbach's alpha was .91 . For questions $1-4$, the responses ranged from "not at all" to "about once a day." The ranked mean responses for all of these questions indicated that on average the behavior occurred more than "once a week" and less than "once a day." The questions were: "how often do you engage in private prayer or meditation?", $(\mathrm{m}=$ 5.79); "in talking with family and friends, how often do you mention spiritual matters?", $(m=5.48)$; "how often do you read spiritually related materials?", $(m=5.43)$; "how often do you share with others the problems and joys of living according to your spiritual beliefs?", $(\mathrm{m}=5.24)$.

For the second portion of the questionnaire, questions $5-10$, the responses ranged from $1-6$, where 1 = strongly disagree, 2 = disagree, $3=$ disagree more than agree, $4=$ agree more than disagree, $5=$ agree, and $6=$ strongly agree. The responses to all of these questions indicate that the participants' responses occurred more than "agree" and less than "strongly agree." The ranked mean responses for questions in the second section of the questionnaire were as follows: "my spiritual views have had an influence upon my life," with a mean of 5.67; "my spirituality is a significant part of my life," with a mean of 5.65; "I frequently feel very close to God or a 'higher power' in prayer, during public worship, or at important moments in my daily life," with a mean of 5.63; "forgiveness is an important part of my spirituality," with a mean of 5.60; "my spirituality is especially 
important to me because it answers many questions about the meaning of life," with a mean of 5.56; and "I seek spiritual guidance in making decisions in my everyday life," with a mean of 5.39 .

Participants in the present study held strong spiritual views and engaged in spiritually related interactions at least once a week and close to once a day. The participants indicated that they engaged in private prayer and meditation about once a day. They also indicated that their spiritual views have a strong influence on their lives and that spirituality is a significant part of their lives.

\section{Research Q3: What is the relationship between dietary intakes, exercise habits, and BMI of African American women?}

The first stage in answering this question was to complete analyses of the data relating to dietary intake, exercise, and BMI. Following these data analyses, correlations were completed among the variables. There were no significant correlations between BMI and the diet and exercise habits of the participants.

\section{Diet}

As part of the interview process, study participants were asked to complete the Brief 2000 Block Dietary Data sheet. This questionnaire takes into consideration the frequency of the foods consumed over the past year. This information was used to determine percent of calories from the energy nutrients based on the Dietary Guidelines for Americans (US DHHS) and daily servings of the different food groups based on the 
Food Guide Pyramid (US DHHS). This information was also used to determine mean nutrient intakes for the participants.

Table 12 summarizes the following dietary characteristics of the participants. The range of percent of calories from total fat was $13-57$ with a mean of $34.28 \pm 7.25$. The range of percent of calories from protein was 6 - 28 with a mean of $15.81 \pm 3.61$. The range of percent of calories from carbohydrates was $26-83$ with a mean of $51.52 \pm 9.16$. The range of percent of calories from sweets and desserts was $0-64$ with a mean of $13.88 \pm 10.61$. The range of daily servings of vegetables ranged from $0-20$ with a mean of $3.31 \pm 3.00$. The range of daily servings of fruits and fruit juices ranged from $0-6$ with a mean of $1.34 \pm 1.00$. The range of daily servings of breads, cereals, rice, and pasta ranged from $0-14$ with a mean of $3.02 \pm 1.99$. The range of daily servings of meat, fish, poultry, beans, and eggs ranged from $0-11$ with a mean of $1.73 \pm 1.343$. The range of daily servings of milk, yogurt, and cheese ranged from 0 - 5 with a mean of $0.80 \pm 0.68$. The range of daily servings of fats and oil, sweets, and soda ranged from 0 - 6 with a mean of $1.78 \pm 1.15$.

On average, the participants in the present study consumed greater than recommended amounts of fats (34\%); below adequate intakes of carbohydrates (52\%); and adequate intakes of protein (15\%). On average, the participants consumed 4.65 servings from the fruit and vegetable groups, which is below the recommended five fruits and vegetables per day.

Seventy-three percent of participants in the present study consumed more than $30 \%$ of their calories from fat. When looking at percent of calories from carbohydrates, 
Table 12

Dietary Characteristics of African American Women ( $N=\mathbf{2 6 0})$

Characteristic

Mean + SD

Range

$\%$ Kcal from

Fat

$34.28 \pm 7.25$

$13-57$

Protein

$15.81 \pm 3.61$

$6-28$

Carbohydrates

$51.52 \pm 9.16$

$26--83$

Sweets, Desserts

$13.88 \pm 10.61$

$0-64$

Daily Servings of

Vegetables

$3.31 \pm 3.00$

$0-20$

Fruits \& Fruit juices

$1.34 \pm 1.00$

$0-6$

Breads, Cereals, Rice, Pasta

$3.02 \pm 1.99$

$0-14$

Meat, Fish, Poultry, Beans, Eggs

$1.73 \pm 1.34$

$0-11$

Milk, Yogurt, Cheese

$0.80 \pm 0.68$

$0-5$

Fats \& Oil, Sweets, Sodas

$1.78 \pm 1.15$

$0-6$

$66 \%$ of the participants consumed less than the recommended $55 \%$ of calories from carbohydrates. For percent of calories from saturated fat, $74 \%$ consumed more than $10 \%$ of their calories from saturated fat. When categorizing participants on grams of dietary fiber, $89 \%$ consumed less than the recommended 25 grams of dietary fiber. For servings from fruits and vegetables per day, $66 \%$ consumed less than the recommended five servings per day. 
The aforementioned categories were used to determine the Healthy Eating Scale for the present study. The Healthy Eating Scale ranged from 0 to 5 and was based on $30 \%$ or less from fat, more than $55 \%$ from carbohydrates, $10 \%$ or less from saturated fat, 25 or more grams from dietary fiber and more than five servings from the fruit and vegetable category. For the Healthy Eating Scale, only $3 \%$ of the participants met all five categories, followed by $9 \%$ meeting at least four of the five categories, $13 \%$ in both three and two of the five categories, $19 \%$ meeting one of the five categories, and finally by $43 \%$ meeting none of the five categories.

A separate correlation was performed for the HPLP II Nutrition subscale to the Healthy Eating Scale $(r=.427, p<.001)$. The HPLP II Nutrition subscale consists of questions related to the respondent's consumption of servings of food groups from the Food Guide Pyramid. Additionally, questions include U.S. Dietary Guideline parameters of sodium and fat. This significant correlation provides validation of the Health Eating Scale to represent the nutritional intake of the participants.

Table 13 summarizes the Block Dietary Questionnaire characteristics of the participants. Respondents consumed 1,368.28 \pm 774.66 calories with a range of $200-$ 5,552 calories. Respondents consumed from $9-254$ grams of protein with a mean of $54.66 \pm 33.87$ grams of protein. Respondents consumed from $5-257$ grams of total fat with a mean of $52.89 \pm 33.69$ grams. Respondents consumed from $24-686$ grams of carbohydrates with a mean of $173.77 \pm 100.86$ grams. Respondents consumed from 84 $1,815 \mathrm{mg}$ of calcium with a mean of $507.09 \pm 309.04 \mathrm{mg}$. Respondents consumed from 
Table 13

Dietary Intake of the participants $(\mathrm{N}=260)$ measured using the Block Dietary Questionnaire

\begin{tabular}{lcc} 
& Mean + SD & Range \\
Characteristic & & \\
\hline & $1368.28 \pm 774.66$ & $200-5552$ \\
Kcal & $54.66 \pm 33.87$ & $9-254$ \\
Protein (g) & $52.89 \pm 33.69$ & $5-257$ \\
Total fat (g) & $173.77 \pm 100.86$ & $24-686$ \\
Carbohydrate (g) & $507.09 \pm 309.04$ & $84-1815$ \\
Calcium (mg) & $835.98 \pm 462.59$ & $144-2625$ \\
Phosphorus (mg) & $10.01 \pm 5.88$ & $2-41$ \\
Iron (mg) & $1698.90 \pm 997.92$ & $236-6592$ \\
Sodium (mg) & $2275.40 \pm 1359.30$ & $341-7406$ \\
Potassium (mg) & $10869.03 \pm 11370.85$ & $771-66876$ \\
Vitamin A (IU) & $1245.82 \pm 1190.37$ & $98-6872$ \\
Vitamin A (RE) & $1.19 \pm 0.66$ & $0-4$ \\
Thiamin (mg) & $1.24 \pm 0.70$ & $0-4$ \\
Riboflavin (mg) & $14.12 \pm 8.52$ & $2-63$ \\
Niacin (mg) & $128.29 \pm 94.33$ & $10-564$ \\
Vitamin C (mg) & $17.61 \pm 11.340$ & $2-88$ \\
Saturated Fat (g) & $19.46 \pm 12.98$ \\
Oleic Acid (g) & $11.22 \pm 7.62$ & $1-99$ \\
Linoleic Acid (g) & $173.67 \pm 122.21$ & $1-52$ \\
Cholesterol (mg) & $14.36 \pm 9.73$ & $10-705$ \\
Total Dietary Fiber (g) & $295.38 \pm 177.95$ & $2-59$ \\
Folate (mcg) & $7.04 \pm 4.56$ & $43-1340$ \\
Vitamin E (a-TE) & $7.18 \pm 4.54$ & $1-28$ \\
Zinc (mg) & $1.48 \pm 0.88$ & $1-32$ \\
Vitamin B6 (mg) & $217.32 \pm 128.61$ & $0-5$ \\
Magnesium (mg) & $108.61 \pm 100.50$ & $32-766$ \\
Vitamin D (IU) & $194.31 \pm 213.26$ & $2-764$ \\
Vitamin K (ug) & $3.18 \pm 2.71$ & $11-1480$ \\
Vitamin B12 (ug) & $1.93 \pm 2.77$ & $0-20$ \\
Dietary fiber from beans (g) & $8.04 \pm 6.81$ & $0-23$ \\
Dietary fiber from vegetables \& fruits (g) & $1-54$ \\
Dietary fiber from grains (g) & $4.80 \pm 3.39$ & $0-30$ \\
& & \\
& & \\
& & \\
& & \\
& &
\end{tabular}


$144-2,625 \mathrm{mg}$ of phosphorus with a mean of $835.98 \pm 462.59 \mathrm{mg}$. Respondents consumed from $2-41 \mathrm{mg}$ of iron with a mean of $10.01 \pm 5.88 \mathrm{mg}$. Respondents consumed from $236-6592 \mathrm{mg}$ of sodium with a mean of $1,698.90 \pm 997.92 \mathrm{mg}$. Respondents consumed from $341-7,406 \mathrm{mg}$ of potassium with a mean of $2,275.40 \pm$ $1,359.30 \mathrm{mg}$. Respondents consumed from 2 - 88 grams of saturated fat with a mean of $17.61 \pm 11.340$ grams. Respondents consumed from $10-705 \mathrm{mg}$ of cholesterol with a mean of $173.67 \pm 122.21 \mathrm{mg}$. Respondents consumed from $2-59$ grams of total dietary fiber, with a mean of $14.36 \pm 9.73$ grams. Consumption of dietary fiber was divided into several different categories. Consumption of dietary fiber from beans ranged from $0-23$ grams with a mean of $1.93 \pm 2.77$. Consumption of dietary fiber from vegetables and fruits ranged from 1 - 54 grams with a mean of $8.04 \pm 6.81$. Consumption of dietary fiber from grains ranged from $0-30$ grams with a mean of $4.80 \pm 3.39$.

\section{Differences of Vitamin and Mineral Intake by Age}

Table 14 summarizes the differences of vitamin and mineral intake of African American women by age group. There was a significant difference in percent of participants meeting DRI for iron without supplementation, $\chi^{2}(2, N=260)=43.28, p<.001$ and with supplementation, $\chi^{2}(2, \mathrm{~N}=260)=21.66, \mathrm{p}<.001$. Without iron supplementation, $48 \%$ of participants 51 and over met the DRI; however, only $13 \%$ of participants between 18 and 30 years old, and $9 \%$ of participants between 31 and 50 years old met the DRI. Similarly, $80 \%$ of participants 50 and older met their DRI with supplementation, but only $50 \%$ of participants between 18 and 30 years old, and less than half (45\%) between 31 and 50 year olds met their DRI. 


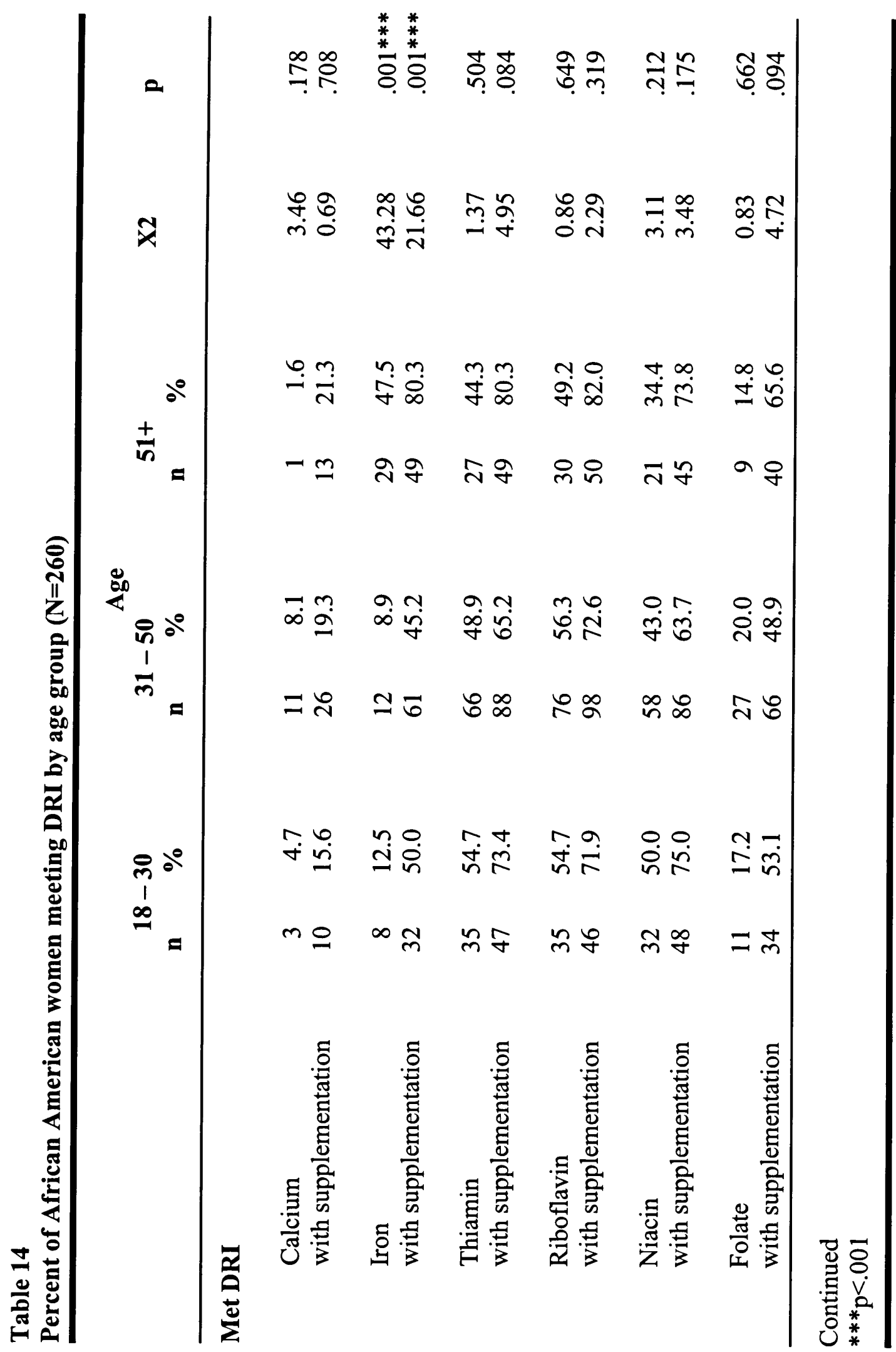




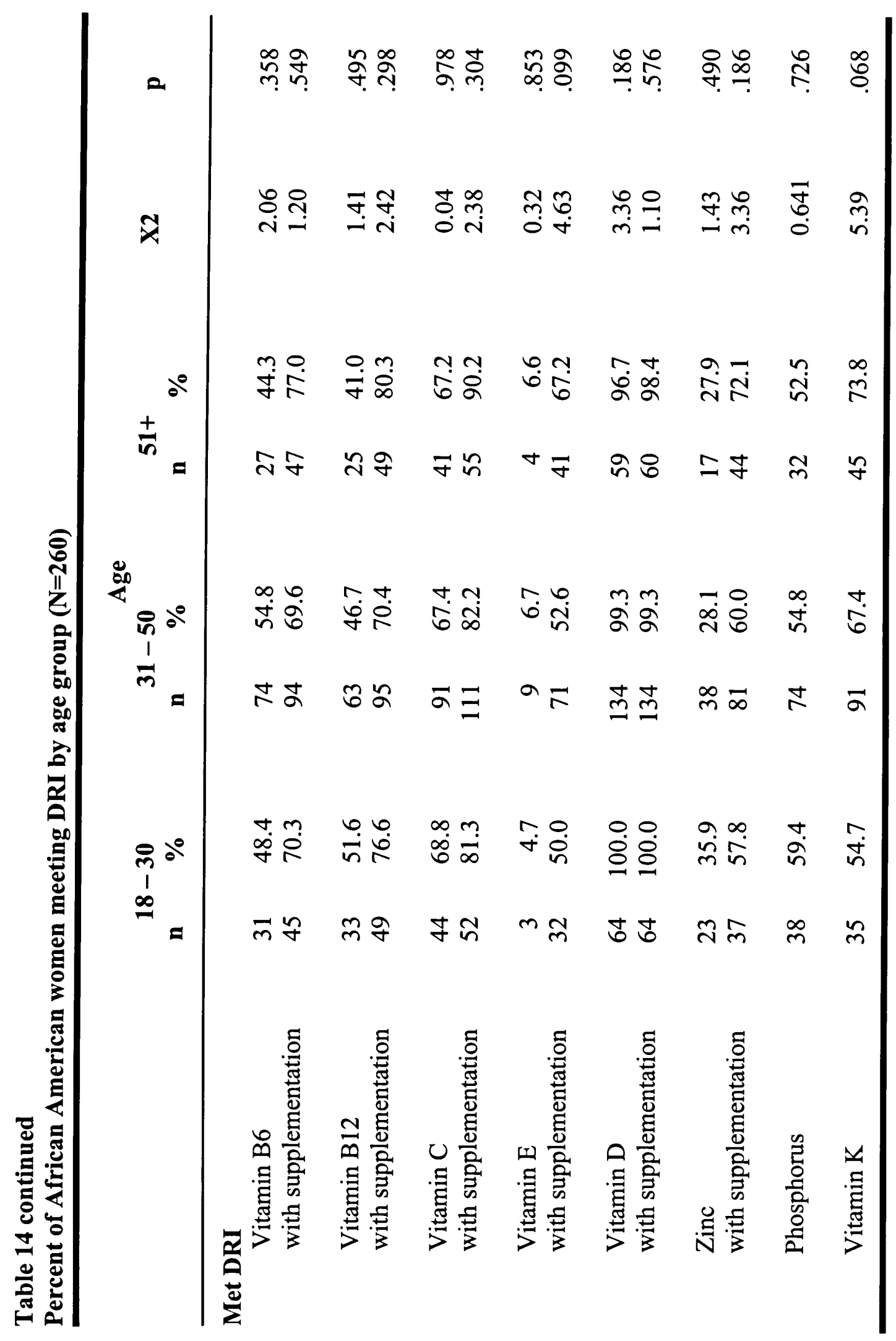

a 


\section{Correlations of BMI and Nutrient Intake}

Nutrition was significantly correlated with BMI. Table 15 summarizes the correlations of BMI and nutrient intake. For nutrient intake, BMI was positively associated with caffeine, percent fat, percent of calories from sweets, percent of fat calories (alcoholic beverages excluded), supplemented vitamin C, supplemented vitamin $\mathrm{E}$, and supplemented beta carotene $(\mathrm{r}=.131, \mathrm{p}=.035 ; \mathrm{r}=.134, \mathrm{p}=.031 ; \mathrm{r}=.163, \mathrm{p}=.008 ; \mathrm{r}$ $=.125, \mathrm{p}=.044 ; \mathrm{r}=.141 ; \mathrm{p}=.023 ; \mathrm{r}=.209, \mathrm{p}=.001 ; \mathrm{r}=.138, \mathrm{p}=.026)$. Those individuals with higher BMI had significantly higher intakes of caffeine, percent fat, percent of calories from sweets, percent fat calories (alcoholic beverages excluded), supplemented vitamin $\mathrm{C}$, supplemented vitamin $\mathrm{E}$, and supplemented beta carotene.

\section{Correlations of BMI and Nutrient Intake within Age Groups Separately}

Table 16 summarizes the correlations of BMI and nutrient intake within age groups, separately. Younger women (18 - 30 years of age) with higher BMIs were positively associated with caffeine consumption $(r=.277, p=.027)$. Middle age women between 31 and 50 years old with higher BMIs were positively associated with oleic acid, percent of calories from sweets, supplemented Vitamin E, and supplemented selenium intake $(\mathrm{r}=.177, \mathrm{p}=.040 ; \mathrm{r}=.180, \mathrm{p}=.037 ; \mathrm{r}=.182, \mathrm{p}=.035 ; \mathrm{r}=.199, \mathrm{p}=.021)$. Younger women with higher BMIs consumed more caffeine, and middle age women with higher BMIs consumed greater amounts of oleic acid, calories from sweets, supplemented Vitamin E, and supplemented selenium. 


\section{Table 15}

Correlations between BMI and Nutrient Intake ( $\mathbf{N}=\mathbf{2 6 0})$

\section{BMI}

Caffeine

Percent Fat

Percent Sweets

Percent fat (alcoholic beverages excluded) .125*

Supplemented Vitamin C

Supplemented Vitamin E

Supplemented Betacarotene

${ }^{*} \mathbf{p}<.05,{ }^{* *} p<.01$
$.131^{*}$

$.134^{*}$

$.163^{* *}$
$.209 * *$

$.138^{*}$

\section{Table 16}

Correlations between BMI and Nutrient Intake with age groups separately $(\mathrm{N}=\mathbf{2 6 0})$

$$
\begin{array}{clc} 
& \text { Age } & \\
18-30 & 31-50 & 51+ \\
(n=64) & (n=135) & (n=61)
\end{array}
$$

Oleic Acid

$.177^{*}$

Caffeine

$.277^{*}$

Percent Sweets $.180^{*}$

Supplemented Vitamin E $.182^{*}$

Supplemented Selenium $.199 *$

${ }^{*} \mathrm{p}<.05,{ }^{* *} \mathrm{p}<.01$ 


\section{ANOVA of Nutrient Intake by BMI Categories}

One way ANOVA were performed on total calorie and total fat calories by BMI category for each age group separately. For participants between 31 and 50 years old, there was a marginally significant difference in total calories by the BMI category, $\mathrm{F}(2,132)=2.61, \mathrm{p}=.078$. Fisher's least significant difference post hoc test showed that on average, obese women $(\mathrm{m}=1,559 \mathrm{kcal})$ consumed significantly more total calories than underweight women $(\mathrm{m}=1,224 \mathrm{kcal}), \mathrm{p}<.05$.

For participants between 31 and 50 years old, there was a significant difference in total fat calories by the BMI category, $\mathrm{F}(2,132)=3.43, \mathrm{p}=.035$. Fisher's least significant difference post hoc test showed that on average, obese women ( $m=63$ grams) consumed significantly more total fat calories than underweight women $(\mathrm{m}=46$ grams $), \mathrm{p}<.05$.

\section{HPLP II Nutrition}

Table 17 summarizes the descriptive statistics for nutrition of the HPLP II scale. The nutrition scale focuses on adherence to the principles set forth in the Food Guide Pyramid, some of the Dietary Guidelines, and reading food labels. The Cronbach's alpha range for these questions was 0.79 . The range of responses for each question was 1 (never) to 4 (routinely), where $1=$ never, $2=$ sometimes, $3=$ often, and $4=$ routinely. The mean responses to the following questions occurred more than "sometimes," but less than "often": "eat breakfast" $(\mathrm{m}=2.78)$; "read labels to identify nutrients, fats, and sodium" $(\mathrm{m}=2.71)$; "eat only $2-3$ servings from meat, poultry, fish, and dried beans" $(m=2.60)$; "eat $2-4$ servings of fruit each day" $(m=2.42)$; "eat $3-5$ servings of vegetables each day" $(\mathrm{m}=2.36)$; "choose a diet low in fat, saturated fat, and cholesterol" 
Table 17

Descriptive Statistics for Nutrition of the HPLP II $(\mathrm{N}=\mathbf{2 6 0})$

Scale Items

Mean $\pm \quad$ SD

Choose a diet low in fat, saturated fat, and cholesterol.

2.34

.92

Limit use of sugars and foods containing sugars.

2.32

.85

Eat 6-11 servings of bread, cereal, rice and pasta each day.

Eat 2-4 servings of fruit each day.

Eat 3-4 servings of vegetables each day.

Eat 2-3 servings of milk, yogurt, or cheese each day.

Eat only 2-3 servings from meat, poultry, fish, and dried beans.

Read labels to identify nutrients, fats, and sodium.

Eat breakfast.

HPLP II Nutrition Subscale Mean 2.40 \pm .57

Cronbach's alpha $=.79$, range $1-4$ where $1=$ never, $2=$ sometimes, $3=$ often, 4 = routinely

$(\mathrm{m}=2.34)$; "limit use of sugars and foods containing sugars" $(\mathrm{m}=2.32)$; and "eat $2-3$ servings of milk, yogurt, or cheese each day" $(\mathrm{m}=2.12)$. One mean response indicated that the behavior occurred more than "never," but slightly less than "sometimes": "eat 6 11 servings of bread, cereal, rice and pasta each day" $(\mathrm{m}=1.90)$. The HLPL Nutrition subscale with an overall respondent average of 2.40 with a standard deviation of 0.57 was the second lowest of six of the HPLP II subscales for this particular population. 


\section{HPLP II Physical Activity}

Table 18 summarizes the descriptive statistics for physical activity of the HPLP II scale. The physical activity scale pertains to adherence to a regular pattern of physical activity. The Cronbach's alpha for the physical activity subscale was 0.85 . The range of scores for each question was 1 (never) to 4 (routinely), where $1=$ never, $2=$ sometimes, 3 $=$ often, and $4=$ routinely. The average response to the questions indicated that the behavior occurred more than "sometimes," but less than "often": "get exercise during usual daily activities" ( $m=2.67)$; "exercise vigorously for 20 minutes at least three times per week" $(\mathrm{m}=2.21)$; "follow a planned exercise plan" $(\mathrm{m}=2.17)$; "do stretching exercises at least three times per week" $(\mathrm{m}=2.09)$; "take part in light to moderate physical activity" $(\mathrm{m}=2.07)$; and "take part in leisure-time physical activities" ( $\mathrm{m}=$ 2.07). Two questions had mean responses indicating that the behavior occurred more than "never," but less than "sometimes": "reach my target heart rate when exercising" $(\mathrm{m}=1.98)$; and "check my pulse rate when exercising" $(\mathrm{m}=1.59)$.

The HPLP II Physical Activity subscale with an overall respondent average of 2.11 with a standard deviation of 0.66 was the lowest of the six HPLP II subscales for this particular population. The participants in the present study "sometimes" exercised and "sometimes" followed an exercise plan. They took part in light to moderate physical activity or leisure time physical activity "sometimes", but they almost "never" checked their pulse rate or reached their target heart rate when exercising. 


\section{Scale Items}

Mean \pm

2.17

2.07

2.07

2.09

2.67

1.59

1.98
.92

1.05

.95

.92

.90

.99

.81
Reach my target heart rate when exercising.
Check my pulse rate when exercising.

HPLP II Physical Activity Subscale Mean: $2.11 \pm .66$

Cronbach's alpha $=.85$, range $1-4$ where $1=$ never, $2=$ sometimes, $3=$ often, $4=$ routinely

\section{Body Mass Index (BMI)}

Table 19 summarizes the BMI of the participants. The distribution of BMI was nearly uniform across normal, overweight, and obese categories. About a third of the respondents were of overweight with a BMI of $25-<30(32 \%)$, followed by one-third who were normal weight with a BMI $18.5-<25(33 \%)$, and those who were obese with a BMI of 30 or more $(34 \%)$, and those who were classified as underweight with a BMI $<18.5(2 \%)$. 
BMI

$\begin{array}{llrr}\text { Underweight } & <18.5 & 4 & 1.5 \\ \text { Normal weight } & 18.5-<25 & 86 & 33.1 \\ \text { Overweight } & 25-<30 & 83 & 31.9 \\ \text { Obese } & >30 & 87 & 33.5 \\ \text { Total } & & 260 & 100.0\end{array}$

Research Questions 4: What is the relationship between sociodemographics, dietary patterns (as measured by the HPLP II Nutrition Subscale and the Healthy Eating Scale) and exercise habits of African American women?

The relationship of sociodemographics and the dependent variables of diet and exercise are shown in Table 20. Several sociodemographic variables were significantly related to diet and exercise. Both the HPLP II Nutrition subscale and the Healthy Eating Scale measured diet. Exercise was measured using the HPLP II Physical Activity subscale. Education was positively associated to physical activity $(r=.214, p=.001)$ and diet as expressed by the HPLP II Nutrition subscale $(\mathrm{r}=.330, \mathrm{p}<.001)$. Work status was negatively associated with physical activity $(\mathrm{r}=-.132, \mathrm{p}=.033)$ and diet as expressed by the HPLP II Nutrition Subscale $(\mathrm{r}=-.126, \mathrm{p}=.043)$.

In summary, the relationship of sociodemographics, dietary patterns, and exercise habits show those individuals with higher education had better exercise habits and dietary habits. It was also found that individuals who worked more, exercised less and had 
Correlations between Sociodemographics, Diet and Exercise $(\mathrm{N}=\mathbf{2 6 0})$

\begin{tabular}{|c|c|c|c|}
\hline & $\begin{array}{c}\text { HPLP Physical } \\
\text { Activity }\end{array}$ & HPLP Nutrition & $\begin{array}{c}\text { Healthy Eating } \\
\text { Score }\end{array}$ \\
\hline Age & -.029 & .094 & .069 \\
\hline Education & $.214^{* *}$ & $.330 * *$ & .115 \\
\hline Work Status & $-.132 *$ & $-.126^{*}$ & .013 \\
\hline Single & .034 & -.066 & -.008 \\
\hline Divorced/Widowed & -.055 & .022 & .003 \\
\hline Married & .016 & .043 & .005 \\
\hline \multicolumn{4}{|c|}{ Number in Household } \\
\hline & -.056 & -.083 & -.007 \\
\hline Income & -.004 & .079 & .020 \\
\hline Religious Service & & & \\
\hline Attendance & -.019 & -.012 & -.059 \\
\hline
\end{tabular}

poorer diets. The measure of diet in both instances was based on consuming the recommended servings of the Food Guide Pyramid: 6 - 11 servings of bread, cereal, rice and pasta each day; $2-4$ servings of fruit each day; $3-4$ servings of vegetables each day; 2-3 servings of milk, yogurt, or cheese each day; and 2-3 servings from meat, poultry, fish, and dried beans. 


\section{Research Question 5: What is the interrelationship of spirituality, sociodemographics, and BMI?}

To answer this question, correlations within the category of spirituality and sociodemographics were calculated.

\section{Correlations of Spirtuality Variables}

Tests of association are shown in Table 21. Using Pearson's correlations several of the spirituality variables were found to be significantly correlated to one another. Selfesteem was significantly correlated with stress management, interpersonal relations, spiritual perspective scale, spiritual growth, and health responsibility $(r=.397, p<.001 ; r$ $=.413, \mathrm{p}<.001 ; \mathrm{r}=.127, \mathrm{p}=.041, \mathrm{r}=.526, \mathrm{p}<.001$, and $\mathrm{r}=.425, \mathrm{p}<.001)$. Stress management was significantly correlated with interpersonal relations, SPS, spiritual growth, and health responsibility $(\mathrm{r}=.492, \mathrm{p}<.001 ; \mathrm{r}=.273, \mathrm{p}<.001, \mathrm{r}=.603, \mathrm{p}<.001$, and $\mathrm{r}$ $=.488, \mathrm{p}<.001)$. Interpersonal relations was significantly correlated with SPS, Spiritual Growth, and Health Responsibility $(\mathrm{r}=.212, \mathrm{p}<.001 ; \mathrm{r}=.713, \mathrm{p}<.001 ; \mathrm{r}=.482, \mathrm{p}<.001)$. SPS was significantly correlated with spiritual growth and health responsibility $(\mathrm{r}=.262$, $\mathrm{p}<.001 ; \mathrm{r}=.128, \mathrm{p}=.038$ ). Spiritual growth was significantly correlated with health responsibility $(\mathrm{r}=.524, \mathrm{p}<.001)$.

Tests of association are shown in Table 22. Using Pearson's correlations several of the sociodemographic variables were found to be significantly correlated to one another. The interrelationship of spirituality, sociodemographics and BMI are shown in Table 23. Spirituality was significantly correlated to both sociodemographics and BMI. 
Correlations Among Spirituality Variables ( $\mathrm{N}=\mathbf{2 6 0})$

$\begin{array}{lllllc}\text { Health } & \text { SPS } & \begin{array}{l}\text { Spiritual } \\ \text { Growth }\end{array} & \begin{array}{l}\text { Inter } \\ \text { Rel. }\end{array} & \begin{array}{l}\text { Stress } \\ \text { Manage- }\end{array} & \begin{array}{c}\text { Self } \\ \text { Esteem }\end{array}\end{array}$

Health

Responsibility

SPS

$.128^{*}$

$.128 *$

$.524 * *$
$262 * *$

$.482 * * \quad .492 * *$

$.425^{* *}$

$.262^{* *}$

$.212^{* *} \quad .273^{* *}$

$.127 *$

Spiritual

Growth

$.524 * *$

$.262 *$

$.713 * * \quad .603 * *$

$.526^{* *}$

Interpersonal

Relations

$.482 * *$

$.212^{* *} .713^{* *}$

$.488^{* *}$

$.413^{* *}$

Stress

Management .492**

$.273^{* *} \quad .603^{* *}$

$.488^{* *}$

$.397^{* *}$

Self-

Esteem

$.425^{* *}$

$.127^{*}$

$.526^{* *}$

$.413^{* *} \quad .397^{* *}$

${ }^{*} \mathbf{p}<.05,{ }^{* *} \mathbf{p}<.01$

For the sociodemographic parameters, age was positively associated with health responsibility, SPS and stress management $(\mathrm{r}=.160, \mathrm{p}=.010 ; \mathrm{r}=.248, \mathrm{p}<.001 ; \mathrm{r}=.149$, $\mathrm{p}<.001)$. Education was positively associated with health responsibility, spiritual growth, interpersonal relations, stress management, and self-esteem $(r=.278, p<.001 ; r=.383$, $\mathrm{p}<.001 ; \mathrm{r}=.347, \mathrm{p}<.001 ; \mathrm{r}=.140, \mathrm{p}<.001 ; \mathrm{r}=.209, \mathrm{p}<.001)$. Work status was negatively associated with stress management $(r=-.154, p=.013)$. Being single was negatively associated with health responsibility and SPS $(r=-.140, \mathrm{p}=.024 ; \mathrm{r}=-.226, \mathrm{p}<.001)$. 


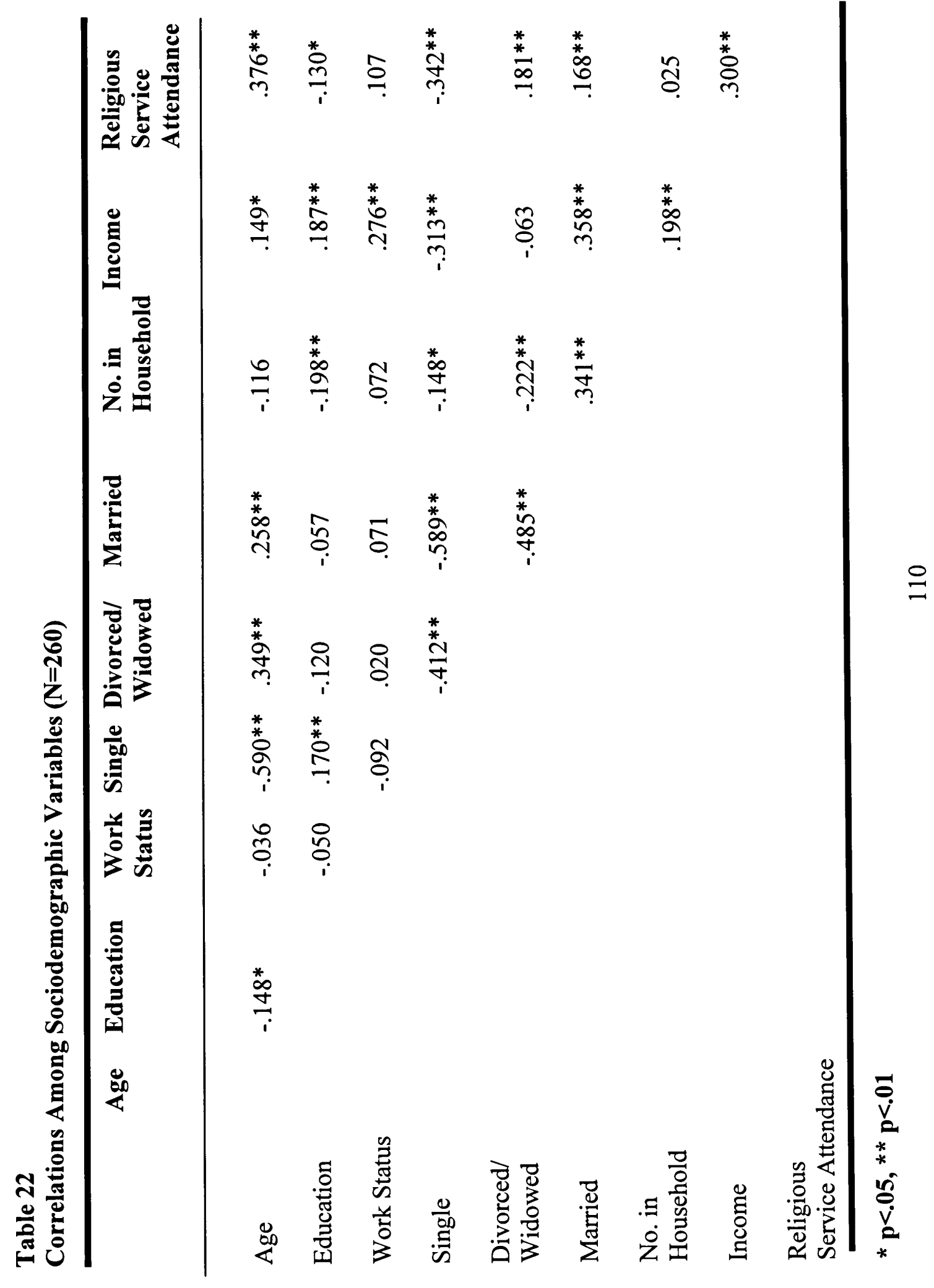


Correlations between Spirituality, Sociodemographics and BMI $(\mathbf{N}=\mathbf{2 6 0})$

\begin{tabular}{|c|c|c|c|c|}
\hline $\begin{array}{l}\text { Health } \\
\text { Respons. }\end{array}$ & SPS & $\begin{array}{l}\text { Spiritual } \\
\text { Growth }\end{array}$ & $\begin{array}{l}\text { Inter } \\
\text { Rel. }\end{array}$ & $\begin{array}{l}\text { Stress } \\
\text { Manage- }\end{array}$ \\
\hline
\end{tabular}

$\begin{array}{lllllll}\text { Age } & .160^{* *} & .248^{* *} & -.032 & -.069 & .149^{*} & .120 \\ \text { Education } & .278^{* *} & .020 & .383^{* *} & .347^{* *} & .140^{*} & .209^{* *} \\ \text { Work Status } & .030 & .117 & -.072 & -.048 & -.154^{*} & -.078 \\ \text { Single } & -.140^{*} & -.226^{* *} & -.028 & -.039 & -.118 & -.047 \\ \text { Divorced/ } & & & & & & \\ \text { Widowed } & .055 & .069 & -.044 & -.132^{*} & -.035 & .043 \\ \text { Married } & .086 & .157^{*} & .066 & .155^{*} & .145^{*} & .007 \\ \text { No. in } & & & & & & \\ \text { Household } & -.115 & -.035 & .011 & -.012 & .032 & -.089 \\ \text { Income } & .331^{* *} & .152^{*} & .209^{* *} & .306^{* *} & .121 & .175^{* *}\end{array}$

Religious

Service

$\begin{array}{lrrrrrr}\text { Attendance } & .091 & .522^{* *} & .055 & .037 & .103 & .053 \\ \text { BMI } & -.066 & .157^{*} & -.092 & -.075 & -.025 & -.122^{*}\end{array}$

${ }^{*} \mathrm{p}<.05,{ }^{* *} \mathrm{p}<.01$ 
Being divorced or widowed was negatively associated with interpersonal relations $(r=$ $.132, \mathrm{p}=.033)$. Being married was positively associated with SPS, interpersonal relations and stress management $(r=.157, p=.011 ; r=.155, p=.012 ; r=.145, p=.019)$. Income was positively associated with health responsibility, spiritual perspective scale, spiritual growth, interpersonal relations, and self-esteem $(\mathrm{r}=.331, \mathrm{p}<.001 ; \mathrm{r}=.152, \mathrm{p}=.014 ; \mathrm{r}=$ $.209, \mathrm{p}=.001 ; \mathrm{r}=.306, \mathrm{p}<.001 ; \mathrm{r}=.175, \mathrm{p}=.005)$. Religious service attendance was positively associated with SPS $(\mathrm{r}=.522, \mathrm{p}<.001)$. Anthropometry as measured by BMI was positively associated with SPS $(r=.157, \mathrm{p}=.011)$ and negatively associated with self-esteem $(\mathrm{r}=.122, \mathrm{p}=.049)$.

In summary, persons who are older have better health responsibility, engage more in spiritually related interactions, and have better stress management. Those individuals with a higher education have better health responsibility, spiritual growth, interpersonal relations, stress management, and self-esteem. Those individuals who work more often have less stress management. Individuals who are single have less health responsibility, and are less likely to engage in spiritually related activities. Those individuals who are divorced or widowed have less emphasis on interpersonal relations. Persons who are married engage in spiritually related interactions more, emphasize interpersonal relations, and have better stress management. Individuals who have higher incomes have better health responsibility, engage more frequently in spiritually related interactions, and have better spiritual growth, interpersonal relations, and higher self-esteem. Those who frequently attend religious services engage in spiritually related interactions. Those who have higher BMIs engage in spiritually related interactions and have lower self-esteem. 


\section{Research Question 6: What role does spirituality play in the lives of African}

\section{American women as it relates to their diet and exercise habits?}

The relationship of spirituality and diet and exercise is shown in Table 24 .

Spirituality was significantly correlated to diet and exercise. Health responsibility was positively associated with physical activity and diet as expressed by both the HPLP II Nutrition subscale and the Healthy Eating Scale $(r=.294, p<.001 ; r=.451, p<.001 ; r=$ $.193, \mathrm{p}=.002$ ). Spiritual growth was positively associated to physical activity and diet as expressed by both the HPLP II Nutrition subscale and the Healthy Eating Scale $(r=.314$, $\mathrm{p}<.001 ; \mathrm{r}=.428, \mathrm{p}<.001 ; \mathrm{r}=.158, \mathrm{p}=.011)$. Interpersonal relations was positively associated with physical activity, and diet as expressed by the HPLP II Nutrition subscale $(\mathrm{r}=.215, \mathrm{p}<.001 ; \mathrm{r}=.339, \mathrm{p}<.001)$. Stress management was positively associated with physical activity and diet as expressed by both the HPLP II Nutrition subscale and the Healthy Eating Scale $(\mathrm{r}=.488, \mathrm{p}<.001 ; \mathrm{r}=.539, \mathrm{p}<.001 ; \mathrm{r}=.264, \mathrm{p}<.001)$. Self-esteem was positively associated with physical activity and diet as expressed by both the HPLP II Nutrition subscale and the Healthy Eating Scale $(r=.139, p=.025 ; r=.224, p<.001 ; r$ $=.130, \mathrm{p}=.036)$.

In summary, individuals with better health responsibility, higher spiritual growth, stress management, and self-esteem also scored higher on the physical activity subscale and had better diets as expressed by both the HPLP II Nutrition subscale scores and the Healthy Eating Score. Those individuals with stronger interpersonal relations also scored higher on the physical activity subscale and had better diets as expressed by the HPLP II Nutrition subscale score. 


\section{HPLP Physical}

Activity
HPLP Nutrition

Healthy Eating Score

Health

Responsibility

$.294 * *$

$.451^{* *}$

$.193^{* *}$

Spiritual Perspective

Scale

.098

$-.025$

Spiritual

Growth

$$
.314^{* *}
$$

$.428^{* *}$

$.158^{*}$

Interpersonal

Relations

$.215^{* *}$

$.339^{* *}$

.099

Stress

Management

$.488^{* *}$

$.539 * *$

$.264 * *$

Self

Esteem

$.139 *$

$.224^{* *}$

$.130 *$

${ }^{*} p<.05,{ }^{*} p<.01$

Research Questions 7: Which variables are the best predictors of a healthy diet (as determined by scores from the HPLP II Nutrition Subscale and the Healthy Eating Scale) and exercise patterns in African American women?

\section{Hierarchical Regression}

Hierarchical regression was employed to determine if the addition of information regarding the independent variables of spirituality, sociodemographics, and BMI 
improved prediction of the health promoting behavior of diet as expressed by the HPLP II Nutrition subscale.

The results (see Table 25 ) show that $15 \%$ of the variability of HPLP II Nutrition was explained by sociodemographics, $F(9,250)=4.96, p<.001$. Education was the most significant sociodemographic predictor of diet, $\beta=.34, p<.001$. An additional $25 \%$ of the variability of HPLP II Nutrition was explained by the spirituality variables, F $(6,244)=17.29, \mathrm{p}<.001$. The most significant predictors overall were stress management, $\beta=.42, \mathrm{p}<.001$, and health responsibility, $\beta=.21, \mathrm{p}<.001$. When allowing for marginal significance, self-esteem, $\beta=-.11, p=.066$ was a predictor.

Hierarchical regression was employed to determine if the addition of information regarding the independent variables of sociodemographics and spirituality improved prediction of the health promoting behavior of exercise as expressed by the HPLP II Physical Activity subscale.

The results (see Table 26) show that 7\% of the variability of HPLP II Physical Activity was explained by the sociodemographics, $\mathrm{F}(9,250)=2.04, \mathrm{p}<.036$. Education was the most significant sociodemographic predictor of physical activity, $\beta=.21, p=$ .003. An additional $22 \%$ of the variability of HPLP II Physical Activity was explained by the spirituality variables, $\mathrm{F}(6,244)=12.94, \mathrm{p}<.001$. The most significant predictors of physical activity overall were education, $\beta=.14, \mathrm{p}=.029$, and stress management, $\beta=$ $.49, \mathrm{p}<.001$. 
Table 25

Hierarchical Regression of Sociodemographic, Anthropometry, and Spirituality Variables on the Health Promoting Behavior of Diet as expressed by the HPLP II Nutrition Subscale $(\mathbf{N}=\mathbf{2 6 0})$

Characteristic

Diet

$\beta$

p

Model 1

Age

.110

Education

.336

Work Status

$-.121$

.161

Single

$-.082$

$<.001 * * *$

Divorced/Widowed

$-.001$

.051

Number in Household

.001

.329

.983

Income

.020

.990

Religious Service Attendance

$-.005$

.783

BMI

$-.089$

.936

.157

$$
R^{2}=.151, F(9,250)=4.96, p<.001
$$

Model 2

Age

Education

Work Status

Single

Divorced/Widowed

Number in Household

Income

Religious Service Attendance

BMI

Self-Esteem

Stress Management

Interpersonal Relations

Spiritual Perspective Scale

Spiritual Growth

Health Responsibility
.048

.231

$-.042$

$-.040$

.028

$-.010$

$-.059$

$-.018$

$-.054$

$-.113$

.418

$-.019$

$-.042$

.065

.214
.490

$<.001 * * *$

.442

.582

.638

.859

.357

.781

.320

.066

$<.001^{* * *}$

.806

.500

.451

$.001^{* * *}$

$$
R^{2}=.405, F(6,244)=17.29, p<.001
$$


Table 26

Hierarchical Regression of Sociodemographic and Spirituality Variables on the Health Promoting Behavior of Physical Activity as expressed by the HPLP II

Physical Activity Subscale (N=260)

Characteristic

Physical Activity

$\beta$

p

Model 1

Age

$-.013$

.878

Education

.205

$.003 * *$

Work Status

$-.125$

.054

Single

$-.051$

.561

Divorced/Widowed

$-.055$

.450

Number in Household

$-.013$

.853

Income

$-.029$

.696

Religious Service Attendance

.048

.501

BMI

$-.073$

.266

Model 2

$$
R^{2}=.068, F(9,250)=2.04, p=.036
$$

Age

Education

Work Status

Single

Divorced/Widowed

Number in Household

Income

Religious Service Attendance

BMI

Self-Esteem

Stress Management

Interpersonal Relations

Spiritual Perspective Scale

Spiritual Growth

Health Responsibility
$-.092$

.141

$-.054$

$-.017$

$-.023$

$-.040$

$-.054$

.009

$-.038$

$-.101$

.492

$-.109$

.005

.030

.118
.225

$.029 * *$

.365

.827

.727

.532

.441

.900

.519

.133

$<.001^{* * *}$

.187

.936

.750

.104

$$
R^{2}=.293, F(6,244)=12.94, p<.001
$$


Hierarchical regression was employed to determine if the addition of information regarding the independent variables of sociodemographics and the moderating variables of spirituality improved prediction of the healthy eating scale.

The results (see Table 27) show that $3 \%$ of the variability of the Healthy Eating Scale was explained by the sociodemographic, $F(9,250)=0.96, p<.475$. An additional $7 \%$ of the variability of Healthy Eating Scale was explained by the spirituality variables, $F(6,244)=3.39, p<.003$. Stress management was the most significant predictor of the healthy eating scale, $\beta=.28, \mathrm{p}=.001$.

\section{Canonical Correlations}

A canonical correlation analysis was performed between a set of health promoting behavior variables and the set of sociodemographic, BMI, and spirituality variables. The health promoting behavior set included nutrition, healthy eating scale, and physical activity. The sociodemographic, BMI, and spirituality variables included age, education, work status, marital status, number in household, income, religious service attendance, BMI, self-esteem, spiritual growth, interpersonal relations, stress management, health responsibility, and spiritual perspective scale.

One canonical correlation was statistically significant, $r=.67, F(45,720)=4.07$, $\mathrm{p}<.001$. Data on the pair of canonical variates appear in Table 28. Shown in the table are correlations between the variables and the canonical variates, standardized canonical variate coefficients, with-in-set variance accounted for by the canonical variates (percent of variance), redundancies, and canonical correlations. Total percent of 
Table 27

Hierarchical Regression of Sociodemographic and Spirituality Variables on the Healthy Eating Scale $(\mathbf{N}=\mathbf{2 6 0})$

Characteristic

\section{Healthy Eating Scale}

$\beta$

p

Model 1

Age

.157

.061

Education

.127

.067

Work Status

.032

.628

Single

.038

.669

Divorced/Widowed

.007

.920

Number in Household

.052

.464

Income

$-.004$

.959

Religious Service Attendance

$-.078$

.283

BMI

$-.056$

.403

Model 2

$$
R^{2}=.033, F(9,250)=0.96, p=.475
$$

Age

Education

Work Status

Single

Divorced/Widowed

Number in Household

Income

Religious Service Attendance

BMI

Self-Esteem

Stress Management

Interpersonal Relations

Spiritual Perspective Scale

Spiritual Growth

Health Responsibility
.106

.096

.087

.044

.015

.038

$-.039$

$-.050$

$-.030$

.010

.278

$-.057$

$-.090$

$-.009$

.075
.209

.183

.192

.620

.843

.591

.618

.530

.649

.890

$.001^{* *}$

.541

.238

.935

.355

$$
R^{2}=.108, F(6,244)=3.39, p=.003
$$


Table 28

Correlations, Standardized Canonical Coefficients, Canonical Correlations, Percents of Variance, and Redundancies between Measures of Health Promoting Behaviors and Independent and Moderating Variables.

First Canonical Variate

Measures of Health Promoting Behaviors

Nutrition

Healthy Eating Scale

.42

Physical Activity
$-.75$

.01

$-.38$

Percent of Variance .56

Redundancy

Sociodemographics, Anthropometry \& Spirituality

\begin{tabular}{lrr} 
Age & .09 & .00 \\
Education & .49 & -.34 \\
Work Status & -.22 & .08 \\
Single & -.05 & .06 \\
Divorced/Widowed & -.01 & -.02 \\
Number in Household & -.13 & .03 \\
Income & .09 & .10 \\
Religious Service Attendance & -.02 & .02 \\
BMI & -.15 & .08 \\
Self-Esteem & .33 & .18 \\
Spiritual Growth & .66 & -.09 \\
Interpersonal Relations & .50 & .08 \\
Stress Management & .88 & -.74 \\
Health Responsibility & .67 & -.31 \\
Spiritual Perspective Scale & .17 & .04 \\
\multicolumn{1}{c}{ Percent of Variance } & .07 & \\
\multicolumn{1}{c}{ Redundancy } & .16 &
\end{tabular}


variance $(.56)$ and total redundancy $(.25)$ indicate that the correlation between the first pair of variables is very good (.67).

The significant pair of canonical variables indicated that those individuals with good nutrition (.95), increased physical activity (.79), and healthy eating (.42) had better stress management (.88), better health responsibility (.67), higher spiritual growth (.66), better interpersonal relations (.50), more education (.49), and higher self-esteem (.33). The canonical variate pair extracted $56 \%$ of the variance of the health promoting behavior variables from the sociodemographic, anthropometry, and spirituality variables.

\section{OTHER RESULTS}

\section{Health Promoting Life-Style Profile II}

Table 29 summarizes descriptive statistics for the health promoting lifestyle profile total scale and subscales of health responsibility, physical activity, nutrition, spiritual growth, interpersonal relations, and stress management. The overall HPLP IIscale was 2.66 on a 4-point scale, with a range of $1.71-3.94$, indicating that, on average, behaviors occurred more than "sometimes" (2), but less than "often" (3). The means of the subscales were health responsibility $=2.57$, physical activity $=2.11$, nutrition $=2.40$, spiritual growth $=3.22$, interpersonal relations $=3.08$, and stress management $=2.52$.

Cronbach's alpha for the overall HPLP II Scale was 0.93 . The Cronbach's alpha for the subscales were health responsibility $=0.81$, physical activity $=0.85$, nutrition $=0.79$, spiritual growth $=0.84$, interpersonal relations $=0.79$, and stress management $=0.77$. 
Table 29

Descriptive Statistics for Health Promoting Lifestyle Profile Total Scale and Subscales $(\mathbf{N}=\mathbf{2 6 0})$

\begin{tabular}{lrrrc}
\hline Scale & Mean & SD & Range & $\begin{array}{c}\text { Cronbach's } \\
\text { Alpha }\end{array}$ \\
\hline Total HPLP & 2.66 & .42 & $1.71-3.94$ & .93 \\
Health Responsibility & 2.57 & .59 & $1.22-4.00$ & .81 \\
Physical Activity & 2.11 & .66 & $1.00-4.00$ & .85 \\
Nutrition & 2.40 & .57 & $1.00-3.78$ & .79 \\
Spiritual Growth & 3.22 & .51 & $1.89-4.00$ & .84 \\
$\begin{array}{l}\text { Interpersonal } \\
\quad \text { Relations }\end{array}$ & 3.08 & .50 & $1.89-4.00$ & .79 \\
Stress Management & 2.52 & .56 & $1.25-4.00$ & .77 \\
& & & &
\end{tabular}




\section{CHAPTER V \\ DISCUSSION}

The current study afforded an opportunity to investigate the spirituality of African American women as it relates to their health promoting behaviors of diet and exercise. Study participants were African American women residing in Central and South Florida (Orlando, West Palm Beach, and Miami). The data from the study was used to answer the questions on whether spirituality is related to the health promoting behaviors of diet and exercise habits of African American women. The study also explored the relationship of sociodemographics, BMI, and spirituality variables of these African American women.

This descriptive cross-sectional correlational study collected sociodemographic, anthropometric (self-reported height and weight), dietary, exercise, and spirituality data to answer the two primary questions of the study: What is the role of spirituality in impacting the health promoting behaviors (diet and exercise) of African American women? Of the independent variables of spirituality, sociodemographics, and BMI, which are the best predictors of diet and exercise?

\section{Research Question 1: What are the sociodemographic characteristics of study participants?}

The participants were from all income levels, with the largest percentage of the participants (27\%) having a household income over $\$ 60,000$. The majority of the participants in this study had some college degree, vocational degree, or had attended some college (87\%). This is very representative of what is usually found in Black 
churches. Black churches used in other studies also tended to have a mixture of individuals at all income levels, and all educational levels (Smith, 1989; Reniscow et al., 2001). Census data maps used to determine prominent residential areas of African Americans did not include educational or income levels, only ethnicity of the residents (homer.ssd.census.gov., Accessed 11/07/00). However, this income level is well below the Florida household income for 1999 where $37.6 \%$ earned more than $\$ 50,000$ (http://factfinder.census.gov/servlet/, Accessed 6/18/03).

The high income and educational levels of the participants coincides with the interest often shown by this subset of the church-going population in educational and health seminars. Additionally, African American women who participate in social groups such as sororities, because of the costs involved, are usually of higher income groups.

\section{Religion}

The majority of people of African descent residing in the South are of a Baptist religion following. In the present study, $65 \%$ of the participants considered themselves Baptist. Most people of African descent feel that religion is an integral part of their identity. In the present study, most respondents attended religious services more than once a week (46\%). Only $3 \%$ of the participants have never attended religious services, and only $7 \%$ attend religious services rarely. For the most part, $90 \%$ of the women who participated in this study attend religious services at least occasionally.

Data were collected on attendance of religious services to determine the relationship of this variable with other independent and dependent variables. 
Noteworthy, at this point in a descriptive discussion, is that attendance at some place of worship or membership in some community group is essential for the women in this study.

Strawbridge et al. (2001) looked at religious attendance and increasing good health behaviors. Strawbridge et al. found that religious attendance was associated with improved mental health and possibly with maintaining good mental health. Strawbridge et al. also purports that frequent attendees of religious services evidence a higher prevalence of good health behaviors and higher levels of social involvement (Strawbridge et al., 2001). Rojas (1996) postulated that high levels of spiritual well-being and frequent church attendance allow low-income Hispanic women to cope with the stresses of poverty and remain essentially healthy (Rojas, 1996). Other research shows that positive relationships between religious involvement and health have been found in many areas, (Levin et al., 1994; Levin, 1994) including self-ratings of health (Levin et al., 1993), long-term well-being and life satisfaction, (Levin et al., 1995; Levin et al., 1996), and psychological well-being (Levin \& Chatters, 1998).

The present study has tried to differentiate between religiosity and spirituality, noting the latter is represented by connectedness with self, others, and the environment. However, since accessing this population is important for any health intervention, churches could be an ideal venue, not because of the religious focus, but as a trusted meeting place. 
The rates of chronic disease in the United States are higher among ethnic minorities. This increased prevalence is usually seen mostly in African American women. Obesity tends to be the precursor to many of the other chronic diseases (e.g., hypertension, diabetes, coronary heart disease). Despite evidence that body weight is generally inversely correlated to educational level and socioeconomic status, obesity appears to be common in African Americans of all education and socioeconomical status levels (Melnyk \& Weinstein, 1994). In the present study population, $66 \%$ were either overweight or obese. These results are similar to the NHANES $1999-2000$ findings, which indicate that $64 \%$ of the total U.S. adult population is either overweight or obese (NCHS, accessed 3/17/03). Several studies have found Black women to be at increased risk of both overweight and obesity (Smith, 1989; Kumanyika \& Charleston, 1992; Anderson et al., 2002; Flegal et al., 2002; and Freedman et al., 2002). The majority of these studies found that Black women are overweight and obese despite the fact that they are more educated and live at a higher SES level. These women were also church-going Black women (Lewis \& Green, 2000; Reniscow et al., 2001). The findings of these studies were similar to the findings in the present research study.

\section{Research Question 2: How do African American women score on the various spirituality subscales?}

In the present study, Burkhardt's Model of Spirituality provided the theoretical framework. It addresses spirituality in three areas which are connectedness with self, others, and the environment. 
Connectedness with self, measures of self-esteem and spiritual growth, determined the spiritual views of these women and their feelings of self-worth. The women scored low on the Rosenberg Self-Esteem Scale with a mean score of 2.43 out of 4. On the HPLP II Spiritual Growth subscale, the mean score was 3.22 \pm .51 ; this indicated that these women feel connected with a force greater than themselves, have a sense of purpose in life, and are seeking personal development.

For connectedness with others, which was measured using HPLP II Stress Management, the women's mean score was $2.52 \pm .56$; also, for the HPLP II Interpersonal Relations, the women's mean score was $3.08+.50$ out of 4 . Connectedness with others measures if these women connect with others, including family, friends, social groups, and churches. The mean score for stress management in this group of women show that they do recognize stressful situations, and that they act to confront these and achieve some sense of relaxation. The mean score on interpersonal relationships in this group of women indicate that they maintain relationships that involve a sense of closeness and intimacy.

For connectedness with the environment which was measured using the Spiritual Perspective Scale and HPLP II Health Responsibility subscale, showed if these women considered themselves having a sense of reflection and harmony in their lives. For the Spiritual Perspective Scale, these women had a mean score of 5.48 out of 6 , which indicates that they are engaged in spiritually related interactions and that they had spiritual connections when making decisions in their lives. For the HPLP II Health Responsibility subscale, these women had a mean score of $2.57 \pm .59$ out of 4 ; in essence, these women do feel that they are somewhat responsible for their health. 
Other studies have used the HPLP II instrument to operationalize spirituality, while this instrument used four measures of the HPLP II Scale (Spiritual Growth, Stress Management, Interpersonal Relations, and Health Responsibility) along with two other additional instruments, the Rosenberg Self-Esteem Scale, and the Spiritual Perspective Scale. These additional scales and the exclusion of the HPLP II Nutrition and HPLP II Physical Activity made this research unique. In previous research, it had been conjectured that using health responsibility, spiritual growth, and interpersonal relations reflect the multidimensional definition for spiritual health (Waite et al., 1999). The present study used an all encompassing definition of spirituality of connectedness with self, others, and the environment, thereby making the addition of other questionnaires imperative to the understanding of the concept of spirituality.

For this discussion section, a comparison of the four subscales (Spiritual Growth, Interpersonal Relations, Stress Management, and Health Responsibility) for women in the present study with other research is presented. The HPLP II was used in a study by Waite et al. (1999).

The Waite et al. (1999) sample was 55\% female, and $85 \%$ White, and showed that individuals had the following mean scores on the spiritual growth $(2.92 \pm 0.53)$, interpersonal relations $(2.81 \pm 0.49)$, stress management $(2.38 \pm 0.49)$, and health responsibility $(2.00 \pm 0.52)$ scales. The women in the present study scored higher on all four subscales with mean scores for spiritual growth $(3.22 \pm 0.51)$, interpersonal relations $(3.08 \pm 0.50)$, stress management $(2.52 \pm 0.56)$, and health responsibility $(2.57 \pm 0.59)$ respectively. The reason why the participants of the present study demonstrated higher spirituality could be due to the fact that they are women and that they are African 
American. This gives further credence to providing gender- and cultural- specific intervention tools that incorporate a spiritual base.

Next, it is important to see how well these women scored on the Spiritual Perspective Scale (SPS) and to compare these means with other studies. Tuck, (1997) found that study participants had a mean score of 5.334 on the SPS, which is a measure of one's spiritual perspective. The study was done on a convenience sample of 50 registered nurses employed in long-term public mental health facilities. The sample was $88 \%$ female and $94 \%$ Caucasian. The present study participants had a mean score of 5.48 , which indicates that their spiritual perspective were higher than the women in the aforementioned study.

Other scores on the SPS include a study by Reed (1986) of nurses working with the terminally ill, which reported a mean score of $4.13 \pm 1.28$. In another study by Reed (1991), SPS was reported for nurses caring for selected populations: terminally ill clients, $\mathrm{m}=4.530$; nonterminally ill hospitalized clients, $\mathrm{m}=4.157$; and healthy nonhospitalized adults, $m=4.160$. All of the means from these previous studies are well below the means score of the present study of 5.48. Reed (1986) showed that individuals who are terminally ill had higher SPS scores, while in the present study it was not known if any of the participants were terminally ill. Healthy nonhospitalized patients in Reed's (1991) study scored lower compared to the healthy nonhospitalized patients in the present study, who scored 5.48.

The SPS measures a more traditional definition of spirituality in that it incorporates feeling very close to God or a "higher power." This group of African American women demonstrates spirituality based on Burkhardt's model, but also 
demonstrates some of the traditional behaviors of spirituality. The SPS did not correlate in the overall model that predicted health promoting behaviors in this group of women; this could be explained by the fact that the majority of women in the study scored high on this scale. Therefore, the lack of variability in the results of this measure was not useful in predicting their success in health promoting behaviors.

Pullen et al. (1996) found that SPS scores differ for men and women with men scoring slightly lower $(m=4.733)$, as compared to women $(m=5.429)$. The score for women is similar to scores in the present study $(m=5.48)$. This indicates that for women in the present study, they were similar in their spiritual perspectives as women in the study by Pullen et al. (1996). Overall, African American women in the present study are very spiritual, scoring high on the SPS $(m=5.48)$ and scoring higher on other measures of the Burkhardt.

\section{Research Question 3: What is the relationship among dietary intakes, exercise}

\section{habits, and BMI of African American women?}

In the present study, when using a simple test of association, there were no significant correlations between BMI and the diet and exercise habits of the participants. Kayrooz (1998) conducted the "Living in God's Healthy Temple (LIGHT Way)" study in East Baltimore with 26 churches randomly selected from a list of 240 churches. The purpose of the study was to determine the fat intake of this predominantly African American population. Obesity is defined as a BMI value $\geq 27.3$ for women, which approximates $120 \%$ of desirable weight and has been used by the National Institutes of Health as a reference for defining obesity. Kayrooz et al. (1998) found that $61 \%$ of the 
African American women in his study were obese, their mean cholesterol intake was $212.6 \pm 49.5$, and $82.3 \%$ had high school or some college education.

In the present study, $34 \%$ of the respondents were obese (a BMI greater than 30 ), had a mean cholesterol intake of $173.67 \pm 122.21,36.1 \%$ graduated from high school or attended college, and $62.7 \%$ graduated from college. Also, in the present study, participants had almost half the obesity rates of the LIGHT Way study; however, this could be explained by the difference in cut-points for obesity that were used. The present study revealed one third of the participants as overweight, in addition, one third were obese. The cholesterol intakes reported in the present study were much lower than the LIGHT Way study. The educational levels of the women in the present study were much higher compared to those in the LIGHT Way study. The decreased cholesterol intake and decreased obesity could be due to the increased education in this group of African American women or the lower socioeconomic status of East Baltimore as compared to the targeted Florida regions.

Women in both studies tend to choose foods that are high in fat; this is probably due to long-standing cultural food traditions of African Americans. These food preferences could also be associated with inadequate knowledge about the sources of dietary fat and cholesterol. Choosing foods high in fat and cholesterol only increases these women's prevalence of obesity. When looking at current trends of the NHANES II, NHANES III, and the NHANES 1999-2000, we see that the trend of obesity is steadily increasing (Flegal et al., 2002). 


\section{Research Question 4: What is the relationship between sociodemographics, dietary patterns (as measured by the HPLP II Nutrition Subscale and the Healthy Eating Scale) and exercise habits of African American women?}

\section{Diet}

Decreasing Americans' intake of fat and saturated fat is a national health priority (DHHS, 2000; DHHS, 2010). When comparing percentage of total fat and saturated fat intakes, Kayrooz (1998), "Living in God's Healthy Temple (LIGHT Way)," found that based on the NHANES III data, the average fat intake was $33.9 \%$ and for saturated fat, $11.9 \%$. In the present study, the average fat intake was $35 \%$, which does fall in range with those percentages found in the NHANES III data. These averages are $5 \%$ more than the U.S. Dietary Guideline of less than $30 \%$ of calories from total fat. The present study also found that the average saturated fat intake for these women was $12 \%$, which is almost the same as the percentages found in the NHANES III data and only $2 \%$ above the current U.S. Dietary Guideline of less than $10 \%$ of total fat from saturated fat. The women in the present study do not meet the recommended less than $30 \%$ calories from fat, and less than $10 \%$ of total fat from saturated fat. However, the Acceptable Macronutrient Distribution Ranges (AMDR) for fat is 20-35\%, published by the Institute of Medicine (2002) for Dietary Reference Intakes.

Increasing Americans' intake of fruits and vegetables is a national health priority (Havas et al., 1995; DHHS, 2000; DHHS, 2010; Reniscow et al., 2001). Thompson et al. (1999) examined baseline rates of fruit and vegetable consumption among adults in the 5A-Day research trials in order to identify any regional and sociodemographic differences 
associated with daily servings (Thompson et al., 1999). Thompson (1999) found that for all individuals 30 and younger, their mean fruit and vegetable consumption was 3.7 servings per day, for those individuals 50 and older, their mean fruit and vegetable consumption was 3.7, and for those between 30 and 49 years old, their mean consumption was 3.4 servings. Thompson et al. (1999) also examined the fruit and vegetable intake of adult members of 50 rural Black churches in North Carolina and found that their mean daily servings of fruits were 2.1 , their mean daily servings of vegetables were 1.5 , and their mean daily servings of fruits and vegetables were 3.5. For the African American respondents in this study, the mean daily fruit and vegetable intake was 3.66. The present study found that for study participants, their mean vegetable intake was $3.31 \pm 3.003$ and for fruit intake it was $1.34 \pm 0.997$. When compared to the aforementioned study, the present study participants consumed less fruits and more vegetables.

When Thompson (1999) examined fruit and vegetable intakes across level of education, another sociodemographic characteristic, consumption rates were as follows: college graduates consumed 3.9 servings, those with some college consumed 3.5 servings, and those with some high school or were high school graduates consumed 3.4 servings. This implies that fruit and vegetable intake is directly related to educational attainment, meaning that as education increased, fruit and vegetable intake increased. This was also evident in the present study, women at higher educational levels scored higher on the HPLP II Nutrition subscale and had higher scores on the Healthy Eating Index. 
Currently, the average number of fruit and vegetable servings Americans eat has increased a half serving between 1989 and 1996, but only $23 \%$ eat the recommended two to three servings of fruit and only $41 \%$ eat the recommended three to five servings of vegetables each day (www.gao.gov, Accessed 09-30-02).

For the participants in the present study, many are meeting the recommended three to five servings of vegetables with a mean of $3.31 \pm 3.003$, but they are not meeting the recommended two to three servings of fruit with a mean of $1.34 \pm 0.997$.

One study of Black churches by Reniscow et al. (2001) examined the "Eat for Life" program, which is a multicomponent intervention designed to increase fruit and vegetable consumption among African Americans that was delivered through Black churches. This program showed increased fruit and vegetable consumption among African American church goers when motivational interviews were used. Motivational interviewing appears to be a promising strategy for modifying dietary behavior; Black churches are an excellent setting to implement and evaluate health promoting programs (Reniscow et al., 2001).

The fact that African American church goers show increased fruit and vegetable consumption has implications for utilizing nutrition education to increase fruit and vegetable intake in this group of women which focuses on their spirituality. Women who have a strong spiritual base may be more attentive to nutrition education that designates that they are treating their bodies well by consuming adequate fruits and vegetables. This is directly related to their spirituality and that they have some connection with life and nature. 
Calcium intake was another area of deficiency in the diet of African American study participants. The average number of servings of dairy products was less than one per day (0.8) with a mean intake for calcium of $507 \mathrm{mg}$. This is clearly below the U.S. Dietary Guideline (2000) of 2-3 servings of dairy products and the Dietary Reference Intake (DRI) of 1000-1200 mg for these age groups (Institute of Medicine, 1999). The health consequences of low calcium intake include a $10 \%$ incidence of osteoporosis in African American women (Institute of Medicine, 1999). Calcium intake has been associated with reduction in hypertension with Dietary Approaches to Stop Hypertension (DASH) (Sacks et al., 2001) and was reinforced in the Seventh Report of the Joint National Committee on Prevention, Detection, Evaluation, and Treatment of High Blood Pressure (Chobanian et al., 2003).

\section{Exercise}

The study by Ahijevych and Bernard (1994) found physical activity scores of 1.95 \pm .65 compared to the present study where scores were $2.11 \pm .66$, which may indicate that the African American women in the present study tended to be somewhat more active than those in the aforementioned study. Physical activity for these African American women indicates that they answered "more than sometimes" and "less than often" to: follow a planned exercise program, exercise vigorously for 20 or more minutes at least three times a week, take part in light to moderate physical activity, take part in leisure-time physical activities, do stretching exercises at least 3 times per week, get exercise during usual daily activities, check pulse rate when exercising, and reach target heart rate when exercising. Since these women did not answer questions on duration and 
type of exercise and only the HPLP II Physical Activity Score was used, it can be concluded that for the most part these women are somewhat more active.

Brady and Nies (1999) found that African American women living at increased poverty levels actually had higher exercise levels $2.30 \pm .77$ when compared to those with decreased poverty levels $1.72 \pm .76$. For all women in the Brady and Nies study, the mean for exercise was $2.05 \pm .81$. The women in the present study had a mean for exercise of $2.11 \pm .66$. This indicates that the women in the present study were somewhat physically active. The five-item scale based on self-reported exercise behaviors were ranked as 1 (never), 2 (sometimes), 3 (often), and 4 (always). Thus, even if these women never exercised, their mean score would be 1.0. The women in the present study yielded a mean score of 2.11, which means they exercised sometimes. As in the Brady and Nies study and in the present study, specific prescriptions for exercise need to be developed that are culturally specific, practical., and inexpensive; this may increase physical activity in this group of women (Brady \& Nies, 1999). The participants in the present study scored lowest on the subscale of physical activity compared to all other subscales on the HPLP II. A study by Ford et al. (2001) examined achieving a healthy lifestyle among Americans. The study states that Americans still have a long way to go and although there has been success in improving some lifestyle parameters, progress has been minimal in increasing fruit and vegetable intakes (Ford et al., 2001), moreover, there has been little progress in increasing physical activity. Although participants in this study score higher when compared to some of the aforementioned studies, they still are not where they should be. Prevalence of obesity is increasing, more specifically in ethnic 
minorities; it is likely that it is directly related to decreased physical activity in this group of women, but also contributed to poor food choices and increased kilocalories.

A study by Ford et al.(2001) analyzed four healthy lifestyle characteristics. The lifestyle characteristics reviewed were smoking, moderate or vigorous physical activity, consuming greater than five fruit and vegetables, and being at a normal weight. The study found that only $6.8 \%$ of the U.S. population reflected all four healthy factors. Participants 65 and older were more likely to reflect all four healthy lifestyle factors when compared to younger participants. In this study, 37\% of African American women were at a normal weight, compared to the present study in which $33 \%$ were at a normal weight. The dissertation results were slightly lower than the Ford et al. study.

\section{Research Question 5: What is the interrelationship of spirituality, sociodemographics, and BMI?}

The findings indicate that several of the sociodemographic variables were positively associated with the components of spirituality as defined by Burkhardt. For example, income and education were related to several of the constructs measured by the HPLP II. Age and being married also positively correlated with three of the spiritual components. Self-esteem was positively correlated with income and education, but negatively associated with BMI.

Spirituality is often difficult to define (Musgrave et al., 2002); for the purposes of this study, spirituality incorporates Burkhardt's Theory of Spiritual Interconnectedness, which includes connectedness with self, others, and the environment. The measures of spirituality are self-esteem, spiritual growth, interpersonal relations, stress management, 
health responsibility, and the Spiritual Perspective Scale. Specifically, connectedness with self is measured by self-esteem and spiritual growth; connectedness with others is measured by interpersonal relations and stress management; and connectedness with the environment is measured by health responsibility and spiritual perspective scale.

In analyzing previously published research, Faith et al. (1998) found that in three of the four studies, there were no significant correlations of relative body weight and selfesteem. Understanding the association between relative body weight and self-esteem is important for several reasons. First, the high prevalence of obesity in the African American population in and of itself speaks to the importance of understanding the psychological implications of elevated body weight (Faith et al., 1998). Second, it has been conjectured that African American women may be accepting of and hence prone toward obesity because it is less central to their self-esteem, however, it is a major risk factor (Faith et al., 1998; Allison et al., 1997; Flynn \& Fitzgibbon, 1998; Gore, 1999; Anderson et al., 2002). Therefore, issues of self-esteem, overweight and obesity are essential to understanding this population. Although the present study had a negative correlation of BMI and self-esteem, it was a relatively weak correlation (-.122) accounting for only $1 \%$ of the variance $\left(\mathrm{r}^{2}\right)$. The BMI measures a ratio of weight to height, which when classified according to current guidelines can mislabel an individual with large bone structure or muscle mass as overweight (Janssen et al., 2002).

Anderson et al. (2002) found in a national survey of overweight and obese women trying to lose weight that women who were non-Hispanic Black were more likely to express satisfaction with their body weight compared to non-Hispanic White women. The study had similar findings, to other research, which indicated that Black women are 
more likely than non-Hispanic White women to express satisfaction with their body size (Flynn \& Fitzgibbon, 1998; Anderson et al., 2002). It is important to realize that African American women often define obesity in terms of their culture (Gore, 1999). The cultural context in which these definitions were explained was in reference to historical influences on family from the time of slavery to present views of "weight." Being overweight in the African culture usually was a sign of prosperity in slavery times and this may have been translated from generation to generation. Views about weight and body size, eating patterns, and attitudes toward food were passed from generation to generation (Gore, 1999).

Previous research has established that African American women still have better self-esteem in the presence of overweight and obesity suggesting interventions should focus not on weight loss, but on the adoption of health promoting behaviors. The women in this present study experienced lower self-esteem in the presence of overweight and obesity. This is an important issue that needs further investigation. It is possible that the higher educational level of subjects in the present study modifies their self concept compared to African American women in previous studies. Regardless, based on the findings of this study, self-esteem cannot be ignored as a factor in the adoption of health promoting behaviors.

Some other measures that are pertinent to the understanding of spirituality are health responsibility, spiritual growth, and interpersonal relations. Jefferson et al. (2000) found a mean score on HPLP II health responsibility of $2.59 \pm .59$, HPLP II Spiritual Growth of $2.96 \pm .59$, and HPLP II Interpersonal relations of $2.95 \pm .53$ compared to the current study that found the mean scores of $2.57 \pm .59,3.22 \pm .51$, and $3.08 \pm .50$, 
respectively. The scores on health responsibility in the study by Jefferson (Jefferson et al., 2000) were similar to those found in the present study. However, the women in the present study scored higher on Spiritual Growth and Interpersonal Relations.

Ahijevych and Bernard (1994) explored some other measures of spirituality and found scores on HPLP II Interpersonal Relations to be $2.90 \pm .59$, which were very similar to the findings in the present study. The present study found interpersonal relations scores of $3.08 \pm .50$ with a range of $1.89-4.00$. Interpersonal relations are important because it usually answers the questions whether individuals discuss issues with persons close to them. Interpersonal relations are major indicators of how individuals are handling the daily stresses of life.

It is important to note that for health responsibility, the participants scored lowest on attending educational programs on personal health care. The respondents' mean score was more than "never" and less than "sometimes." This means that, typically, respondents do not attend education programs on personal health care. However, in the present study, for two of the three churches, the numbers in attendance were very high, perhaps due to the session's unique focus. At Macedonia Missionary Baptist, the average attendance at the Intermediate Women's Study group was 40 . For this program advertised as "Spirituality and Your Health," there were 100 women in attendance, and 79 women completed questionnaires. At Bethel Full Gospel Baptist Church, the WISE Women's Group usually has an average of 25 women in attendance, but when this was advertised 67 women were in attendance, and a total of 47 women completed questionnaires. At Macedonia Missionary Baptist Church the majority of women participated with only about 21 women not filling out questionnaires. At Bethel Full 
Gospel Baptist Church 20 women did not fill out the questionnaires. This speaks to the fact that Black women are looking to their church as a place of support and a place of significant health care resources (Smith, 1989; Eng, 1993; Yanek et al., 2001).

For the women's social groups, the regular numbers of women attended both meetings as well as the advertised meeting on "Spirituality and Your Health." The majority of women who attended women's social groups reported high levels of church attendance. This could be explained by the fact that women in Black churches want to know more about their spirituality and how it is linked to their health promoting behaviors of diet and exercise, hence, their increased attendance at such events. The advertisement of this event could also explain the increased attendance at such events. The events were advertised in church newsletters, on the marquis and visual announcement boards at churches, and from the pulpit by the Pastors of the churches. The advertisement of this event was done in newsletters to members and also announced by the leaders of the social group, one month prior to the meetings.

On the HPLP II Spiritual Growth, the mean score for "feel connected with some force greater than myself' is the highest reported item on all HPLP II scale (3.52). This is similar to the response to the question on the SPS, "I frequently felt very close to God or a 'higher power' in prayer, during public worship, or at important moments in my daily life" in which individuals responded a mean of 5.63 out of 6 . This indicates that individuals either agreed or strongly agreed with the aforementioned statement. HPLP II Spiritual Growth and SPS were correlated $(\mathrm{p}<.01)$. Spirituality on one hand means an inner quality that facilitates connectedness with the self, other people, and nature. On the other hand, the traditional definition involves one's acknowledgement of and relationship 
with a Supreme Being (Musgrave et al., 2002). Scoring high on the previously mentioned question on the HPLP II Spiritual Growth and on the aforementioned question on the SPS could mean for women of color, it appears, that the latter definition is more appropriate. These findings are similar to findings found by Musgrave et al. (2002). Musgrave found that women of color accept a more traditional definition, "spirituality is often defined as a basic or inherent quality in all humans that involves a belief in something greater than the self and a faith that positively affirms life" (Musgrave et al., 2002).

Women's spirituality may significantly influence what they think and believe. Further, spirituality is associated with positive health outcomes for women. The relationship of spirituality and health could provide an important perspective for public health interventions (Musgrave et al., 2002).

\section{Research Question 6: What role does spirituality play in the lives of African}

\section{American women as it relates to their diet and exercise habits?}

There were several significant correlations between spirituality and diet and exercise habits of African American women in the present study. Health responsibility was positively correlated with physical activity and diet as expressed by the nutrition subscale and the Healthy Eating Score. Spiritual growth and stress management were also positively associated with diet and exercise.

A study by Jefferson et al. (2000) found that African American women who were diabetic, responding to the HPLP II had the highest mean scores in spiritual growth (2.96 $\pm 0.59)$, interpersonal relations $(2.95 \pm 0.53)$, and health responsibility $(2.59 \pm 0.59)$. 
Lower mean scores were obtained in stress management $(2.33 \pm 0.50)$ and nutrition $(2.31$ $\pm 0.54)$. The lowest mean scores in Jefferson et al. were seen in physical activity $(1.92 \pm$ 0.42 ). The present study found physical activity scores of $2.11 \pm .66$, which were also the lowest mean scores for this group of women.

\section{Research Question 7: Of the independent variables of spirituality,} sociodemographics, and BMI, which are the best predictors of a healthy diet (as determined by scores from the HPLP II Nutrition Subscale and the Healthy Eating Scale) and exercise patterns in African American women?

When identifying the "best predictors," initially each dependent variable was examined using Hierarchical Regression. Predictors varied per variable. Diet as measured by the HPLP II Nutrition subscale was significantly associated with education, stress management, and health responsibility. Several research studies found that stress management and health responsibility were significantly correlated. Physical activity as measured by the HPLP II Physical Activity subscale was significantly associated with education and stress management. Diet as measured by the Health Eating Scale was significantly associated with stress management.

A more holistic look uses the canonical correlations. The variables that seem to be good predictors of diet and exercise in African Americans were the following: individuals with good nutrition, increased physical activity, and healthy eating had higher levels of stress management, better health responsibility, higher spiritual growth, better interpersonal relations, more education, and higher self-esteem. It is important to note that most of the items that these women scored higher on were items that were identified 
as spiritual. Five of the six items identified in the definition of spirituality were significant in this canonical correlation.

From this analysis, health promoting behavior intervention protocols should focus on ways to improve the stress management, health responsibility, spiritual growth, interpersonal relations, and self-esteem of participants along with a message of diet and exercise. The educational attainment of the participants in this study also played a role in their success. However, it was not the single most important predictor of achieving health promoting behaviors.

\section{Summary}

The first analysis showed the following simple associations: Education was associated with HPLP II Physical Activity; and Stress Management was associated with HPLP II Nutrition, Healthy Eating Scale (HES), and HPLP Physical Activity.

The second level of analysis was multiple regression analysis of HPLP II Physical Activity, HPLP II Nutrition, and Healthy Eating Scale. Education was an important predictor for HPLP II Nutrition and HPLP II Physical Activity. Stress management continued as a strong predictor for all three measures of dependent variables. Health responsibility was mainly a predictor for HPLP II Nutrition.

The final picture was drawn from the canonical correlation analysis that analyzed all three dependent variables (HPLP II Nutrition, Health Eating Scale, and HPLP II Physical Activity) together as a set. All sociodemographic, BMI, and spirituality variables were combined together as the second canonical set. Fifty-six percent of the 
variance of the dependent variables was accounted for in the first canonical correlation.

Of the six most important, independent variables, five were spiritual.

Figure 5 reflects the final model from this study. Education is the strongest independent variable of the set of sociodemographics. All of the spirituality variables except Spiritual Perspective Scale added to the prediction of health promoting behaviors. The Burkhardt model of spirituality of connectedness with self, others, and environment clearly provideed the necessary framework. The tool for measuring self-esteem (Rosenberg Self-Esteem Scale) posed questions on satisfaction with self, positive reflection on self, seeing self as a success, and proud of something about self (Rosenberg, 1965). The tool for measuring spiritual growth (HPLP II Spiritual Growth Subscale) posed questions about long term-goals, if an individual finds each day interesting and challenging, if she connects with a force greater than herself, and if she believes her life has purpose. Both self-esteem and spiritual growth are part of connectedness with self. Both of these measures are also identified in Burkhardt's theory of spiritual interconnectedness with connectedness with self. Burkhardt's theory focuses on whether individuals view their own potential, or if individuals demonstrate self-love.

The tool for measuring interpersonal relations (HPLP II Interpersonal Relations Subscale) posed questions that deal with discussing problems and concerns with others, whether she has support from a network of caring people, can settle conflict with others with discussion, praise others for their achievements, and have meaningful and fulfilling relationships with others. The tool for measuring stress management (HPLP II Stress Management Subscale) posed questions about getting enough sleep, taking time to relax daily, accepting things in life that she cannot change, using methods to control stress, and 
Figure 5.

Prediction Model of Health Promoting Behaviors.

Independent Variables

Health Promoting Behaviors

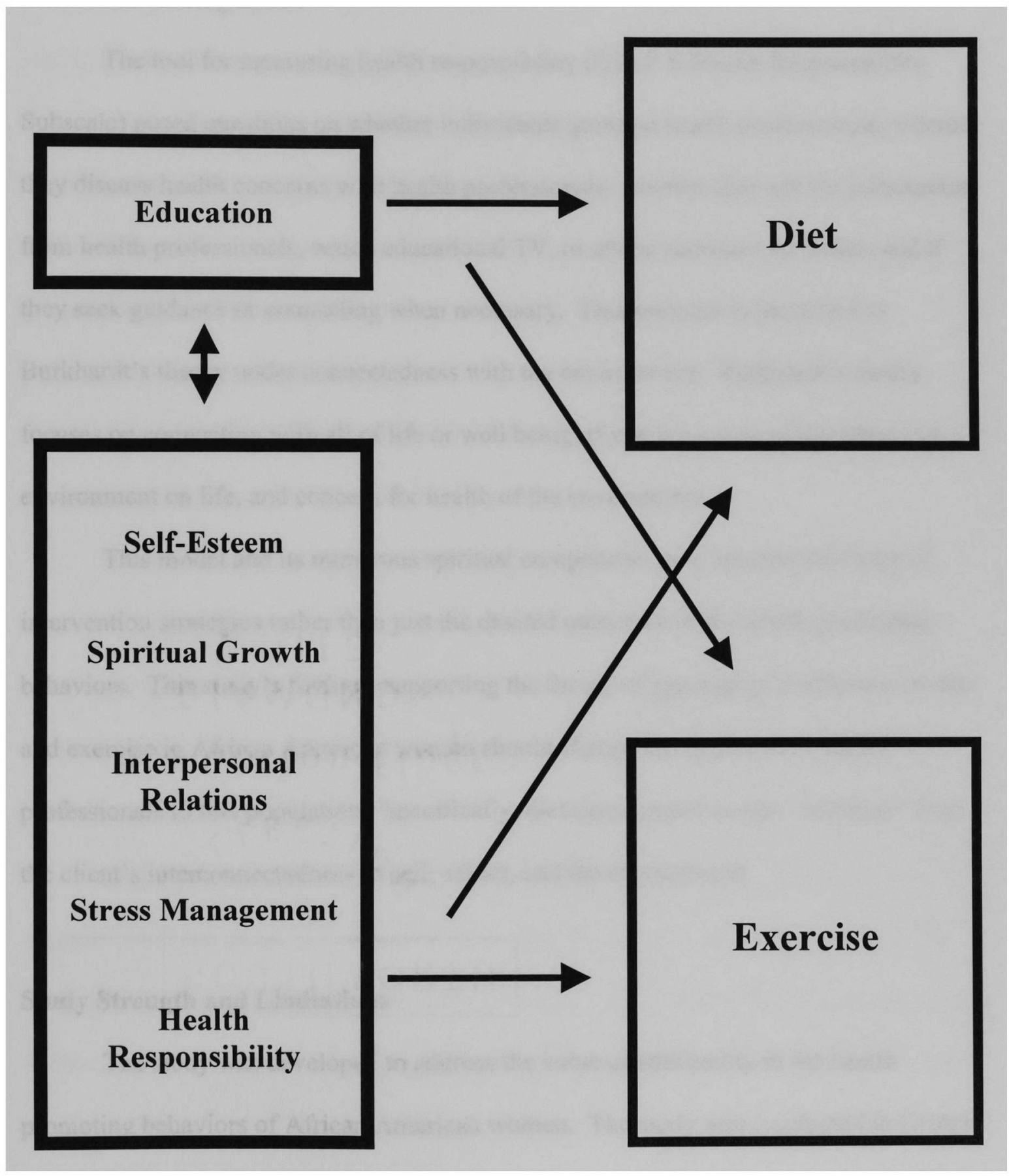


relaxing or meditating at least 15 minutes per day. Both of these measures are also identified in Burkhardt's theory, under the construct of connectedness with others. Burkhardt's theory focuses on connecting in life giving ways and about losing this connection causing stress.

The tool for measuring health responsibility (HPLP II Health Responsibility

Subscale) posed questions on whether individuals question health professionals, whether they discuss health concerns with health professionals, whether they ask for information from health professionals, watch educational TV, or attend seminars on health, and if they seek guidance or counseling when necessary. This measure is identified in Burkhardt's theory under connectedness with the environment. Burkhardt's theory focuses on connecting with all of life or well being, if you are aware of the effects of environment on life, and concern for health of the environment.

This model and its numerous spiritual components now become the focus of intervention strategies rather than just the desired outcomes of the health promoting behaviors. This study's findings supporting the theory of spirituality's influence on diet and exercise in African American women should change the approach of health professionals to this population. Specifically, dietitians cannot isolate "nutrition" from the client's interconnectedness to self, others, and the environment.

\section{Study Strength and Limitations}

The study was developed to address the value of spirituality in the health promoting behaviors of African American women. The study was conducted in Central and South Florida, which enabled the collection of data from a diverse group of African 
American participants in the state. A descriptive cross-sectional correlational design was used to collect the data in a relatively short period of time. A convenience sample was used to identify sites and recruit participants in the present study, which made recruitment relatively inexpensive. This type of recruitment limits the generalizability of study results to the general population.

The women in the present study were educated at various levels with the majority having some college or above and having similar socio-economic status (SES) levels, which likely compromises the external validity of the study. This study cannot be generalized to all African American women in the United States because other populations are more diverse in regard to their sociodemographic and socioeconomic status. Results of this study should be limited to the geographic locale in which the study was carried out.

The occurrence of bias should be addressed in any type of research design. Interviewer bias: Interviews are generally subject to interviewer bias. Using only one interviewer generally minimizes interviewer bias. The present study used one interviewer, the investigator, who followed specific written instructions to minimize interviewer bias in the present study.

Self-reporting bias: Self-reporting bias occurs when participants fail to report an exposure they are aware of because of their attitudes, beliefs, and perceptions. In this study, diet is an area when reporting bias can occur. It is possible that participants would deliberately not indicate the correct amount of food they consumed, or deliberately not mention certain foods if they feel that they will be judged for eating, or not eating those foods. The BMI constructed from self report is an issue particularly because it is an area 
where reporting bias can occur. It is possible that participants would deliberately not indicate their correct weight and height if they feel they would be judged.

Selection bias: The study sample was a convenience sample and therefore by using this type of sample there are issues with regard to external validity.

Information bias: Information bias occurs when data gathering methods are inadequate and this could result in incorrect information being collected. Since data in this study was provided by the participant and not from medical records, it is likely that different types of information bias may have occurred during the study. However, this type of data collection is used widely and yields credible data; there is no evidence that credible data were not collected in the case of this study. To ensure that there was no information bias, the instruments and procedures used to collect data for the present study were standardized, valid, and reliable.

A limitation of this study is not taking waist-hip-ratios, the inclusion of waist-hipratio with BMI gives a better picture of whether these women were at increased risk of chronic disease. It would have given information on whether these women were pear shaped or apple shaped. This gives some indication of risk for heart disease, which is prevalent in this group of women. 


\section{CHAPTER VI}

\section{SUMMARY, CONCLUSIONS, AND RECOMMENDATIONS}

\section{Summary}

Public health data show that African Americans have not adopted health promoting behaviors of diet and exercise for chronic disease management. The focus of this study was spirituality, which is so important in the lives of many African American women as it relates to health promoting behaviors. Spirituality was adopted as the broader paradigm rather than the more narrow concept of religiosity, for example, attending a place of worship and believing in a supreme being. The best theoretical framework for spirituality as it relates to health (Burkhardt, 1989), initially used in the nursing research literature, was adopted and measures were selected for the three elements of the framework: connectedness with self, others, and environment.

The study used a descriptive cross-sectional correlational design to investigate the relationships of the independent variables of spirituality, sociodemographics, and BMI, to the dependent variables of diet and exercise, in answering the two primary questions: What is the role of spirituality in impacting the health promoting behaviors of African American women? Of the independent variables of spirituality, sociodemographics, and BMI, which are the best predictors of diet and exercise?

African American women in Central and South Florida $(\mathrm{n}=286)$ participated from churches and social groups in Miami, Orlando, and West Palm Beach resulting in 260 usable questionnaires. The current study was the first to measure spirituality in a group 
of African American women and determine if their spirituality had any affect on them engaging in the health promoting behaviors of diet and exercise.

The mean age of the study participants was $41 \pm 13$. Of the study participants, $55 \%$ had at least a four-year college degree. The household income of half of the study participants was less than $\$ 45,000$. Twenty-one percent of the study participants did not work. Forty percent of the participants were married, and $34 \%$ had never been married. The majority of the study participants were either overweight or obese $(66 \%)$.

This study used several different validated and reliable measures: connectedness with self was measured using the Rosenberg Self-Esteem Scale and the HPLP II Spiritual Growth subscales, which together measured self-esteem or self-concept and whether an individual engaged in personal development. Connectedness with others was measured using the HPLP II Interpersonal Relations and HPLP II Stress Management, which together measured whether an individual connects in life-giving ways with family, friends, or social groups and if there is a loss of connectedness which causes conflict. Finally, connectedness with the environment was measured using the HPLP II Health Responsibility subscale and the Spiritual Perspective Scale (SPS), which both measured whether an individual has a sense of connection with all of life and nature. Diet was measured with the Block Brief 2000 Dietary Questionnaire and the HPLP II Nutrition subscale. Exercise was measured by the HPLP II.

Connectedness with self was operationalized to include Self-Esteem (Rosenberg's Scale) and Spiritual Growth (HPLP II). Self-esteem was the single best predictor of diet and exercise when employing hierarchical regression. Burkhardt's connectedness with the environment included the measure of Health Responsibility (HPLP II) and was a 
predictor of improved diet. Education rose as the single significant sociodemographic variable to predict positive dietary habits.

Initial tests of association indicated some of the independent variables (education and stress management) had significant relationships to the dependent variables of diet and exercise. Canonical correlation analysis, which treats the dependent variables as a set, and the independent variables as a set was able to depict a more complete view of the situation. This test helped to identify a significant pair of canonical variates, which indicated individuals with traits of good nutrition, increased physical activity, and healthy eating, while also having better stress management, better health responsibility, higher spiritual growth, better interpersonal relations, more education, and higher self-esteem. This significant finding points to five of the six spirituality variables plus education accounting for $56 \%$ of the variance, indicating that all three components of the spirituality model, connectedness with self, others and the environment, can be used with reasonable assurance with this population. Additionally, it can be stated that as diet and exercise improved, so did these specific spiritual components as well as education. Spirituality is of important benefit to African American women who are experiencing challenges to their health and well-being. The message of prevention of chronic disease, adoption of health promoting behaviors, and coping with health problems are prominent, but not always well communicated. The intersection of spirituality and health for African American women can make a difference in their health experience, helping to eliminate health disparities and promoting positive health outcomes (Musgrave et al., 2002). This study's findings of the relationship of stress management, health responsibility, spiritual 
growth, interpersonal relations and self-esteem to health promoting behaviors concur with Musgrave's conclusions.

\section{Conclusions}

The Burkhardt model of spirituality is a useful framework to evaluate and conceptualize issues of self, others, and the environment, which impact this population. The conclusions of the study are that spirituality influences health promoting behaviors of both diet and exercise. The study also concluded that educational attainment in this group of African American women was an additional factor in the presence of health promoting behaviors of both diet and exercise. Furthermore, this provides an intervention protocol that includes spiritual sensitivity.

This study provided baseline data on the spiritual health and nutritional status of African American women in Central and South Florida. The public health implications of the reported decreased intakes of fruits, vegetables, fiber, calcium, and increased fat intakes are serious. Appropriate measures should be taken to further investigate and make policy decisions regarding necessary interventions. Some of these implications include a greater healthcare cost, and a society that is more overweight and obese, which will lead to increased prevalence of chronic disease.

Over the last two decades, Healthy People 2000 (HP2000, 1989) and Healthy People 2010 (HP2010, 1999) have set recommendations for improving diet not only in the general population but in the African American population, more specifically, African American women. The messages have been to reduce energy and fat intakes, while increasing fruit, vegetable, calcium and fiber intake. Additionally, for hypertension, 
reduction in sodium is added to the educational approach. Appropriate emphasis has not been made to ensure that African American women were heeding these messages. The women in this study were still not consuming adequate fruits and vegetables in their diet, thereby not consuming adequate amounts of dietary fiber. These behaviors have implications for several different dietary problems, which increase the chronic disease risk for heart disease, obesity, osteoporosis, and diabetes. This also has implications for an increase in prevalence of cancer associated with an increase in dietary fat consumption. However, although the "average" nutritional intake of this population contained specific deficiencies, it should be noted that the major finding was as an individual's diet improved, so did five of the six spiritual variables (self-esteem, spiritual growth, interpersonal relations, stress management, and health responsibility).

\section{Recommendations}

Based on this study in Central and South Florida, adequate information is known about the participants' spirituality, diet, and exercise to proceed with a planned intervention to a similar group of volunteers. Additionally, it has been shown that these women can be accessed for health promoting activities. The venues for the interventions include churches or social groups, wherever these women congregate and are willing to participate. However, rather than a "religious" approach, the church would need to agree to the spiritual concepts addressed by this study's model: self-esteem, spiritual growth, interpersonal relations, stress management, and health responsibility.

Although this study reflects a cross-sectional sample, since it is not a representative sample, it cannot be assumed that all church-going women in Central and 
South Florida are reflected in these results. It is recommended, therefore, that further testing of this model would be necessary in other environments (states or localities).

For Americans in general., especially African American women, close attention must be paid to their lack of dietary intakes of fruits, vegetables, fiber, calcium, iron, and increased intake of fat. The intakes of these nutrients are of particular importance to the increased incidence of obesity in this group of women. It also has some bearing on whether these women will develop chronic diseases later in life. The more recent findings of Dietary Approaches to Stop Hypertension (DASH) point to these same parameters (Sacks et al., 2001).

Although many studies show that education plays a critical role in allowing women to transcend racial and social class boundaries, it is important to realize that in this group of women there are some crucial cultural boundaries such as dietary patterns that seem less easy to change, although their educational attainment has been met. It is evident that culture plays an important role in these women's decisions as they relate to their diet and spiritual patterns. Spirituality, specifically the interconnectedness with self, others, and the environment, may be the missing link to changing the diet and lifestyle patterns of these African American women. The findings of the present study provide new information to the field of diet and disease prevention. This study focused on the importance of spirituality as defined by Burkhardt (1989) in the health promoting behaviors of African American women, which is a unique contribution to this body of knowledge. The discussion section detailed the components of Burkhardt's spirituality model, which could provide the theoretical framework of an intervention trial. Experts in self-esteem, spiritual growth, interpersonal relations, stress management, and health 
responsibility combined with expertise in diet and exercise are needed for a multidisciplinary team approach. Focusing on interventions to improve the participants' spirituality is believed to have a positive impact on other aspects of their lives. For example, when African American women learn better stress management, their knowledge of improved dietary practices has a better chance of succeeding. Similarly, their spiritual growth, including feeling connected to a force greater than themselves and the belief that life has purpose, contributes to their ability to adhere to healthier food and exercise practices.

The findings of this study are an appropriate place to start when considering interventions for African American women. It is important to note the focus of measurable behavior should be food and exercise choices, appropriate portion sizes, and not weight loss, although many studies in the past have focused on weight loss when conducting studies with African American women in a church setting (Kumanyika \& Charleston, 1992; McNabb et al., 1997; Yanek et al., 2001). Another study focused on a healthy lifestyle approach, without focusing on weight loss (Riebe et al., 2003). Notably, none of these church-based studies included spirituality. Hence, a spirituality focus that targets health promoting behaviors as a desired outcome, while avoiding a weight loss approach, is recommended.

Although the purpose of this study relates spirituality with health promoting behaviors, it is the long-term goal of chronic disease management for this population, which is the impetus for this study. It is with this goal in mind that numerous strategies have been considered. The Seventh Report of the Joint National Committee on Prevention, Detection, Evaluation and Treatment of High Blood Pressure recently 
recommended lifestyle modifications include losing weight if overweight, eating more lowfat dairy foods, fruits and vegetables as part of the DASH eating plan, reducing dietary sodium, exercising more and limiting alcohol consumption (Chobanian et al., 2003).

These recommended lifestyle modifications are congruent with those assessed in this study. What we now conclude is that only focusing on the nutrition message without taking in account the whole person, that is, her spirituality (connectedness with self, others and environment), leads to less effective health outcomes. The health community must embrace the spiritual nature of African American women for successful implementation of health promoting behaviors. 


\section{REFERENCES}

Adams-Campbell LL, Rosenberg L, Washburn RA, Rao RS, Kim KS, Palmer J. Descriptive epidemiology of physical activity in African American women. Preventive Medicine. 2000;30:43-50.

Ahijevych K, Bernhard L. Health-promoting behaviors of African American women. Nursing Research. 1994;43(2):86-89.

Ainsworth BE, Berry CB, Schnyder VN, Vickers SR. Leisure-time physical activity and aerobic fitness in African American young adults. Journal of Adolescent Health. 1992;13:1-6.

Ainsworth BE, Irwin ML, Addy CL, Whitt MC, Stolarczyk LM. Moderate physical activity patterns of minority women: the cross-cultural activity participation study. $J$ of Women's Health \& Gender-Based Med. 1999;8(6):805-813.

Allison DB, Edlen-Nezin L, Clay-Williams G. Obesity among African American women: prevalence, consequences, causes, and developing research. Women's Health: Research on Gender, Behavior, and Policy. 1997;3(3\&4):243-274.

American College of Sports Medicine. Position stand: the recommended quantity and quality of exercise for developing and maintaining cardiorespiratory and muscular fitness in healthy adults. Med Sci Sports Exerc. 1990;22:265-274.

American Heritage College Dictionary. Boston, MA: Houghton Mifflin; 2002.

American Institute for Cancer Research. AICR/WCRF Expert Panel Report. Available at http://www.aicr.org/reportsummairc.html, Accessed March 5, 2003.

Anderson LA, Eyler AA, Galuska DA, Brown DR, Brownson RC. Relationship of satisfaction with body size and trying to lose weight in a national survey of overweight and obese women aged 40 and older, United States. Preventive Medicine. 2002;35:390396.

Baecke JAH, Burema J, Frijters JER. A short questionnaire for the measurement of habitual physical activity in epidemiological studies. Am J Clin Nutr. 1982;36:936-942.

Baker-Fletcher K. Sisters of Dust, Sisters of Spirit: Womanist Wordings of God and Creation. Minneapolis, MN: Fortress Press; 1998.

Bensley RJ. Defining spiritual health: a review of literature. $J$ Health Educ. 1991;22(5):287-290. 
Bensley RJ. Spiritual health as a component of worksite health promotion/wellness programming: a review of literature. J Health Educ. 1991;22(6):352-354.

Blank MB, Mahmood M, Fox JC, Guterbock T. Alternative mental health services: the role of the black church in the south. Am J Pub Hlth. 2002;92(10):1668-1672.

Blascovich J, Tomaka J. Measures of self-esteem: In: Robinson JP, Shaver PR, Wrightsman LW, eds. Measures of Personality and Social Psychological Attitudes. New York: Academic Press; 1991;115-60.

Block G, Wakimoto P, Block T. A revision of the Block Dietary Questionnaire and database, based on NHANES III data. Am. J. Epidemiology. 1998.

Brady B, Nies MA. Health-promoting lifestyles and exercise: a comparison of older African American women above and below poverty level. $J$ Holistic Nurs. 1999;17(2):197-207.

Burkhardt MA. Spirituality: an analysis of the concept. Holistic Nurs Pract. 1989;3(3):69-77.

Carmichael SL, Iyasu S, Hatfield-Timajchy K. Cause-specific trends in neonatal mortality among black and white infants, United States, 1980-1995. Matern Child Health J. 1998;2:67-76.

Chobanian AV, Bakris GL, Black HR, Cushman WC, Green LA, Izzo JL, Jones DW, Materson BJ, Oparil S, Wright JT, Rocella EJ. The seventh report of the Joint National Committee on Prevention, Detection, Evaluation and Treatment of High Blood Pressure. JAMA. 2003;289:2560-2571.

Collins PH. Black Feminist Thought. New York, NY: Routledge, Chapman \& Hall; 1991.

Cooper RS. Health and the social status of African Americans in the United States. Annals of Epidemiology. 1993;3:137-144.

Domel SB, Alford BB, Cattlett HN, Gench BE, Weight control for black women. J Amer Diet Assoc. 1992;92(3):346-347.

Duelberg S. Preventive health behavior among black and white women in urban and rural areas. Social Sci \& Med. 1992;34:191-198.

Eberst R. Defining health: A multidimensional model. J of School Hlth. 1984;54(3):99104. 
Eng E. The Save Our Sisters Project: a social network strategy for reaching rural black women. Cancer. 1993;72:1071-1077.

Eugene TM. There is a balm in Gilead: black women and the black church as agents of a therapeutic community. Women Therapy. 1995;47:S269-S278.

Faith MS, Monibay E, Kravitz M, Griffith J, Allison DB. Relative body weight and selfesteem among African Americans in four nationally representative samples. Obesity Research. 1998;6(6):430-437.

Felton GM, Parsons MA, Misener TR, Oldaker S. Health-promoting behaviors of black and white college women. Western J Nurs Res. 1997;19(5):654-666.

Flegal KM, Carroll MD, Ogden CL, Johnson CL. Prevalence and trends in obesity among US adults, 1999 - 2000. JAMA. 2002;288(14):1723-1727.

Fletcher GF, Blair SN, Blumenthal J, Caspersen C, Chaitman B, Epstein S, Falls H, Siavarajan ES, Froelicher VF, Pina IL. Statement on exercise: benefits and recommendations for physical activity programs for all Americans. Circulation. 1992;86:340-344.

Fletcher RB. Body composition and self-esteem: a validation of selected self-esteem measures. MAI. 1995;34:1687-799.

Flynn KJ, Fitzgibbon M. Body images and obesity risk among black females: a review of the literature. Ann Behav Med. 1998;20:13-24.

Ford ES, Ford MAD, Will JC, Galuska DA, Ballew C. Achieving a healthy lifestyle among United States Adults: a long way to go. Ethn Dis. 2001;11:224-231.

Foster MF. Health promotion and life satisfaction in elderly black adults. Western J Nurs Res. 1992;14(4):444-463.

Fox AA, Thompson JL, Butterfield GE, Glfadottir U, Moynihan S, Spiller G Effects of diet and exercise on common cardiovascular disease risk factors in moderately obese older women. Am J Clin Nutr. 1996;63:225-233.

Frank DI, Stephens B, Lee SH. Health-promoting behaviors of African American rural women. Clinical Excellence for Nurse Practitioners. 1998;2(3):159-165.

Frazao, E. High costs of poor eating patterns in the United States. In: Frazao E, editor. America's Eating Habits: Changes and Consequences. Washington, DC: U.S. Department of Agriculture. Agriculture Information Bulletin No. 750; 1999. 
Freedman DS, Khan LK, Serdula MK, Galuska DA, Dietz WH. Trends and correlates of class 3 obesity in the United States from 1990 through 2000. JAMA.

2002;288(14):1758-1761.

Furumoto-Dawson AA, Pandey DK, Elliott WJ, deLeon CFM, Al-Hani AJ, Hollenberg S, Camba N, Wicklund R, Black HR. Hypertension in women: the Women Take Heart Project. J of Clin Hypertension. 2003;5(1):38-46.

General Accounting Office, www.gao.gov

Gillis A, Perry A. The relationships between physical activity and health-promoting behaviors in mid-life women. J Advanced Nursing. 1991;16:299-310.

Gillman MW, Pinto BM, Tennstedt S, Glanz K, Marcus B, Friedman RH. Relationships of physical activity with dietary behaviors among adults. Prev Med. 2001;32:295-301.

Goodrick GK, Foreyt JP. Why treatments of obesity don't last. J Amer Diet Assoc. 1991;91:1243-1247.

Gore SV. African American women's perceptions of weight: paradigm shift for advanced practice. Holist Nurs Pract. 1999;13(4):71-79.

Guidry ML, Wilson AM. Health promoting behaviors of African American registered nurses. The ABNF Journal. 1999;10(2):37-42.

Hassed C. Spirituality and Health. Aust Fam Physician. 1999;28(4):29-31.

Havas S, Heimendinger J, Damron D, Nicklas TA, Cowan A, Beresford SA, Sorensen G, Buller D, Bishop D, Baranski T. 5-A-Day for better health - nine community research projects to increase fruit and vegetable consumption. Public Health Reports. 1995;110(1):68-79.

Hawks SR, Hull ML, Thalman RL, Richins PM. Review of spiritual health: definition, role, and intervention strategies in health promotion. Am J Hlth Promotion. 1995;9:371378.

Institute of Medicine, Food and Nutrition Board, Dietary Reference Intakes for Energy, Carbohydrates, Fiber, Fat, Protein and Amino Acids (Macronutrients). Washington, DC: National Academy Press; 2002.

Institute of Medicine, Food and Nutrition Board, Dietary Reference Intakes for Calcium, Phosphorus, Magnesium, Vitamin D, and Fluoride. Washington, DC: National Academy Press; 2002. 
Jacobson, CK, Heaton, TBN, Dennis RM. Black-white differences in religiosity: item analyses and a formal structural test. Social Anal. 1990;51:257-270.

Jakicic JM, Wing RR, Winters-Hart C. Relationship of physical activity to eating behaviors and weight loss in women. Med \& Sci in Sports \& Exercise.

2002;34(10):1653-1659.

Janssen I, Katzmarzyk PT, Ross R. Body mass index, waist circumference, and health risk. Arch Intern Med. 2002;162:2074-2079

Jefferson VW, Melkus GD, Spollett GR. Health-promotion practices of young black women at risk for diabetes. The Diabetes Educator. 2000;26(2):295-302.

Johnson GD, Matre M, Armbrecht G. Race and religiosity: an empirical evaluation of a causal model. Rev Religious Res. 1991;32:252-266.

Juhaeri, Stevens J, Chambless LI, Nieto FJ, Jones D, Schreiner P, Arnett D, Cai J. Associations of weight loss and changes in fat distribution with the remission of hypertension in a bi-ethnic cohort: the Atherosclerosis Risk in Communities Study. Preventive Medicine. 2003;36:330-339.

Kann L, Warren W, Collins JL, Ross J, Collins B, Kolbe LJ. Results from the national school-based 1991 Youth Risk Behavior Survey and progress toward achieving related health objectives for the nation. Public Health Reports. 1993;108(Supp.1):47-56.

Kavanaugh KM. The importance of spirituality. J Long Term Care Adm. 1997;24(4):2931.

Kayrooz K, Moy TF, Yanek LR, Becker DM. Dietary fat patterns in urban African American women. J Comm Health. 1998;23(6):453 - 469.

Kittler PG \& Sucher KP. Cultural Foods: Tradition and Trends.Belmont, CA: Wadsworth/Thomson Learning; 2000.

Koffman DM, Bazzarre T, Mosca L, Redberg R, Schmid T, Wattigney WA. An evaluation of Choose to Move 1999: an American Heart Association physical activity program for women. Arch Intern Med. 2001;161:2193-2199.

Kohl HW, Blair SN, Paffenbarger RS, Macera CA, Kronenfeld JJ. A mail survey of physical activity habits as related to measured physical fitness. Am J Epidemiology. 1988;127(6):1228-1239. 
Kratina D, Tuttle A. What is weight management? Are there circumstances in which some forms of weight management is necessary or desirable? What is the most effective way to manage weight? The Renfrew Center Foundation Perspective. 2001;7(1):5-6.

Krause RM, Eckel RH, Howard B, Appel LJ, Daniels SR, Deckelbaum RJ, Erdman JW, Kris-Etherton P, Goldberg IJ, Kotchen TA, Lichtenstein AH, Mitch WE, Mullis R, Robinson K, Wylie-Rosett J, St. Jeor S, Suttie J, Tribble DL, Bazzarre TL. AHA Dietary Guidelines: Revision 2000: a statement for healthcare professionals from the nutrition committee of the American Heart Association. Circulation. 2000.

Kristal AR, Shattuck AL, Henry HJ. Patterns of dietary behavior associated with selecting diets low in fat: Reliability and validity of a behavioral approach to dietary assessment. J Amer Diet Assoc. 1990;90:214-220.

Kumanyika S. Diet and chronic disease issues in minority populations. J of Nutr Educ. 1990;22:89-95.

Kumanyika SK, Charleston JB. Lose Weight and Win: a Church-Based Weight Loss Program for Blood Pressure Control Among Black Women. Patient Ed and Counseling. 1992:19:19-32.

Kumanyika SK, Morssink C, Agurs T. Models for dietary and weight change in African American women: identifying cultural components. Ethnicity Dis. 1992;2:166-175.

Kuczmarski RJ, Prevalence of overweight and weight gain in the United States. Am J Clin Nutr. 1992;55(2):495S-502S.

Levin JS. The role of the black church in community medicine. J of the Nat'l Med Assoc. 1984;76(5):477-483.

Levin, JS, Lyons JS, Larson DB. Prayer and health during pregnancy: findings from the Galveston Low Birth-weight Survey. South Med J. 1993;86:1022-1027.

Levin JS and Taylor RJ. Gender and age differences in religiosity among Black Americans. The Gerontologist. 1993;33(1):16-23.

Levin, JS, Taylor, RJ, Chatters, LM. Race and gender differences in religiosity among older adults: findings from four national surveys. J Gerontol. 1994;49:S137-S145.

Levin, JS. Religion and health: is there an association, is it valid, and is it causal? Soc Sci Med. 1994;38:1475-1482.

Levin, JS, Chatters LM, Taylor, RJ. Religious effects on health status and life satisfaction among black Americans. J Gerontol B Psychol Sci Soc Sci. 1995:S154-S163. 
Levin, JS, Markides, KS, Ray, LA. Religious attendance and psychological well-being in Mexican Americans: a panel analysis of three-generations data. Gerontologist. 1996;36:454-463.

Levin, JS, Chatters, LM. Religion, health, and psychological well-being in older adults: findings from three national surveys. J Aging Health. 1998;10:504-531.

Lewis RK, Green BL. Assessing the health attitudes, beliefs, and behaviors of African Americans attending church: a comparison from two communities. Jof Community Health. 2000;25(3):211-224.

Mahan LK. and Escott-Stump M. Krause's Food, Nutrition \& Diet Therapy. $9^{\text {th }}$ ed. Philadelphia, PA: W.B. Saunders Company; 1996.

McNabb W, Cook S, Quinn M, Karrison T, Kerver J. The PATHWAYS Church-Based Weight Loss Program for Urban African American Women at Risk for Diabetes.

Diabetes Care. 1997;20(10):1518-1523.

Melynx MG, Weinstein E. Preventing obesity in African American women by targeting adolescents: a literature review. J Amer Diet Assoc. 1994;94:536-540.

Musgrave CF, Allen E, Allen C, Gregory J. Spirituality and health for women of color. Am J Pub Hlth. 2002;92(4):557-560.

Nagai-Jacobson MG, Burkhardt MA. Spirituality: cornerstone of holistic nursing practice. Holistic Nurs Pract. 1989;3(3):18-26.

National Center for Health Statistics, NHANES Data, www.cdc.gov/nchs/nhanes.htm, accessed 3/17/03)

National Center for Chronic Disease Prevention and Health Promotion: Physical Activity and Health: A Report of the Surgeon General. Washington, DC: US Dept of Health and Human Services, 1996.

Nelson TL, Hunt KJ, Rosamond WD, Ammerman AS, Keyserling TC, Mokdad AH, Will JC. Obesity and associated coronary heart disease risk factors in a population of lowincome African American and white women: the North Carolina WISEWOMAN project. Preventive Medicine. 2002;35:1-6.

Neumark-Sztainer D, Rock CL, Thornquist MD, Cheskin LJ, Neuhouser ML, Barnett MJ. Weight-control behaviors among adults and adolescents: associations with dietary intake. Preventive Medicine. 2000;30:381-391. 
Nies MA, Buffington C, Cowan G, Hepworth JT. Comparison of lifestyles among obese and nonobese African American and European American women in the community. Nursing Research. 1998;47(4):251-257.

NIH Consensus Development Panel on Physical Activity and Cardiovascular Health. JAMA. 1996;276:241-246.

Pender NJ, Walker SN, Sechrist KR, Frank-Stromborg M. Predicting Health-Promoting Lifestyles in the Workplace. Nursing Research. 1995;39(6):326-332.

Pettaway L, Frank D. Health promoting behaviors of urban African American female heads of household. The ABNF Journal. 1999;10(1):14-19.

Picot SJ, Debanne SM, Mamazi KH, Wykle ML. Religiosity and perceived rewards of black and white caregivers. Gerontologist. 1997;37:89-101.

Position of the American Dietetic Association and Dietitians of Canada: women's health and nutrition. J Am Diet Assoc. 1999;99:738-751.

Position of the American Dietetic Association: the role of dietetics professionals in health promotion and disease prevention. J Am Diet Assoc. 2002;102:1680-1687.

Pleas J. Long-term effects of a lifestyle-change obesity treatment program with minorities. J of the Nat'l Med Assoc. 1988;80(7):747-752.

Pratt CA. Adolescent obesity: a call for multivariate longitudinal research on African American youth. $J$ of Nutr Educ. 1994;26(2):107-109.

Pullen L, Tuck I, Mix K. Mental health nurses' spiritual perspectives. J of Holistic Nursing. 1996;14(2):85-97.

Ram E. Spiritual leadership in health. World Health. 1988;April:6-9.

Reed PG. Religiousness among terminally ill and healthy adults. Research in Nursing and Health. 1986;9:35-42.

Reed PG. Spirituality and well-being in terminally ill hospitalized adults. Research in Nursing and Health. 1987;10:335-344.

Reed PG. Preferences for spiritually related nursing interventions among terminally ill and nonterminally ill hospitalized adults and well adults. Appl Nurs Res. 1991;4(3):122128.

Reniscow K, Jackson A, Wang T, De AK, McCarty F, Dudley WN, Baranowski T. A motivational interviewing intervention to increase fruit and vegetable intake through black churches: results of the eat for life trial. Amer J of Pub Hlth. 2001;91(10):16861693. 
Riebe D, Greene GW, Ruggiero L, Stillwell KM, Blissmer B, Nigg CR, Caldwell M. Evaluation of a healthy-lifestyle approach to weight management. Preventive Medicine. 2003;36:45-54.

Rojas, DZ. Spiritual well-being and its influence on the holistic health of Hispanic women. In: Torres S, ed. Hispanic Voices: Hispanic Health Educators Speak Out. New York, NY: NLN Press; 1996:213-229.

Rosenberg M. Society and the adolescent self-image. Princeton, NJ: Princeton University Press; 1965.

Sacks FM, Svetkey LP, Vollmer WM, Appel LJ, Bray GA, Harsha D, Obarzanek E, Conlin PR, Miller ER, Simons-Morton DG, Karanja N, Lin PH. Effects on blood pressure of reduced dietary sodium and the dietary approaches to stop hypertension (DASH) diet. NEJM. 2001;344(1):3-10.

Sanjur D. Social and Cultural Perspectives in Nutrition. NJ: Prentice-Hall Inc; 1982.

Satcher D. American Women and Health Disparities. J Am. Med. Womens Assoc. 2001;56(4):131-2,160.

Seaward BL. Stress and human spirituality 2000: at the cross roads of physics and metaphysics. Appl Psychophysiol. Biofeedback. 2000;25(4):286-289.

Sevick MA, Dunn AL, Morrow MS, Marcus BH, Chen GJ, Blair SN. Cost-effectiveness of lifestyle and structured exercise interventions in sedentary adults: results of project ACTIVE. Am J Prev Med. 2000;19:1-8.

Smith ED, The Role of Black Churches in Supporting Compliance with Antihypertensive Regimens. Pub Hlth Nursing. 1989;6(4):212-217.

Soul Food Pyramid, Hebni Nutrition Consultants, Inc. www.soulfoodpyramid.org. Accessed 06/20/03.

SPSS Graduate Pack 11.0 for Windows (2001) Chicago, IL. SPSS Inc.

Strawbridge WJ, Shema SJ, Cohen RD, Kaplan GA. Religious attendance increases survival by improving and maintaining good health behaviors, mental health, and social relationships. Ann Behav Med. 2001;23(1):68-74.

Subar AF, Thompson FE, Kipnis V, Midthune D, Hurwitz P, McNutt S, McIntosh A, Rosenfeld S. Comparative validation of the Block, Willett, and national cancer institute food frequency questionnaires: the eating at America's table study. Am J Epidemiol. 2001;154(12):1089-1099. 
Thompson B, Demark-Wahnefried W, Taylor G, McClelland JW, Stables G, Havas S, Feng Z, Topor M, Heimendinger J, Reynolds KD, Cohen N. Baseline fruit and vegetable intake among adults in seven $5 \mathrm{~A}$ Day study centers located in diverse geographic areas. J Amer Diet Assoc. 1999;99:1241-1248.

Tran TV, Wright R Jr, Berg WE, Creecy RF. The dimensions of subjective well-being among black Americans: a structural model analysis. J Multicultural Social Work. 1994;3:115-136.

Tuck I, Pullen L, Lynn C. Spiritual interventions provided by mental health nurses. Western J of Nurs Res. 1997;19(3):351-363.

United States Census Data. 1990 U.S. Census Data. Available at: http://homer.ssd.census.gov: Accessed November 07, 2000.

United States Census Data. 2000 U.S. Census Data for the State of Florida. http://www.census.gov/census2000/states/fl.html: Accessed June 18, 2003

US Dept of Agriculture, Human Nutrition Information Service. Food Guide Pyramid: A Guide to Daily Food Chocies. (Home and Garden Bulletin No 232). Washington, DC: U.S. Government Printing Office; 1992.

US Dept of Agriculture and Health and Human Serivces. Nutrition and Your Health: Dietary Guidelines for Americans. (Home and Garden Bulletin No 252). $4^{\text {th }} \mathrm{ed}$. Washington, DC: U.S. Government Printing Office; 1995.

U.S. Department of Health and Human Services. Healthy People 2000: National Health Promotion and Disease Prevention Objectives. (DHHS Publication PHS 91-50212). Washington, DC: U.S. Government Printing Office; 1991.

U.S. Department of Health and Human Services. Healthy People 2010: Understanding and Improving Health and Objectives for Improving Health. Washington, DC: U.S. Government Printing Office; 2000.

Villarosa L. Body \& Soul: The Black Women's Guide to Physical Health and Emotional Well-Being. New York, NY: HarperCollins Publishers, Inc.; 1994.

Waite PJ, Hawks SR, Gast JA. The correlation between spiritual well-being and health behaviors. Am J Hlth Promotion. 1999;13(3):159-162.

Walker SN, Sechrist KR, Pender NJ. The health-promoting lifestyle profile: development and psychometric characteristics. Nurs Res. 1987;36:76-81. 
Whitfield KE, Weidner G, Clark R, Anderson NB. Sociodemographic diversity and behavioral medicine. J Consult Clin Psychol. 2002;70:463-481.

Williams DS. Sisters in the Wilderness: The Challenge of Womanist God-Talk.

Maryknoll, NY: Orbis; 1993.

Williamson DF, Kahn HS, Byers T. The 10-yr incidence of obesity and major weight gain in African American and white US women aged 30-55 years. Am J Clin Nutr. 1991;53:1515S-1518S.

Willett W. Invited commentary: a further look at dietary questionnaire validation. $A m J$ Epidemiol. 2001;154(12):1100-1102.

Yanek LR, Becker DM, Moy TF, Gittelsohn J, Koffman DM. Project Joy: faith based cardiovascular health promotion for African American women. Public Health Reports. 2001;116:68-81. 
APPENDICES 
APPENDIX A 


\section{Feasibility Study}

After their informed consent was signed, eligible women in Orange County were asked to fill out the survey. A convenience sample of 35 women age eligible 18 - 55 were recruited in the feasibility study phase of the study and administered the following study instruments:

\section{Instrumentation}

1. Rosenberg Self-Esteem Scale (Form \#1)

2. Health Promoting Lifestyle Profile II (Form \#2)

3. Spiritual Perspective Scale (Form \#3)

4. Food Habits Questionnaire (Form \#4)

5. Sociodemographic Questionnaire (Form \#5)

6. Anthropometry Form (Form \#6)

A standardized protocol was tested which included arrangements, written communication, and instrument administration.

This feasibility study provided valuable information on the mean time questionnaire administration of each instrument for the study. It also allowed decisions to be made on the impact of duration of the instrument administration on potential participation rates of subjects in the study. 
APPENDIX B 


\section{LIST OF CHURCHES AND COMMUNITY SETTING GROUPS}

1. Macedonia Missionary Baptist Church

Rev. Willie C. Barnes

412 E. Kennedy Blvd.

Eatonville, FL 32751

2. Bethel Full Gospel Baptist Church

Bishop Carlos L. Malone Sr.

14440 Lincoln Blvd.

Miami, FL 33176

3. Orthodox Zion Primitive Baptist Church

Rev. James H. Chester

2900 N. Australian Avenue

West Palm Beach, FL 33407

4. Alpha Kappa Alpha Sorority, Inc.

Orlando, FL

West Palm Beach, FL

5. CMS Women's Social Group

Perrine, FL 
APPENDIX C 
Are you interested in your health!

\section{All Women are invited}

Come join us for

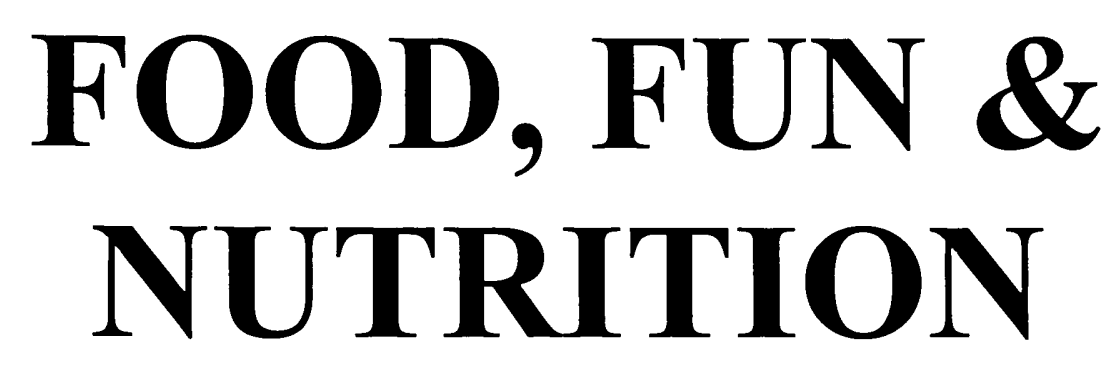

\section{Tuesday, February 12 8:30 PM}

$>$ Get your chance to speak to a Registered Dietitian

$>$ Learn More About Women's Health

$>$ Complete a short questionnaire 
APPENDIX D 


\section{INFORMED CONSENT \\ THE RELATIONSHIP BETWEEN SPIRITUALITY AND HEALTH PROMOTING BEHAVIORS OF AFRICAN-AMERICAN WOMEN}

I freely and voluntarily consent to be a participant in the research project entitled "The Relationship between Spirituality and Health Promoting Behaviors of African-American Women", to be conducted at Florida International University with Deirdra N. Chester MS, RD, as the Principal Investigator.

I understand that the purpose of this research is to obtain important information about the health and nutritional status of African-American women as it relates to spirituality.

I have been told that this interview will last about 1 hour, and I understand that the interview procedure will be as follows:

1. At the interview, I will be asked questions about my spirituality, physical health, diet, and sociodemographic information. My answers will be recorded on questionnaires either by myself, or by the interviewer.

2. I will have my weight, height, waist and hips measured by the interviewer.

I understand that there are no known risks or benefits involved in my participation in this study, other than the feeling of satisfaction for having participated in a project that could possibly provide information that could improve women's health. I have been told that my responses will be kept strictly confidential. All scores on any data will be identified by a code, and my identity will not be revealed to anyone without my expressed permission. There are no costs to me for participation in this study.

I understand that I may withdraw my consent and discontinue participation in this research project at any time with no negative consequences. I have been given the right to ask questions concerning the procedure, and any questions have been answered to my satisfaction. I understand that if any new findings are developed during the time that I am in this which may affect my willingness to continue to be in the study, I will be informed as soon as possible.

I understand that if I desire further information about this research I should contact Deirdra N. Chester, at (305) 408-1613 or Susan P. Himburg, $\mathrm{PhD}$ at (305) 348-3233. I also understand that if I have any questions concerning the rights of human subjects or injury that I feel I have incurred related to the study, I may contact Dr. Bernard Gertsman, the Chairperson of the Institutional Review Board at Florida International University, at 305-348-3115.

I have read and I understand the consent form.

Signature of participant

$\overline{\text { Printed Name Date }}$

I have explained and defined in detail the research procedure in which the participant has agreed to participate and have offered her a copy of this informed consent form.

Date 
APPENDIX E 


\title{
(2) \\ Florida International University
}

Office of the Director

\section{MEMORANDUM}

\author{
To: \\ Deirdra Chester \\ CC: \\ Dr. S. Himburg \\ File \\ From: $\quad$ Yvette Peterson, Coordinator Institutional Review Board \\ Date: $\quad$ August 19,2002 \\ Proposal Y Approval H: The Role of Spirituality in Influencing Health Behaviors in African- \\ American Women" - 090701-00
}

Your study was approved for the use of human aubjects by the Institutional Review Board of Forida International University in September of 2001. As a stipulation of IRB approval you are required to submit anmual reports and a project completion report.

The following is an abbreviated list of items that must le submitted to an IRB Representative by the anniversary of your approval date in order to expedite the review of your proposal and avoid spproval termination. A comprechensive list is provided at the end of Form B:

- Form B - (NEW) Application for the use of Human Subjects, Continuation/Modification

- Consent Documents - Must be renewed annual

- An IRB Protocol - if changes will be made to the original protocol

- Human Sabject Certifications for any new persons on research team

You will be notified in writing of contimued approval. All forms and information regarding the use of human aubjects can be found at the DSRT website at Www.dsrt.fiu.edu. If you have additional questions you may contact the IRB Coordinator, Yvette Peterson, at 348-2494 or by email at inbiacuc@fiu.edu. The Division of Sponsored Research and the Compliance Office has relocated to the MARC building, main office room 430.

University Park

11200 S.W. 8 Street - PC 539

Miami, FL 33199

(BOS) 348-2494 • Fax: (305) 348-4117
Division of Sponsored Research and Training

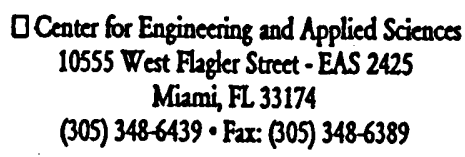

(305) $348-6439$ - F2x: (305) 348-6389 


\section{(20) \\ Florida International University}

Office of the Director

\section{MEMORANDUM}

To:

Deidra N. Chester

CC:

Dr. Susan P. Himburg

File

From:

Yvette Peterson, Coordinator Institutional Review Boupd bs

Date:

February 13, 2002

Proposal Titie:

"The Relationship of Spirituality and Health Promoting Behaviors of Africa American Women" - Approval \# 090701-00

The modification(s) wubmitted to the Institutional Review Board have been approved. The modification requested is to:

Change to the title above

Question 2 removed from the questionnaire

- The Multidimensional Health Locus of Control Queationasire deteted

> The Food Habits Questionnaire replaced by the Brief Food Questionmaire

There are no additional requirements in regards to your atudy. However, if there are changes in the protocol after you commence your study that may increase the risks that the human subjects are exposed to, you are required to resubmit your proposal to i Representative of the IRB for review. Your annual review date is Angust 2002. If you have any questions please contact your Representative or the IRB Coordinator at 348-2494 or by email at Peterson@dsrt. fiu.edu.

DUnivessity Part

11200 S. W. 8 Street - PC 539

Mirmi, Fl 33199

(305) 348-2494 - Fax (305) $348-4117$
Division of Sponsored Research and Training

$\square$ Center for Enginecring and Applied Sciences 10555 West Flagler Street - EAS 2425 Miami, Fl 33174

(305) 3486439 • F2x: (305) 3486389

IDD, ria FRS 1-800-955-8771

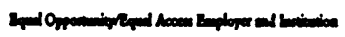




\section{(2) \\ Florida International University}

Office of the Director

\section{MEMORANDUM}

To:

Deidra N. Chester

CC:

Dr. Susan P. Himburg

File

From:

Yvette Peterson, Coordinator Institutional Review Board

Date: $\quad$ September 7,2001

Proposal Title: "The Role of Spirituality in Influencing Health Behaviors of AfricanAmerican Women" - Approval \# 090701-00

The Institutional Review Board of Florida International University approved your study for the use of human subjects on September 7, 2001. Please note your approval number is indicated above. Federal regulations require that you receive annual review of your research. Your annual report will be due in September 2002 or at the time of project completion. You are required to complete the IRB Application in addition to the submission of the following information:

1) The number of human subjects that you have included in your study during the past year.

2) Any problems that occurred with any of the human subjects, e.g. injuries, complaints, etc.

3) Any changes in the protocol of the study that affects the human subjects.

4) An approximate date for completion of your study

5) And upon project completion, a copy of your manuscript, published paper or the abstract of your dissertation or presentation of this data.

In addition to this yearty report, it is still a requirement that any serious incidents related to (2) or (3) above be immediately reported to the IRB. You are required to use copies of your date stamped Informed Consent document for the recruitment of subjects.

Please call the IRB office at 348-2494 with questions or concerns or visit the DSRT web site at nww.dst.fiu.edu .

University Pat

11200 S.W. 8 Street - PC 539

Miami, FL 33199

(305) 348-2494 - Fax: (305) $348-4117$

\section{Division of Sponsored Research and Training}
$\square$ Center for Engineering and Applied Sciences 10555 Vest Flagler Street - EAS 2425 Miami, FL 33174
(305) 348-6439 - Fax: (305) 348-6389

IDD, via FRS 1-800-955-8771

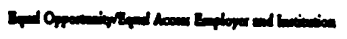


APPENDIX F 


\section{FORM \#1: ROSENBERG SELF-ESTEEM QUESTIONNAIRE}

Participant ID Number:

On the form below, please circle the number for each question that corresponds to your agreement with the statement.

1=Strongly Agree

2=Agree $\quad 3=$ Disagree

4=Strongly Disagree

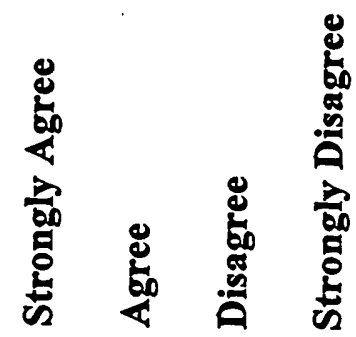

1. On the whole, I am satisfied with myself.

$\begin{array}{llll}1 & 2 & 3 & 4 \\ 1 & 2 & 3 & 4 \\ 1 & 2 & 3 & 4 \\ 1 & 2 & 3 & 4 \\ 1 & 2 & 3 & 4 \\ 1 & 2 & 3 & 4 \\ 1 & 2 & 3 & 4 \\ 1 & 2 & 3 & 4 \\ 1 & 2 & 3 & 4 \\ 1 & 2 & 3 & 4\end{array}$

10. I take a positive attitude toward myself.

123 
Participant ID Number:

DIRECTIONS: This questionnaire contains statements about your present way of life or personal habits. Please respond to each item as accurately as possible, and try not to skip any item. Indicate the frequency with which you engage in each behavior by circling:

$\mathbf{N}$ for never,

S for sometimes,

$O$ for often,

or

$\mathbf{R}$ for routinely

1. Discuss my problems and concerns with people close to me.

N

2. Choose a diet low in fat, saturated fat, and cholesterol.

3. Report any unusual signs or symptoms to a physician or other health professional.

4. Follow a planned exercise program.

5. Get enough sleep.

6. Feel I am growing and changing in positive ways.

7. Praise other people easily for their achievements.

8. Limit use of sugars and foods containing sugar (sweets).

9. Read or watch TV programs about improving health.

10. Exercise vigorously for $\mathbf{2 0}$ or more minutes at least three times a week (such as brisk walking, bicycling, aerobic dancing, using a stair climber).

11. Take some time for relaxation every day.

12. Believe that my life has purpose.

13. Maintain meaningful and fulfilling relationships with others.

14. Eat 6 - 11 servings of bread, cereal, rice and pasta each day.

15. Question health professionals in order to understand their instructions.

16. Take part in light to moderate physical activity (such as sustained walking 30-40 minutes 5 or more times a week).

17. Accept those things in my life which I can not change.

18. Look forward to the future.

19. Spend time with close friends.

$\begin{array}{llll}N & S & O & R\end{array}$

$\begin{array}{llll}\mathrm{N} & \mathrm{S} & \mathrm{O} & \mathrm{R}\end{array}$

$\mathrm{N}$

S

O R

N

S

$\mathbf{O} \mathbf{R}$

N

N

$\mathbf{N}$

N

$\mathrm{N}$

S

$\mathbf{O} \mathbf{R}$

N

S

O R

N

S

O R

$\begin{array}{lll}\mathbf{S} & \mathbf{O} & \mathrm{R}\end{array}$

S

o $\quad \mathbf{R}$

$\mathbf{N}$

$\mathbf{N}$

S

O R

$\begin{array}{llll}N & S & 0\end{array}$

$\mathbf{N}$

S

o R

$\mathrm{N}$

N

N

S

O R

S

O R

$\mathrm{N}$

S

O R

$\mathrm{N}$

N

$\mathrm{N}$

N

S

O R

$\mathbf{S}$

O R

S $\quad \mathbf{R}$


20. Eat 2-4 servings of fruit each day.

21. Get a second opinion when I question my health care provider's advice.

$\begin{array}{cccc}\mathbf{N} & \mathbf{S} & \mathbf{O} & \mathbf{R} \\ \mathrm{N} & \mathrm{S} & \mathrm{O} & \mathrm{R} \\ \mathrm{N} & \mathrm{S} & \mathrm{O} & \mathrm{R}\end{array}$

23. Concentrate on pleasant thoughts at bedtime.

24. Feel content and at peace with myself.

$\begin{array}{cccc}\mathbf{N} & \mathbf{S} & \mathbf{O} & \mathrm{R} \\ \mathrm{N} & \mathrm{S} & \mathbf{O} & \mathbf{R} \\ \mathrm{N} & \mathrm{S} & \mathbf{O} & \mathrm{R} \\ \mathrm{N} & \mathrm{S} & \mathbf{O} & \mathrm{R} \\ \mathrm{N} & \mathrm{S} & \mathbf{O} & \mathrm{R}\end{array}$

28. Do stretching exercises at least 3 times per week.

29. Use specific methods to control my stress.

30. Work toward long-term goals in my life.

31. Touch and am touched by people I care about.

32. Eat 2-3 servings of milk, yogurt or cheese each day.

33. Inspect my body at least monthly for physical changes/danger signs.

34. Get exercise during usual daily activities (such as walking during lunch, using stairs instead of elevators, parking car away from destination and walking).

35. Balance time between work and play.

36. Find each day interesting and challenging.

37. Find ways to meet my needs for intimacy.

38. Eat only 2-3 servings from the meat, poultry, fish, dried beans, eggs, and nuts group each day.

N S O R

N

39. Ask for information from health professionals about how to take good care of myself.

40. Check my pulse rate when exercising.

41. Practice relaxation or meditation for 15-20 minutes daily.

42. Am aware of what is important to me in life.

$\mathbf{N}$

\section{S}

$\mathbf{O} \mathbf{R}$

N

S

O R

$\mathbf{N}$

$\mathbf{S}$

O R

$\mathbf{N}$

S

O R

N

S

$\mathbf{O} \mathbf{R}$

S

O R 
43. Get support from a network of caring people.

$\begin{array}{cccc}N & S & 0 & R \\ N & S & O & R\end{array}$

45. Attend educational programs on personal health care.

N S O R

46. Reach my target heart rate when exercising.

47. Pace myself to prevent tiredness.

N S O R

48. Feel connected with some force greater than myself.

49. Settle conflicts with others through discussion and compromise.

50. Eat breakfast.

51. Seek guidance or counseling when necessary.

52. Expose myself to new experiences and challenges.

N $\quad S \quad O \quad R$

N S $\quad$ O $\quad$ R

N $\quad$ S $\quad$ O $\quad$ R

$\begin{array}{llll}\mathbf{N} & \mathbf{S} & \mathbf{O} & \mathrm{R}\end{array}$

N $\quad$ S $\quad$ O $\quad$ R

N S O R

c S.N. Walker, K. Sechrist, N. Pender, 1995. Reproduction without the author's express written consent is not permitted. Permission to use this scale may be obtained from: Susan Noble Walker, College of Nursing, University of Nebraska Medical Center, Omaha, NE 68198-5330. 
Participant ID Number:

प्वप्व

Introduction and Directions: A person's spiritual views may be an important part of their life. In general, spirituality refers to an awareness of one's inner self and a sense of connection to a higher being, nature, others, or to some purpose greater than oneself. I am interested in your response to the questions below. There are no right or wrong answers, of course. Answer each question to the best of your ability by marking an " $X$ " in the space above that group of words which best describes you.

1. In talking with your family or friends, how often do you mention spiritual matters?

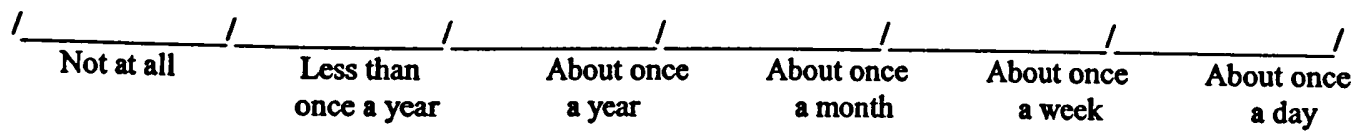

2. How often do you share with others the problems and joys of living according to your spiritual beliefs?

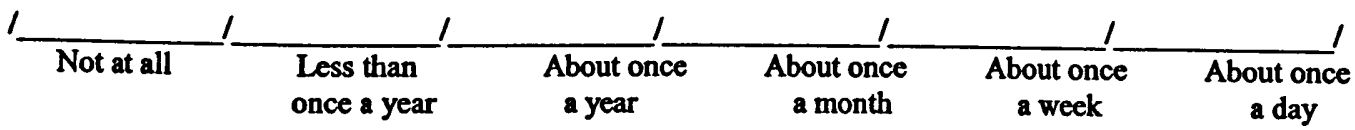

3. How often do you read spiritually-related material?

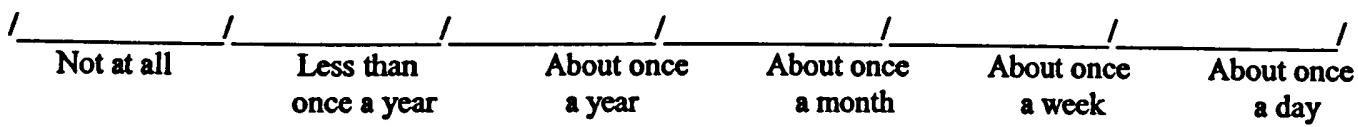

4. How often do you engage in private prayer or meditation?

Not at all $1 \frac{\begin{array}{c}\text { Less than } \\ \text { once a year }\end{array}}{\begin{array}{c}\text { About once } \\ \text { a year }\end{array}} \begin{gathered}\text { About once } \\ \text { a month }\end{gathered} \underset{\begin{array}{c}\text { About once } \\ \text { a week }\end{array}}{\begin{array}{c}\text { About once } \\ \text { a day }\end{array}}$

Directions: Please indicate the degree to which you agree or disagree with the following statements by marking an " $X$ " In the space above the words which best describe you.

5. Forgiveness is an important part of my spirituality.

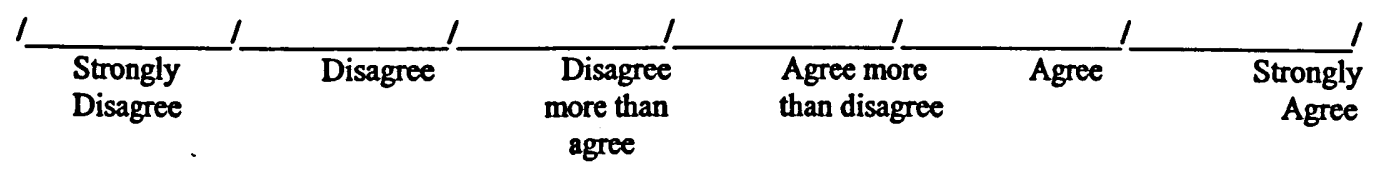

6. I seek spiritual guidance in making decisions in my everyday life.

I

7. My spirituality is a significant part of my life.

\begin{tabular}{|c|c|c|c|c|c|}
\hline I & & & 1 & & \\
\hline $\begin{array}{l}\text { Strongly } \\
\text { Disagree }\end{array}$ & Disagree & $\begin{array}{l}\text { Disagree } \\
\text { more than }\end{array}$ & $\begin{array}{l}\text { Agree more } \\
\text { than disagree }\end{array}$ & Agree & $\begin{array}{c}\text { Strongly } \\
\text { Agree }\end{array}$ \\
\hline
\end{tabular}


8. I frequently feel very close to God or a "higher power" in prayer, during public worship, or at important moments in my daily life.

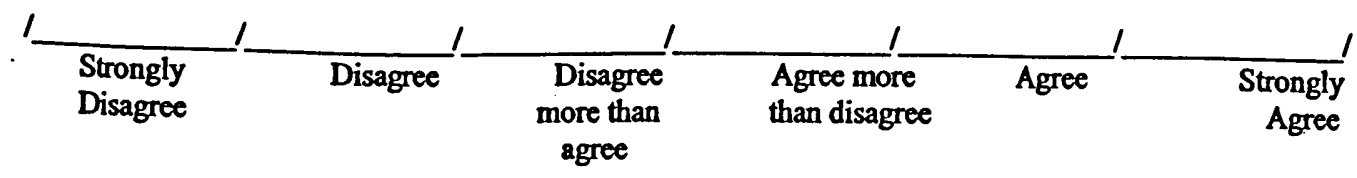

9. My spiritual views have had an influence upon my life.

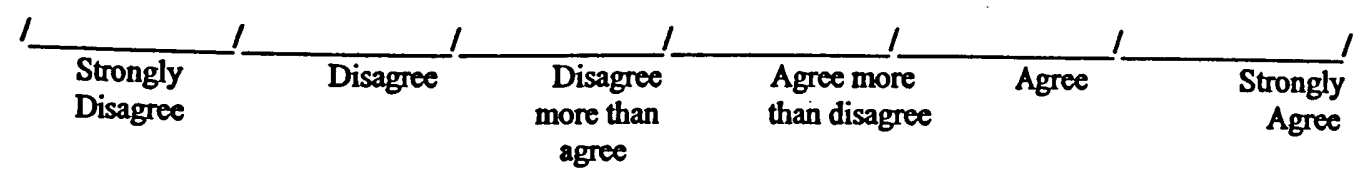

10. My spirituality is especially important to me because it answers many questions about the meaning of life.

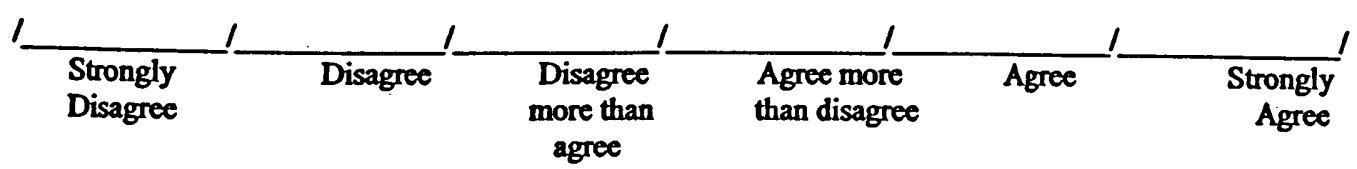

Do you have any views about the importance or meaning of spirituality in your life that have not been addressed by the previous questions?

Thank you very much for answering the questions.

Copyright Reed, 1986 
Participant ID Number:

\section{वपव口}

1. Which of the following do you consider yourself to be?

$\begin{array}{ll}\square & \text { African American or Black, non Hispanic } \\ \square & \text { Black, Hispanic } \\ \square & \text { White, non-Hispanic } \\ \square & \text { White, Hispanic } \\ \square & \text { Caribbean } \\ \square & \text { Asian } \\ \square & \text { Other Please Specify: }\end{array}$

2. How long have you lived in United States? years.

3. What is the highest level you reached in school?

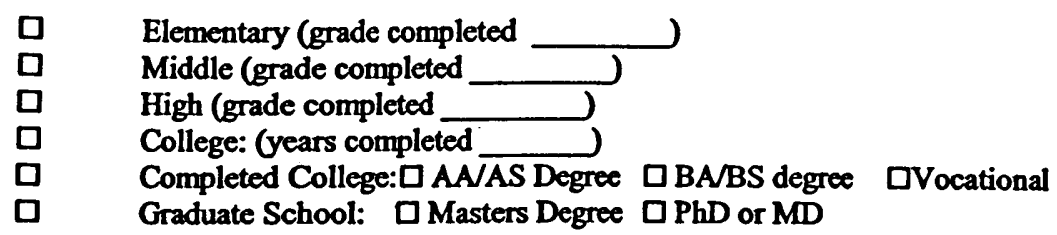

4. What is your current occupation?

5. At present, are you working outside of your home?

$\begin{array}{ll}\text { 口 } & \text { Full time } \\ \square & \text { Part time } \\ \square & \text { Both Full-time and Part-time } \\ \square & \text { Not working outside of the home }\end{array}$

6. What is your current marital status?

$\begin{array}{ll}\square & \text { Single, never married } \\ \square & \text { Divorced or separated } \\ \square & \text { Married } \\ \square & \text { Widowed }\end{array}$

7. How many people live in your household?

How many people live in your household?
C. Children (less than 5 years old) (How many?
․ Children ( 5 -20 years or older) (How many?
‥ Adults ( $21-64$ years old) (How many?
․ Adults ( 65 years or older) (How many?

8. What is your household income?
口 $\$ 15,000$ or less
ㅁ $\$ 15,001-\$ 30,000$

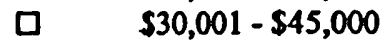
ㅁ $\$ 45,001-\$ 60,000$
ㅁ. Over $\$ 60,000$ 
9. What religious denomination/tradition, if any, do you identify most strongly with

$\begin{array}{ll}\square & \text { Baptist } \\ \square & \text { African Methodist Episcopalian } \\ \square & \text { Episcopalian } \\ \square & \text { Other Please Specify? }\end{array}$

10. How often do you attend religious service?

$\begin{array}{ll}\square & \text { Never } \\ \square & \text { Rarely (1-5 times per year) } \\ \square & \text { Occasionally (6-12 times per year) } \\ \square & \text { Frequently (about } 1-3 \text { times per month) } \\ \square & \text { Once every week } \\ \square & \text { More than once a week }\end{array}$


RESPONDENT D NUMBER

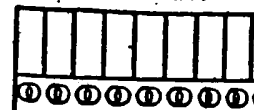

$\triangle 0000000$

DODOCOOOO

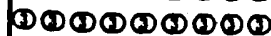

๑DODODOCD

पणत(1)(2)

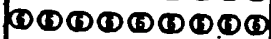

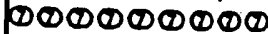

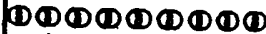

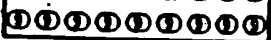

\begin{tabular}{|c|c|c|}
\hline & & \\
\hline$\overline{\sigma t a n}$ & DAY & $4 \sqrt{E}$ \\
\hline$D_{e b}$ & & \\
\hline$\partial \operatorname{Mar}$ & (D) & \\
\hline DApr & 100 & \\
\hline $\begin{array}{l}\text { May } \\
\text { O dun }\end{array}$ & 00 & \\
\hline ded & & \\
\hline Aug & & \\
\hline Sep & & \\
\hline & & \\
\hline & & \\
\hline
\end{tabular}

This form is about the foods you usually eat.

th will take about 15 - 25 minutes to complete.

- Please answer each question as best you can. Estimate If you aren't sure.

- Use only a No: 2 pencl.

- Fill in the circles completely, and erase completely if you make any changes.

Please print your. name in thls box.

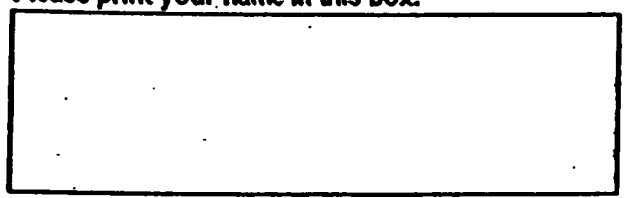

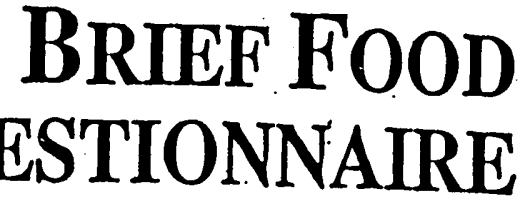

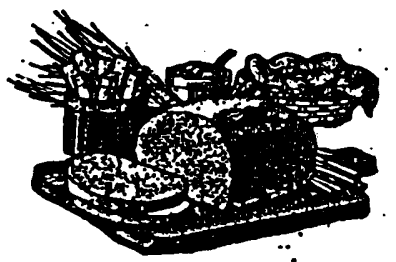

SEX

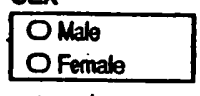

Kremale, ere you preginant or breast feeding?

ONo OYess

O Not lemate
AGE

HEGHT

pounds

pounds

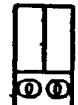

(D)

(2)

(D)

(b)

(5)

(ब)

$\infty$

(0)

QQ

This form is about your usual eating habits in the past year or 80 . This includes all meals or snacks, at home or In a restaurant or carry-out. There are two linds of questions for each food.

HOW OFTEN, on average, did you eat the lood during the past year? "Please DO NOT SKIP any toods. Mark "Never" II you didn't eat $k$.

How muCH did you usually. eat of the lood? "Sometimes we ask how many you eat, such as 1 egg, 2 eggs, etc., ON THE DAYS YOU EAT $\pi$. "Sometimes we ask "how much" as A, B, C or D. LOOKAT THE ENCLOSED PICTURES. For each bod, pick the picture (bouls or plates) that boks the most like the serving stze you usually eat. (ff you don't have pictures: $A=1 / 4$ ap, $B=1 / 2$ ap, $C=1$ cup; $D=2$ cups.)

EXAMPLE: This person drank apple puce twice a week, and had one glass each time. Once a week he ate a "C"-sized serving of rice (about 1 cup).

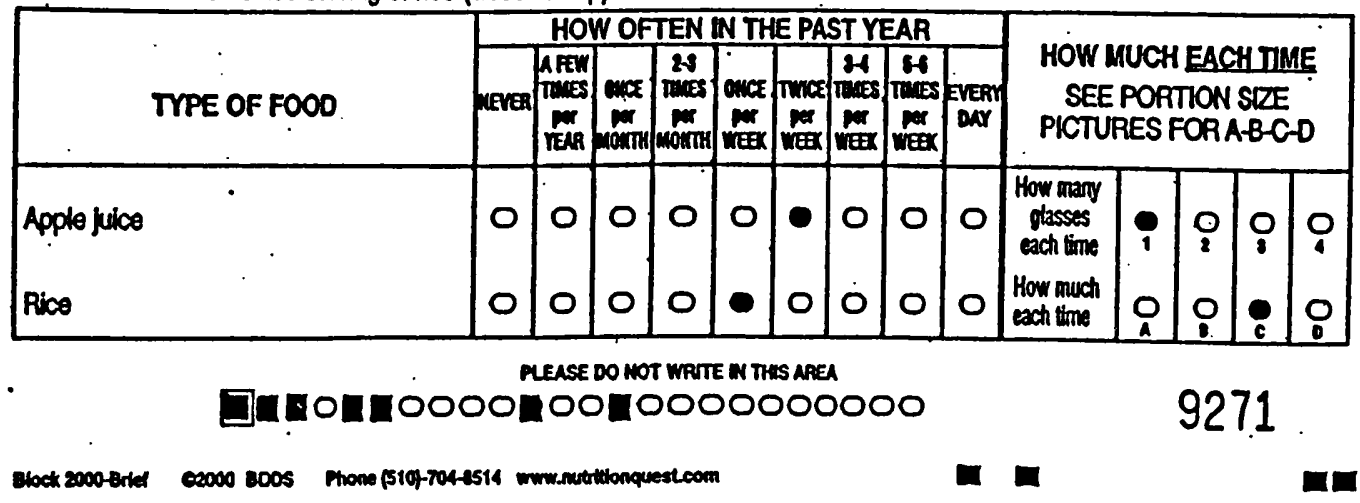




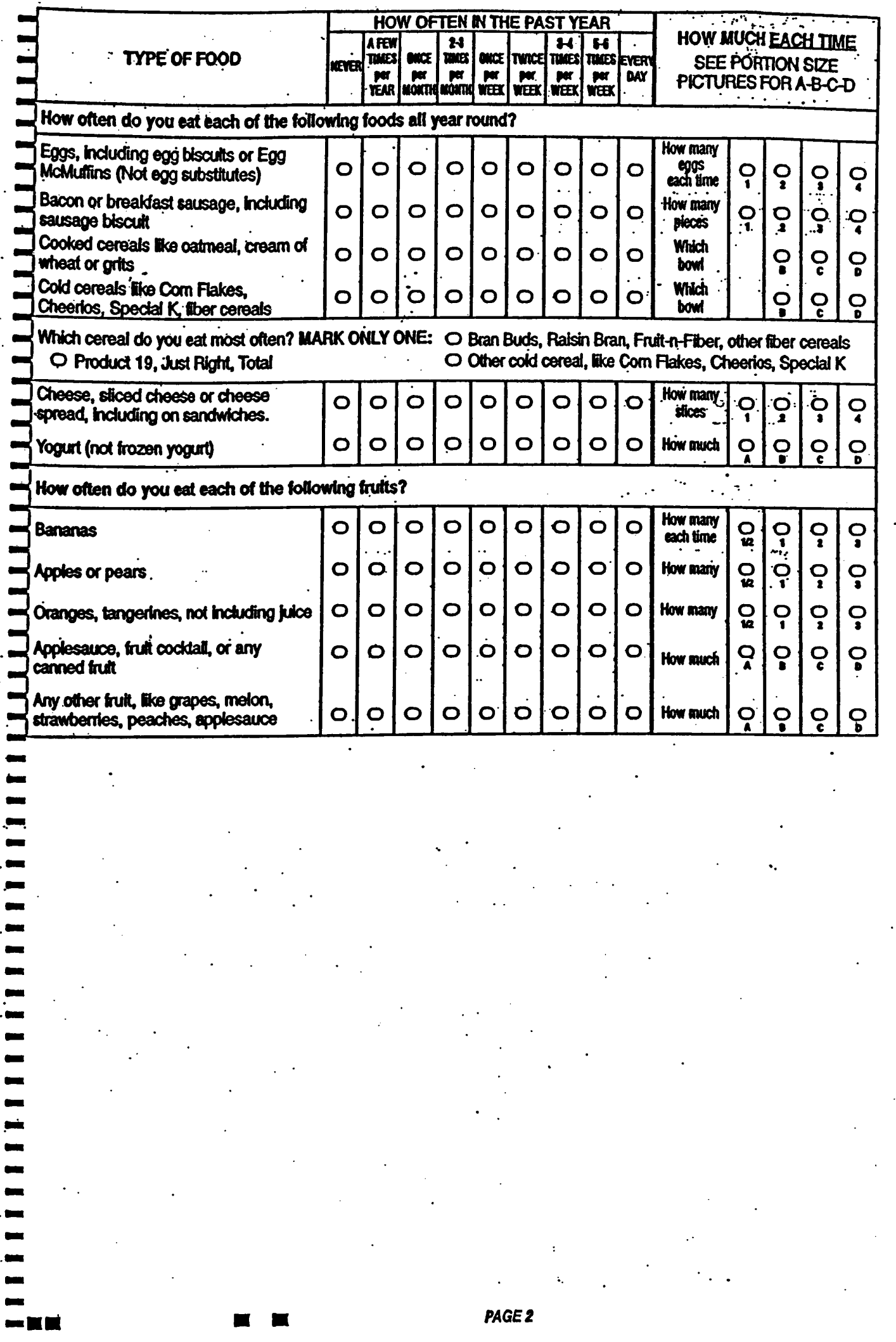




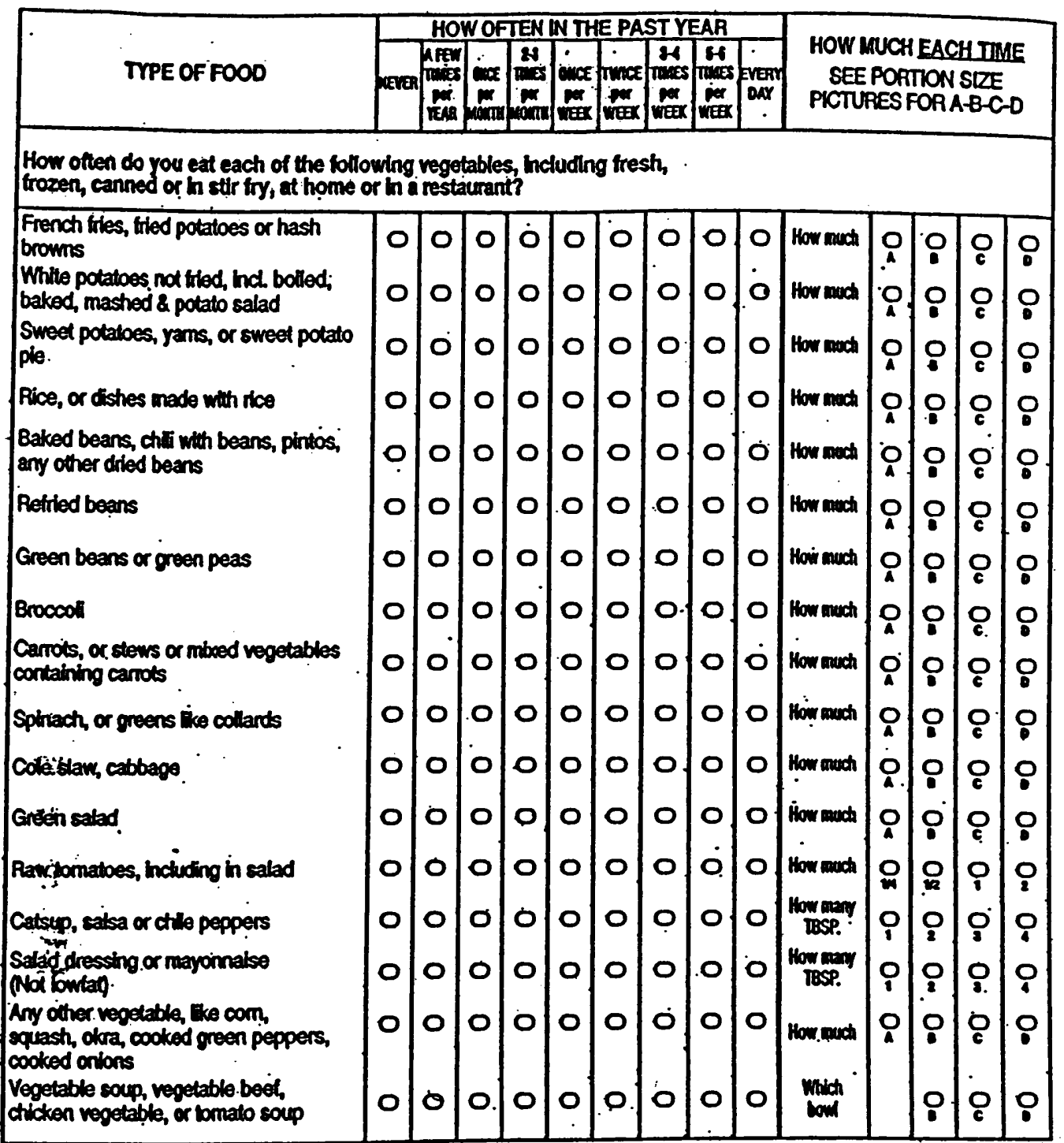




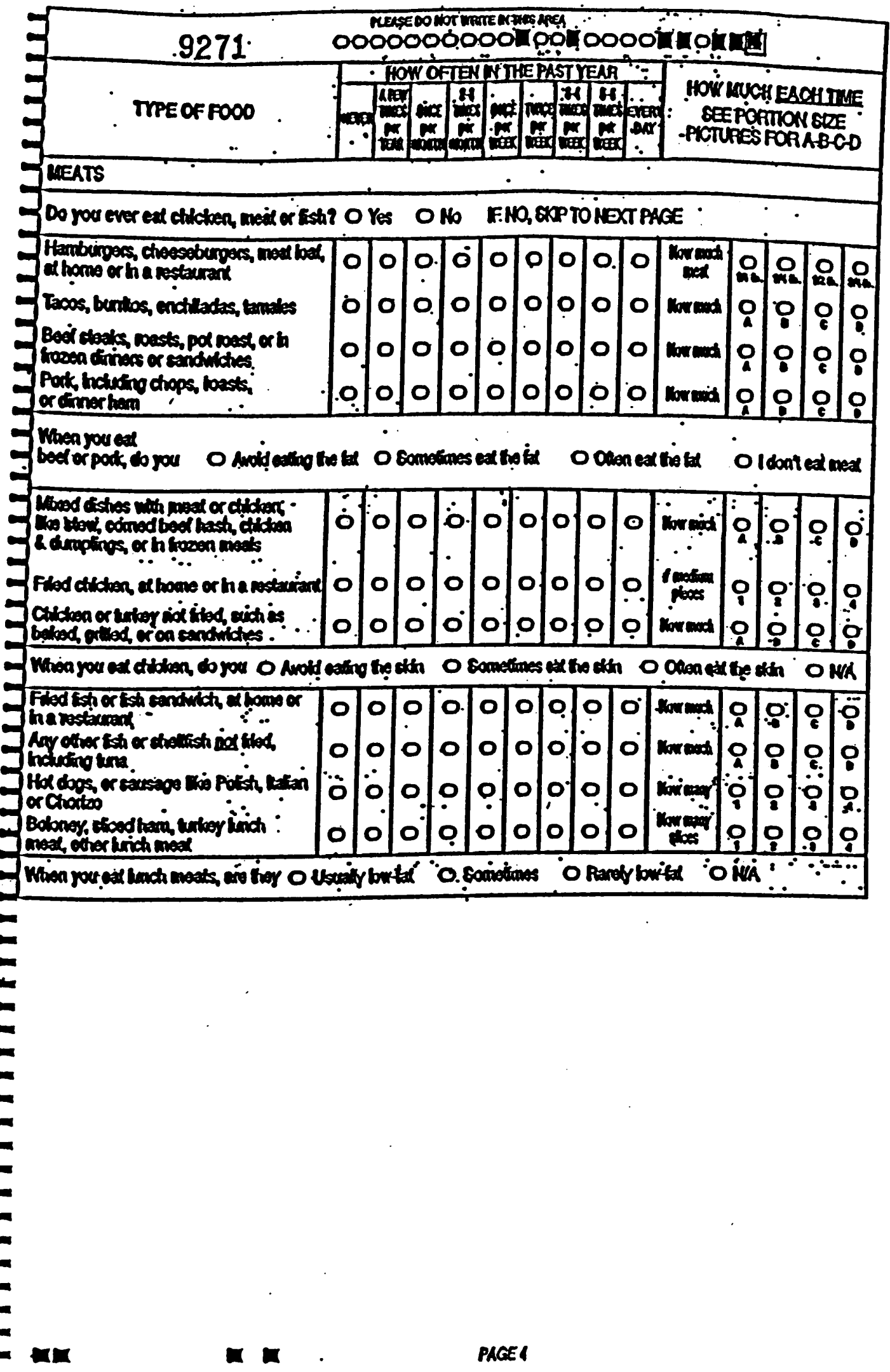




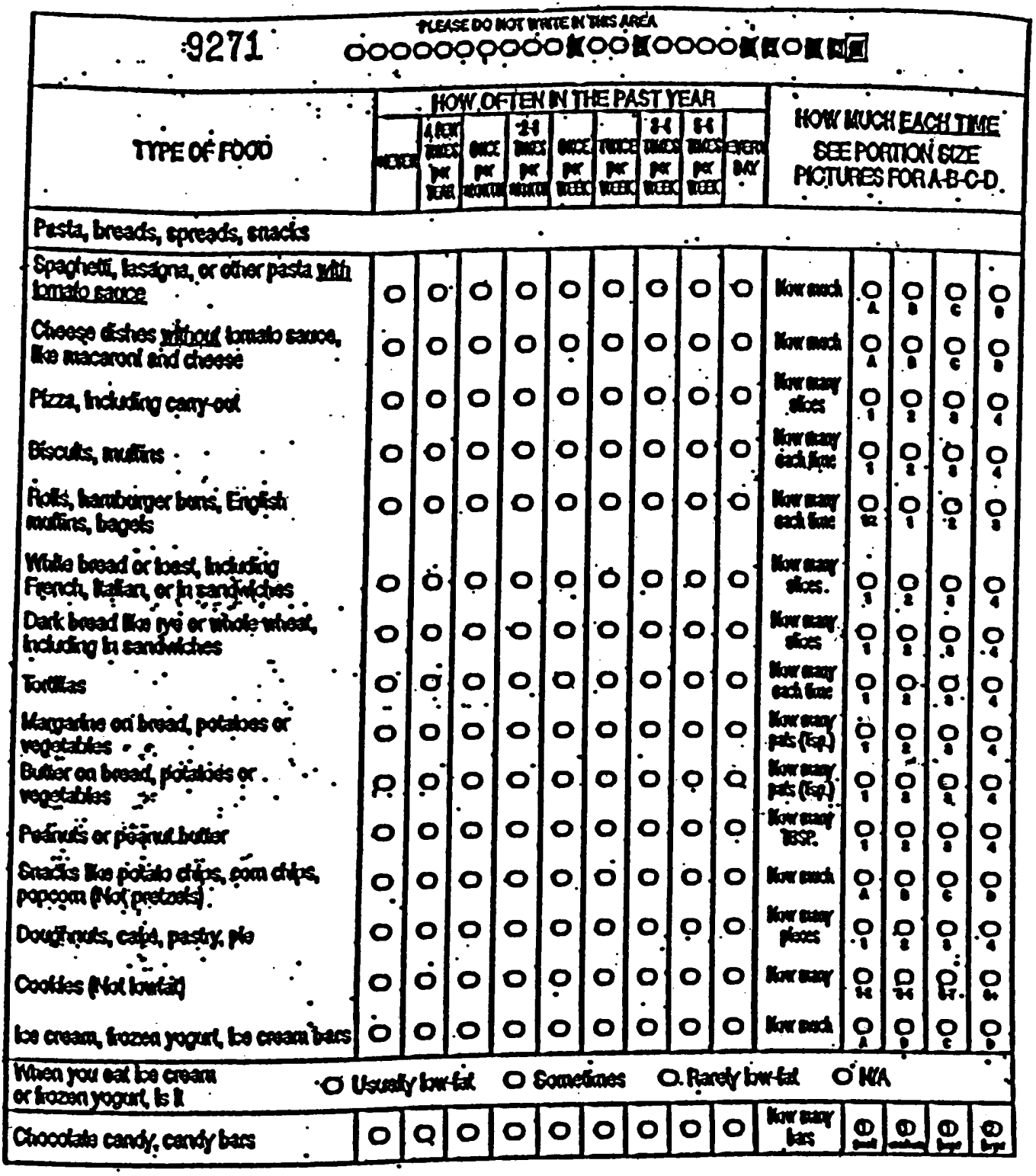




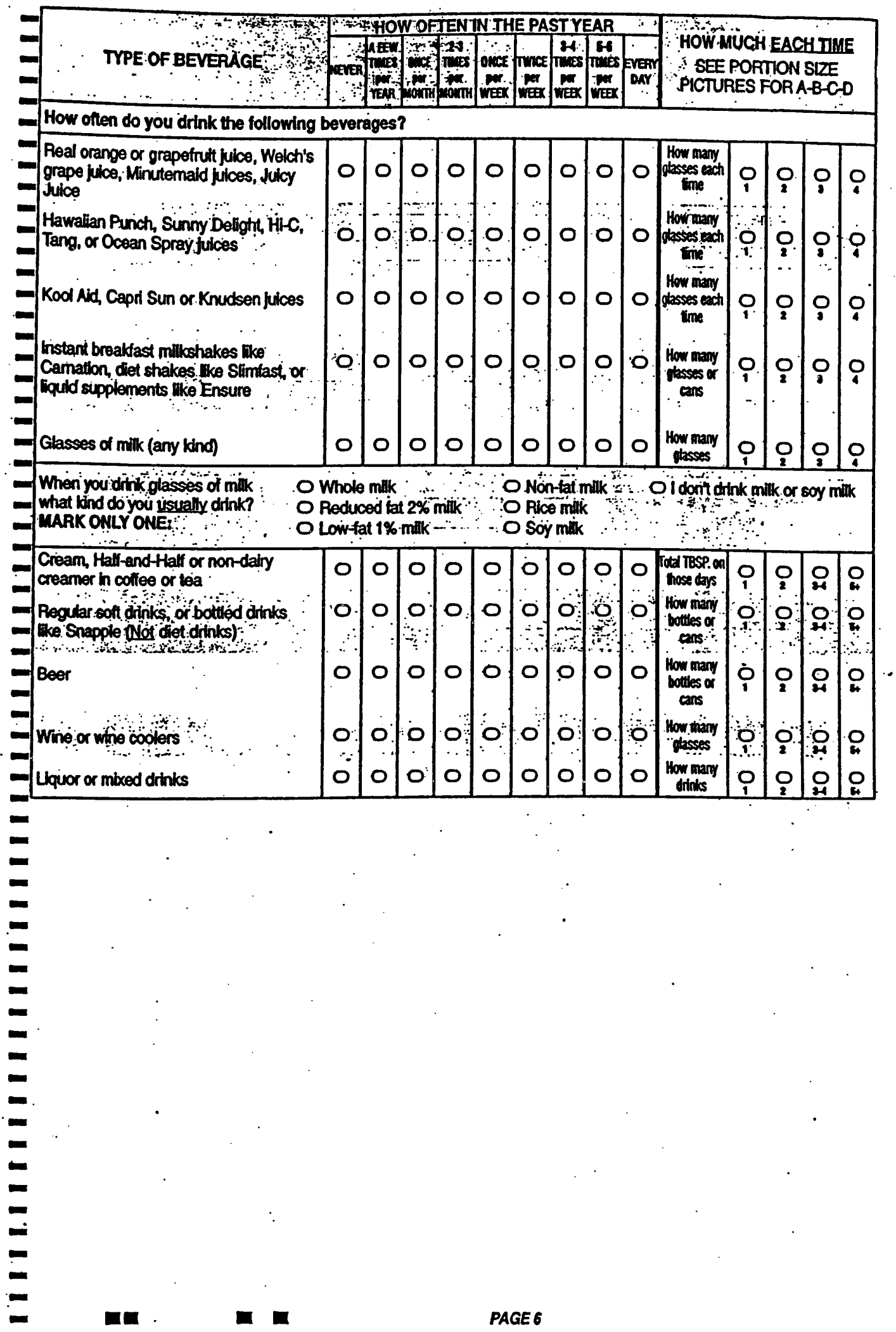


During the past year, have you taken any vitamins or minerals regularty, at least once a month?

- No, not regularty. O Yes, fally regularty 7

(FF YES) WHAT DID YOU TAKE FAIRLY REGULARLY?

\begin{tabular}{|c|c|c|c|c|c|c|c|c|c|c|c|}
\hline \multirow[t]{2}{*}{ VTTAMin TYPE } & \multicolumn{5}{|c|}{ HOW OFTEN } & \multicolumn{6}{|c|}{ FOR HOW MANY YEARS? } \\
\hline & oom & 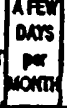 & $\left|\begin{array}{c}1 \\
0,4 \\
\text { mens } \\
\text { weax }\end{array}\right|$ & $\left\{\begin{array}{l}\mathbf{w} \\
\text { ours } \\
m \\
m\end{array}\right.$ & $\begin{array}{l}\text { mean } \\
\text { oux }\end{array}$ & $\begin{array}{l}\text { Less } \\
\operatorname{mim} \\
1 \mathrm{MR} \\
\end{array}$ & rese & ${ }^{2}$ & riveres & of & $\int_{V \in A}^{n}$ \\
\hline 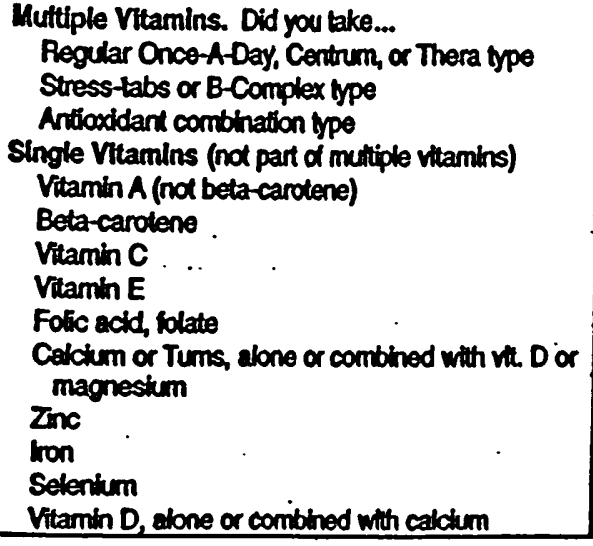 & $\mid \begin{array}{l}0 \\
0 \\
0 \\
0 \\
0 \\
0 \\
0 \\
0 \\
0 \\
0\end{array}$ & $\mid \begin{array}{l}0 \\
0 \\
0 \\
0 \\
0 \\
0 \\
0 \\
0 \\
0 \\
0 \\
0 \\
0 \\
0 \\
0\end{array}$ & $\begin{array}{l}0 \\
0 \\
0 \\
0 \\
0 \\
0 \\
0 \\
0 \\
0 \\
0 \\
0 \\
0 \\
0 \\
0 \\
\end{array}$ & $\left|\begin{array}{l}0 \\
0 \\
0 \\
0 \\
0 \\
0 \\
0 \\
0 \\
0\end{array}\right|$ & $\mid \begin{array}{l}0 \\
0 \\
0 \\
0 \\
0 \\
0 \\
0 \\
0 \\
0 \\
0 \\
0 \\
0 \\
0 \\
0 \\
0\end{array}$ & $\begin{array}{l}0 \\
0 \\
0 \\
0 \\
0 \\
0 \\
0 \\
0 \\
0\end{array} \mid$ & $\begin{array}{l}0 \\
0 \\
0 \\
0 \\
0 \\
0 \\
0 \\
0 \\
0\end{array}$ & $\begin{array}{l}0 \\
0 \\
0 \\
0 \\
0 \\
0 \\
0 \\
0 \\
0\end{array}$ & $\begin{array}{l}0 \\
0 \\
0 \\
0 \\
0 \\
0\end{array}$ & $\mid \begin{array}{l}0 \\
0 \\
0 \\
0 \\
0 \\
0 \\
0 \\
0\end{array}$ & $\begin{array}{l}0 \\
0 \\
0 \\
0 \\
0\end{array}$ \\
\hline
\end{tabular}

If you book vttamin Cor vitamin E:

How many milligrans of wanth $C$ did you usually take, on the days you book $k$ ?

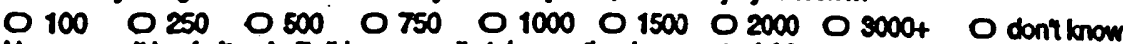
How many its of vitamin $E$ did you usually take, on the days you book $n$

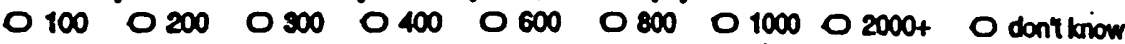

How often do you use fat or oll in coolding?

O Less than once per week O A tow times per woek O Orice a day O Twice a day O 3+ perday

What kinds of fat or of do you usually use in coolding? MARK ONRY ONE OR TWO

O Dont know, or Pain O Butlectmargarthe blend O Lard, falbick, bacon fat

O stick margarine O Low-fat margartine O Cilsco

O Sot tub margarine O com oll, vegetablo oll

O Butter

O Olive oll or canda of

Old you ever ditak more beer, wine or llquor than you do now? O Yes ONO

Do you smoke clgarettes now? O Yes O No

IF YES, Ot the average about how many clgarettes a day do you smoke nown?

O 1-5 O 6-14 015-24 O 2534 O 35 ormore

What is your ettric group? (MARK ONE OR MORE)

O Hispanic or Latino . O Black or African American

O White, not Hispanic O Astan

- American Indian or Alaska Native

O Native Hawalian or Other Paclic lstanider

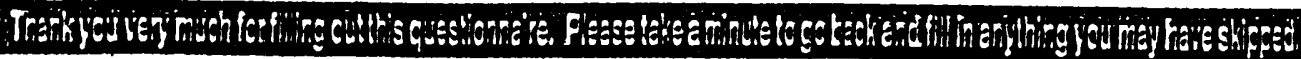

$\therefore$ PLEASE DO NOT WRITE W THIS AREA. 


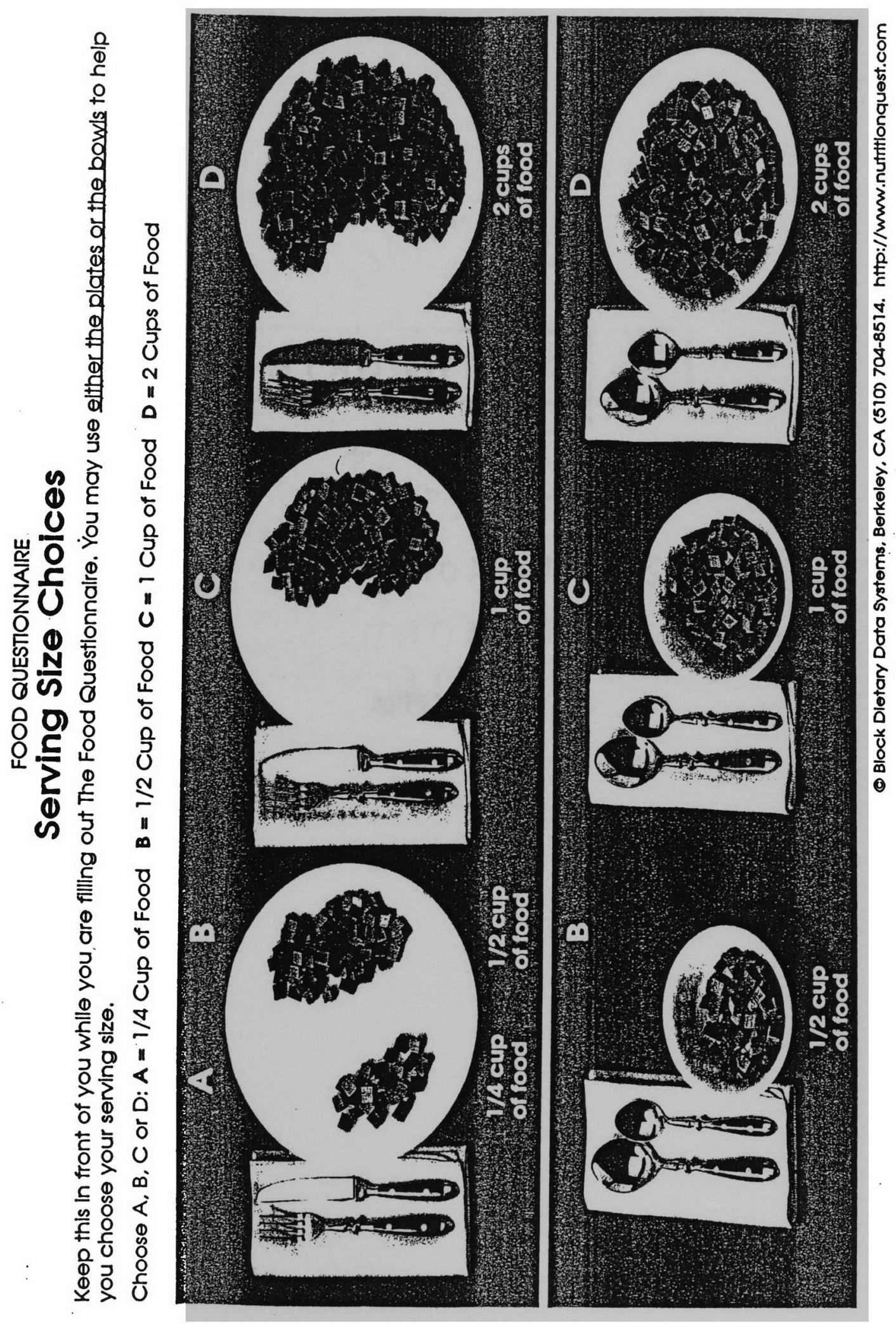


APPENDIX G 


\section{Study Protocol}

1. Telephone interview to explain overall purpose of the study to Pastor or targeted church and leader of social groups.

2. Arrange for delivery of instruments and consent form for approval of study to Pastor or leader of social groups.

3. Contact person designated to facilitate meeting for data collection.

4. Telephone contact person to arrange meeting details. Specifications outlined: appropriate date and time for optimum participation; adequate space for participant to complete instruments without interruption; two volunteers for assistance with study instrument collection; podium and microphone for communication; space for refreshments.

5. Meeting agenda

a. Introduction to study

b. Distribution of Informed Consent

c. Participant question period

d. Collection of completed Informed Consent

e. Distribute Instruments

f. Completion of instruments (allowance for individually answered questions)

g. Collection of instruments

h. Refreshments

i. Closing forum on "Nutritional Issues"

j. Distribution of "Nutrition Information Goody Bags" 
APPENDIX H 


\section{LIST OF NUTRITION INFORMATION \\ "GOODY BAG" CONTENTS}

1. Soul Food Pyramid

Donated by Hebni Nutrition Consultants

2. Banking on Beautiful Bones: A lifetime commitment to calcium Donated by National Dairy Council

3. The Lowdown on Lactose Intolerance: Making the most of milk Donated by the National Dairy Council

4. Down Home Healthy Cookin' Recipes and Healthy Cooking Tips

Donated by the National Institutes of Health - NCI

5. Action Guide for Healthy Eating

Donated by the National Institutes of Health - NCI

6. Your Best Body: A story about losing weight

Donated by the National Institutes of Health - NCI

7. Tips on how to... Eat Less Fat

Donated by the National Institutes of Health - NCI

8. Eat 5 Fruits and Vegetables Every Day

Donated by the National Institutes of Health - NCI

9. Food Diary

Donated by Hebni Nutrition Consultants, Inc.

10. Soul Food Pyramid Bookmark

Donated by Hebni Nutrition Consultants, Inc.

11. The Down Home Healthy Way Bookmark

Donated by the National Institutes of Health - NCI 
VITA

\section{DEIRDRA NICOLE CHESTER}

EDUCATION:

2000

Certificate, Nutrition Epidemiology

Johns Hopkins University

Baltimore, Maryland

1997

Dietetic Internship

Virginia State University

Petersburg, Virginia

1996

MS, Nutrition Science

Florida State University

Tallahassee, Florida

1994 BS, Food and Nutrition Science

Florida State University

Tallahassee, Florida

EXPERIENCE:

$$
\begin{array}{ll}
2001-2003 & \begin{array}{l}
\text { Teaching Assistant } \\
\text { Florida International University } \\
\text { Miami, Florida }
\end{array} \\
1998-2003 & \begin{array}{l}
\text { Graduate Research Assistant } \\
\text { Health Careers Opportunity Program } \\
\text { Florida International University } \\
\text { Miami, Florida }
\end{array} \\
1997-1998 & \begin{array}{l}
\text { Clinical Dietitian/Diabetes Educator } \\
\text { Halifax Medical Center } \\
\text { Daytona Beach, Florida }
\end{array} \\
1994-1996 & \begin{array}{l}
\text { Graduate Research Assistant } \\
\text { MEMS Project } \\
\text { Florida State University } \\
\text { Tallahassee, Florida }
\end{array}
\end{array}
$$

HONORS: 
$5^{\text {th }}$ Annual Dean's List Outstanding Faculty Recognition

2000 - 2003 Gates Millennium Scholar

2000-2001 Eleanora Sense Memorial Scholarship, American Dietetic Association Foundation Scholarship

2001 - 2002 Florence Bayuk Graduate Fellowship in Health Sciences

2001 - 2002 Solona C. McDonald Memorial Scholarship, American Dietetic Association Foundation Scholarship

\section{PUBLICATIONS:}

Chester DN, Weatherspoon LJ, Cook L. Chronic Diet-Related Disease Risk in a Sample of African-American College Students. FASEB J. 2001;15(4):A-264.

Handu DJ, Weatherspoon LJ, Chester DN, Cook L. Chronic Diet-Related Disease Risk in a Sample of African-American and White College Students.

Chester DN, Himburg SP, Lobar S, Johnson PM, Weatherspoon L, Dixon Z. The relationship of spirituality and health promoting behaviors of African-American women. FASEB J. 2003;17(5):A-1105. 